\title{
Photobiological Production of Hydrogen - A Solar Energy Conversion Option
}

Paul Weaver

Stephen Lien

Michael Seibert
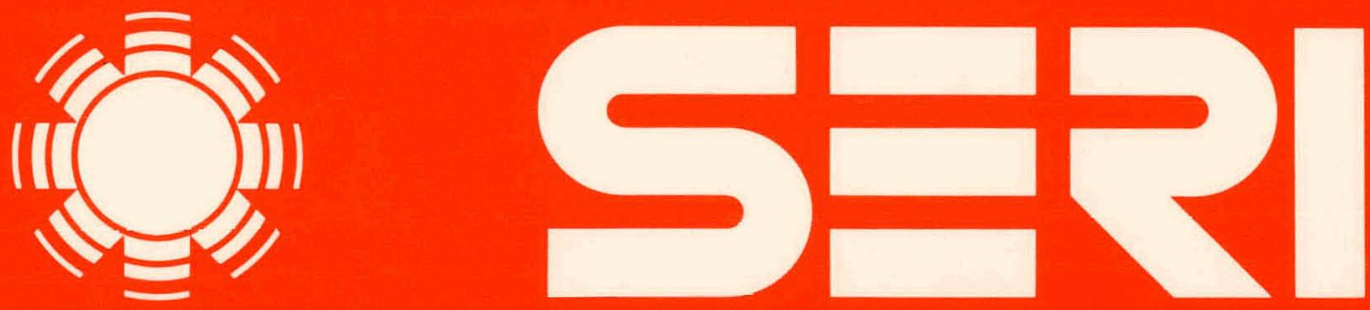

Solar Energy Research Institute A Division of Midwest Research Institute

1536 Cole Buulevard

Golden, Colorado 80401

Operated for the U.S. Department of Energy under Contract No. EG-77-C-01-4042

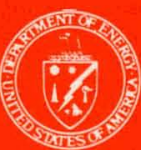




\section{DISCLAIMER}

This report was prepared as an account of work sponsored by an agency of the United States Government. Neither the United States Government nor any agency Thereof, nor any of their employees, makes any warranty, express or implied, or assumes any legal liability or responsibility for the accuracy, completeness, or usefulness of any information, apparatus, product, or process disclosed, or represents that its use would not infringe privately owned rights. Reference herein to any specific commercial product, process, or service by trade name, trademark, manufacturer, or otherwise does not necessarily constitute or imply its endorsement, recommendation, or favoring by the United States Government or any agency thereof. The views and opinions of authors expressed herein do not necessarily state or reflect those of the United States Government or any agency thereof. 


\section{DISCLAIMER}

Portions of this document may be illegible in electronic image products. Images are produced from the best available original document. 


\author{
Printed in the United States of America \\ Available from: \\ National Technical Information Service \\ U.S. Department of Commerce \\ 5285 Port Royal Road \\ Springfield, VA 22161 \\ Price: \\ Microfiche $\$ 3.00$ \\ Printed Copy $\$ 6.50$
}

NOTICE

This report was prepared as an account of work sponsored by the United States Government. Neither the United States nor the United States Department of Energy, nor any of their employees, nor any of their contractors, subcontractors, or their employees, makes any warranty, express or implied, or assumes any legal liability or responsibility for the accuracy, completeness or usefulness of any information, apparatus, product or process disclosed, or represents that its use would not infringe privately owned rights. 
SERI /TR-33-122

UC CATEGORY: UC-13

PHOTOBIOLOGICAL PRODUCTION OF HYDROGEN-A SOLAR ENERGY

CONVERSION OPTION

PAUL WEAVER

STEPHEN LIEN

MICHAEL SEIBERT

JANUARY 1979

This report was prepared as an eccount of work sponsored by the United States Govemment. Neither the

United States noo the United States Department of

Energy, nor any of their employees, nor any of their

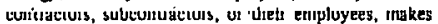

any warranty, express or implied, or assumes any legal

liabillty of responsibility for the accuracy completeness

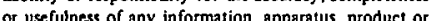

process disclosed, or teprents that is

process diselosed, or represents that ils use would not

infringe privately owned rights.

\section{Solar Energy Research Institute.}

15.36. Cole Roulevard

Golden, Colorado 80401

A Division of Midwest Research Institute

Prepared for the

U.S. Department of Energy

Division of Solar Technology

Under Contract EG-77-C-01-4042 


\section{FOREWORD}

This review was compiled by the Photobiology Staff of the Biological and Chemical Conversion Branch in compliance with Contract EG-77-C-01-4042. for the Division of Solar Technology of the U.S. Department of Energy. Task 3308, of which this report is a part, was identified in the approved SERI FY78 Annual Dperating Plan as a Research Division effort.

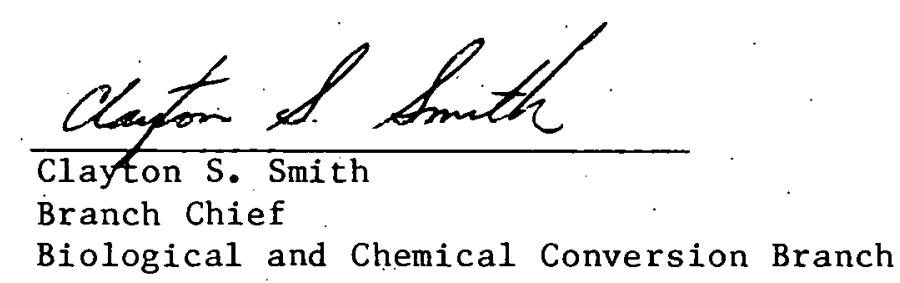

Approved for:

SOLAR ENERGY RESEARCH INSTITUTE

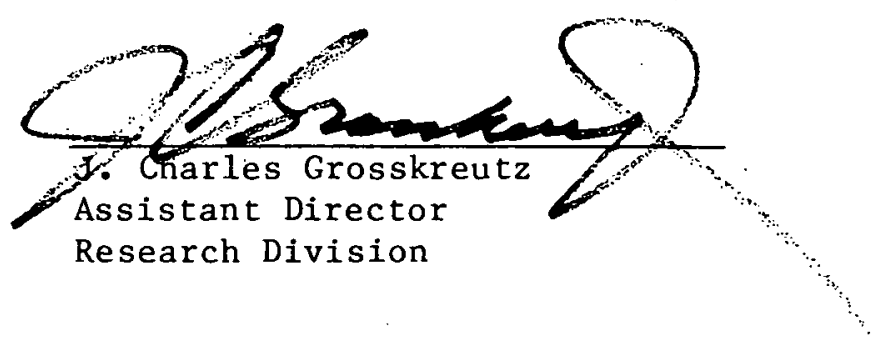


TABLE OF CONTENTS

Page

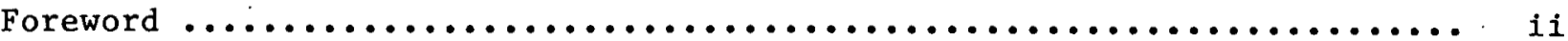

List of Figures...................................... v

List of Tables.......................................... vi

Abstract $\ldots \ldots \ldots \ldots \ldots \ldots \ldots \ldots \ldots \ldots \ldots \ldots \ldots \ldots \ldots \ldots \ldots \ldots \ldots \ldots \ldots \ldots \ldots \ldots \ldots \ldots$

1.0. Introduction $\ldots \ldots \ldots \ldots \ldots \ldots \ldots \ldots \ldots \ldots \ldots \ldots \ldots \ldots \ldots \ldots \ldots \ldots \ldots \ldots \ldots$

1.1 Scope of Report............................... 4

1.2 Hydrogen and the U.S. Energy Future................... 4

1.3 Obstacles to Photobiological Hydrogen Production............ 5

2.0 Historical Overview of Hydrogen Metabolism in

Phototrophic organisms............................. 7

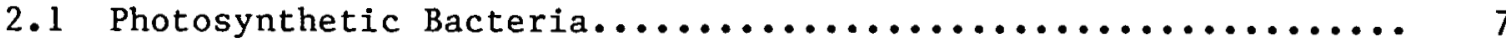

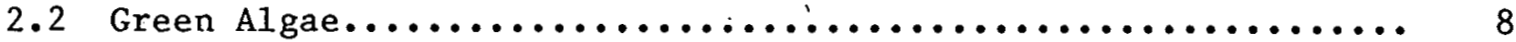

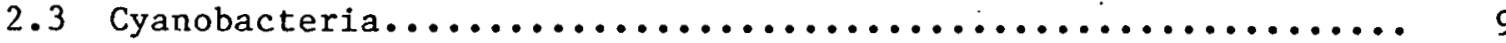

3.0 Key Enzyme and Biochemical Systems...................... 11

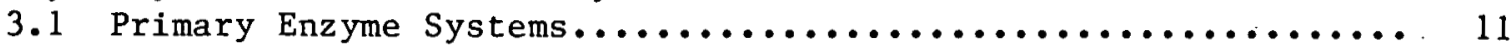

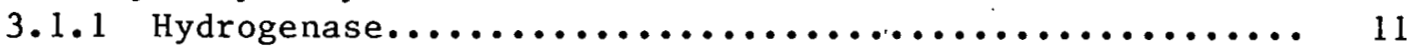

3.1 .2 Nitrogenase............................... 16

3.2 In Vivo Coupling to Photosynthetic Electron Transport....... 21

3.2.1 Photosynthetic Bacteria....................... 21

3.2.2 Oxygenic Photosynthetic Organisms............... 27

3.3 Control Mechanisms................................ 34

4.0 Comparative Rates of Hydrogen Consumption.................. 37

5.0 Light-dependent Hydrogen Production..................... 39

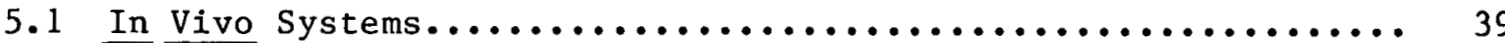

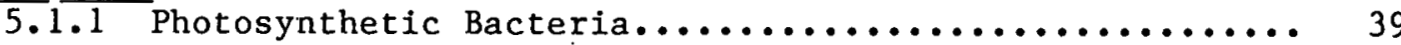

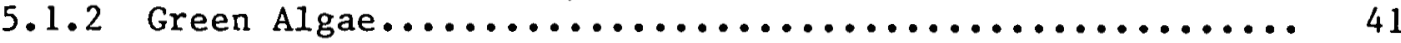

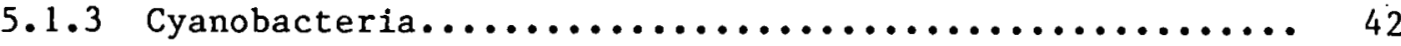

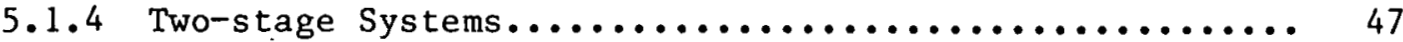

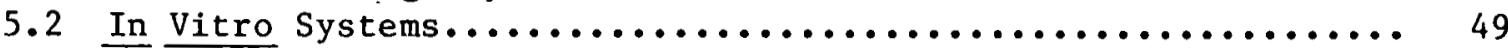

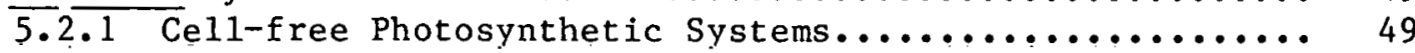

5.2 .2 Cell-free Purple Membrane Systems................ 53

6.0 Technical Problems in Photobiological

Hydrogen Production...................................

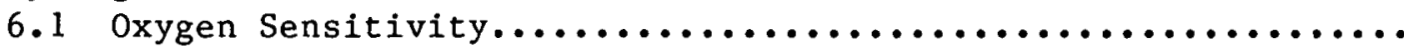

55

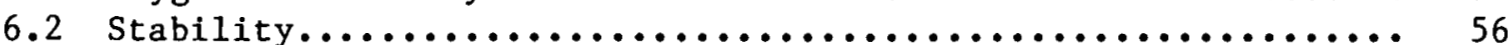

6.2 .1 Whole-cell Cultures......................... 56

6.2 .2 Cel1-free Systems............................ 57 
TABLE OF CONTENTS (Continued)

-

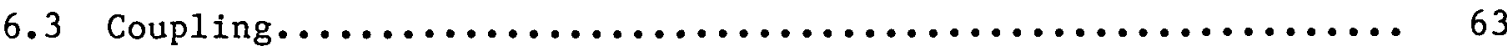

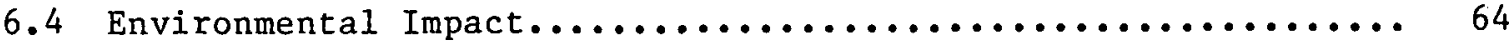

7.0 Prospects for Enhanced Photoproduction of

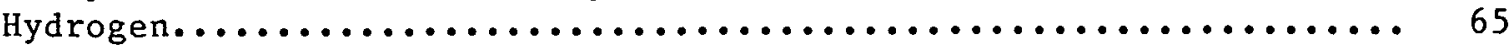

7.1 Isolation of Naturally Adept Strains................. 65

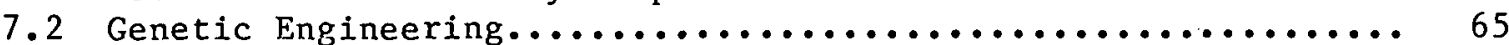

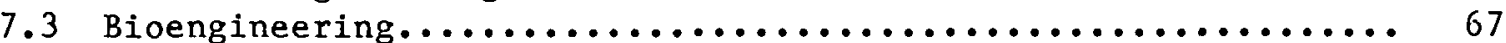

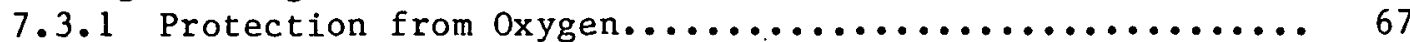

7.3.2 Stabilization of Biological Components............. 68

8.0 Comments and Future Research Directions.................... 71

References......................................... 73 


\section{LIST OF FIGURES}

$\underline{\text { Page }}$

3-1 Primary Photochemistry in Bacterial Photosynthesis.......... 23

3-2 Electron Transport in Photosynthetic Bacteria and Its Relationship to $\mathrm{N}_{2}$ Fixation and $\mathrm{H}_{2}$ Metabolism.......... 25

3-3 Electron Transport Systems of Oxygenic Photosynthetic Organisms.................................... 28

3-4 In Vivo $\mathrm{H}_{2}$ Production in Algae..................... 32

5-1 Two-Stage Biological $\mathrm{H}_{2}$ Production Systems. Using Whole Cells................................ 48 


\section{LIST OF TABLES}

$\underline{\text { Page }}$

3-1 Representative Organisms Exhibiting Hydrogenase Activity..................................... 13

3-2 Representative Organisms Exhibiting Nitrogenase Activity..................................... 19

4-1 Representative Comparative Rates of $\mathrm{H}_{2}$ Uptake............. 38

5-1 Representative Rates of $\mathrm{H}_{2}$ Photoevolution from Photosynthetic Bacteria............................ 40

5-2 Light-induced Hydrogen Production in Cell-free Coupled

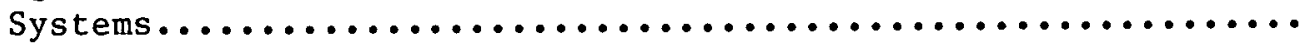




\begin{abstract}
This literature survey of photobiological hydrogen production covers the period from its discovery in relatively pure cultures during the early 1930s to the present. The focus is hydrogen production by phototrophic organisms (and their components) which occurs at the expense of light energy and electron-donating substrates. The survey covers the major contributions in the area; however, in many cases, space has limited the degree of detail provided. Among the topics included is a brief historical overview of hydrogen metabolism in photosynthetic bacteria, eucaryotic algae, and cyanobacteria (blue-green algae). The primary enzyme systems, including hydrogenase. and nitrogenase, are discussed along with the manner in which they are coupled to electron transport and the primary photochemistry of photosynthesis. A number of in vivo and in vitro photobiological hydrogen evolving schemes including photosynthetic bacterial, green algal, cyanobacterial, two-stage, and cellfree systems are examined in some detail. The remainder of the review discusses specific technical. problem areas that currently limit the yield and duration of many of the systems and research that might lead to progress in these specific areas. The final section outlines, in broadest terms, future research directions necessary to develop practical photobiological hydrogenproducing systems. Both whole cell (near- to mid-term) and cell-free (longterm) systems should be emphasized. Photosynthetic bacteria currently show the most promise for near-term applied systems.
\end{abstract}


THIS PAGE INTENTIONALLY LEFT BLANK 


\section{SECTION 1.0}

\section{INTRODUCTION}

The 1973 Arab oil embargo illustrated dramatically that energy is the most important resource maintaining our current standard of living. Unfortunately, reserves of the fossil fuels upon which we currently rely are being depleted rapidly, and sometime within the next 20 years or so, serious shortages may occur. Even now the decline in U.S. gas and oil production has placed severe strains on both our economy and currency.

Alternative energy sources are available but problems abound. Nuclear fission and fast-breeder reactors produce extremely toxic radioactive waste products which even now cannot be disposed of safely. In the long term, they too will be limited by diminishing reserves of uranium ore. A paucity of available sites and severe environmental conflicts limit installation of large new hydroelectric plants. Coal and oil shale reserves are quite extensive, but again environmental problems including mining practices, air pollution, and most recently fears concerning the release of vast amounts of $\mathrm{CO}_{2}$ into the atmosphere limit the utility of these resources. Geothermal energy is quite attractive but is also limited to suitable areas. Nuclear fusion is probably the long-term answer at least for centralized power generation, but this alternative will probably require 50 years to develop and commercialize if, indeed, it is possible at all.

The celebration of "Sun Day" in May 1978 helped focus the attention of both the government and the public at large on another alternative, the potential of solar energy in the nation's energy future. There are presently six solar technology areas identified by the Department of Energy (DOE) as promising for substantial future contribution to our growing energy demands. These are solar heating and cooling, biomass, wind, photovoltalcs (including solarpowered satellites), ocean thermal energy conversion (OTEC), and solar thermal electric.

of these solar terhnologies, the biomass area stands out as the least understood in all its ramifications. In fact, biomass production and conversion are only part of a broader field termed "biological conversion" (Seibert, 1978). Unfortunately, many professionals in various solar and solarrelated fields are still not aware that biological processes might be harnessed for conversion of solar energy into alternative forms by methods other than those leading to generation of biomass.

This does not mean that photosynthetic productivity is important only in agricultural applications and that biomass generation cannot be of considerable future importance as an energy resource. In fact, in George Wald's opinion (1978), "the greatest event on earth was the development of photosynthesis at the whole plant level". Photosynthesis is responsible for all fossil fuel reserves and produces about 3000 quads ( 1 quad $=10^{15} \mathrm{Btu}$ ) of stored energy in the form of biomass throughout the world every year; that is, about ten times the energy man consumes annually (Ha11, 1978). Despite the enormity of the process, photosynthesis in the field is not very efficient .... about $0.1 \%$ worldwide but as high as $1.6 \%$ for certain crop species on an annual 
basis (Ha11, 1978). The primary processes of photosynthesis, on the other hand, are potentially much more efficient and consequently could be used as the basis for modified photosynthetic processes applicable in solar energy conversion (Seibert et al., 1978).

\subsection{SCOPE OF REPORT}

A promising alternative biological process for solar energy conversion has been coined "biophotolysis" by L. 0. Krampitz. The term first appeared a number of years ago (NSF/NASA Solar Energy Panel, 1973) and was defined as the formation of $\mathrm{H}_{2}$ gas from water using the photosynthetic apparatus of green plants and algae. Unfortunately, there is confusion as to the precise definition since photo-synthetic harteria ran also produce $H_{1}$. llowever, photosynthetic bacteria do not use water as the primary reductant, and consequently, bacterial photoproduction of $\mathrm{H}_{2}$ is not strictly included in Krampitz's definition of biophotolysis (though many investigators use the term for both processes).

Confusion from terminology aside, the purpose of this report is to review the field of photobiological $\mathrm{H}_{2}$ production and to assess its potential for applied conversion systems. Included is a brief history of the field, the enzymology and biochemistry of $\mathrm{H}_{2}$ production, $\mathrm{H}_{2}$ evolution systems and rates, technical problems, and future prospects.

\subsection{HYDROGEN AND THE U.S. ENERGY FUTURE}

The successful production of $\mathrm{H}_{2}$ on an economic basis, biological or otherwise, would have a great impact on the United States energy picture. In 1977 the United States used about 0.5 quad* of natural gas to produce both $\mathrm{H}_{2} i$ tself and chemicals such as ammonia and methanol which require $H_{2}$ fnr their. synchesis (burwe $11,19 / 8, C \& E$ News Staff, 1978). This quantity represents about $2.5 \%$ of the total natural gas or $0.7 \%$ of the total energy used in the United States. Although the replacement of half a quad of natural gas with $\mathrm{H}_{2}$ doesn't appear to be particularly important, it must be remembered that the availability of larger amounts could stimulate the realization of a $\mathrm{H}_{2}$ economy as discussed by a number of people (Maugh 1972; Gregory, 1973; Bockris, 1975; Cox and Williamson, 1977; Gregory and Pangborn, 1976). Large quantities of inexpensive $\mathrm{H}_{2}$ would expand its use from a chemical feedstock in industry to a fuel ( $\mathrm{H}_{2}$ is presently too expensive to be used as such). Conceivably, it could replace some or all of the U.S. requirement for natural gas (19 quads in 1977 ) and transportation fuels (20 quads in 1977).

The major advantage of using $\mathrm{H}_{2}$ as a fuel is the improvement to the environment which would result. Hydrogen is a clean fuel, and its use would

*This number does not include $\mathrm{H}_{2}$ produced in oil refinèries for captive use. The total amount of $\mathrm{H}_{2}$ used is probably around 0.7 quad (W. Escher, personal communication). 
lead to decreased air pollution. No sulfur, $\mathrm{CO}_{2}$, or $\mathrm{CO}$ are produced and nitrogen oxides can be limited (Gregory and Pangborn, 1976). In addition, $\mathrm{H}_{2}$ is recyclable. It would ultimately come from water and after combustion would be returned to the atmosphere in the form of water vapor. The major disadvantage of using $\mathrm{H}_{2}$ as a fuel would be the cost of retrofitting pipeline, industrial, and transportation systems. However, this may not be a serious problem because oil and natural gas will not disappear overnight. As conventional fuels become more and more scarce, they would be replaced by $\mathrm{H}_{2}$ on a gradual but continual basis. Thus, retrofitting would be spread over a period of years to coincide with normal replacement of equipment. This approach requires a large amount of planning; however, it is a subject not within the realin of this report. Technological aspects of $\mathrm{H}_{2}$-based energy applications have been reviewed recently by Gregory and Pangborn (1976).

\subsection{OBSTACLES TO PHOTOBIOLOGICAL HYDROGEN PRODUCTION}

The economic photobiological production of $\mathrm{H}_{2}$ is a mid- to long-term goal (1015 years). However, two major barriers are impeding progress, the first technical and the second economic. Although much is known about biological $\mathrm{H}_{2}$ production, a great deal more basic and applied research is necessary before it will be possible to select proper systems for application on any practical scale. A more complete understanding of the primary processes of photosynthesis and the associated dark electron transport reactions is necessary. 'Both structural and functional aspects must be examined. A clearer understanding of the biochemistry and enzymology of hydrogen production is paramount. Through these avenues, knowledge of photobiological mechanisms might lead to the development of chemical analogues. This will, in addition, necessitate much more work on the isolation, characterization, and stabilization of functional biological components. Finally, methods must be developed to couple biological components to complementary in vivo or in vitro biochemical and, perhaps, electrochemical systems so that maximal efficiencies can be realized.

The second barrier is financial. Currently there is no single funding agency supporting photobiological energy conversion. In addition, it is difficult to identify even a million dollars being spent by the various divisions within NSF and DOE on photobiological $\mathrm{H}_{2}$ production. Past support in this area has been at best fragmented, discontinuous, decentralized, and undirected. Fortunately, there is hope. DOE has just announced the formation of a Biological Sciences Division within the Office of Energy Research and SERI has responsibility for program management of photobiological $\mathrm{H}_{2}$ research. 
THIS PAGE INTENTIONALLY LEFT BLANK 
SECTION 2.0

\section{HISTORICAL OVERVIEW OF HYDROGEN METABOLISM IN PHOTOTROPHIC ORGANISMS}

Hydrogen metabolism in biological systems can be described generally by the following equation:

$$
2 \mathrm{H}^{+}+2 \mathrm{e}^{-\stackrel{\text { enzyme }}{\rightleftharpoons}} \mathrm{H}_{2}
$$

The equilibrium of this reaction depends upon both the nature of the enzyme and the imposed conditions under which the enzyme functions. of primary interest, of course, is the photobiological production of $\mathrm{H}_{2}$ [to the right in Equation (1)]. However, all chemical reactions are in principle reversible. Thus, $\mathrm{H}_{2}$ metabolism is discussed as it occurs in either or both directions. Where applicable, comments are made concerning the feasibility of shifting the reaction towards the direction of $\mathrm{H}_{2}$ production.

\subsection{PHOTOSYNTHETIC BACTERIA}

While the ability to evolve or take up molecular $\mathrm{H}_{2}$ is not a common phenomenon in the biosphere, it is prevalent among photosynthetic micro-organisms: One of the first documented observations of $\mathrm{H}_{2}$ metabolism was made by Roelofsen (1934) who reported that a purple sulfur bacterium (now known as Chromatium vinosum strain D) could utilize $\mathrm{H}_{2}$ as an electron donor for $\mathrm{CO}_{2}$ fixation during heterotrophic growth in the light. Photosynthetic bacteria were already known to utilize reduced organic or sulfur compounds as electron donors. Roelofsen's work added $\mathrm{H}_{2}$ to the list of donors and thereby implied the presence of a $\mathrm{H}_{2}$-metabolizing enzyme (hydrogenase). It also played an integral part in Van Niel's (1941) formulation of the unitary hypothesis of photosynthesis.

Ormerod and Gest (1962) demonstrated that Rhodospirillum rubrum could grow as a strict photoautotroph, albeit slowly, with $\mathrm{H}_{2}$ as the sole electron donor. In a comparative survey Klemme (1968) reported that isolates of Rhodopseudomonas capsulata exhibited the fastest growth rates under these stringent conditions. Since these initial observations, representative strains from nearly all genera and species of photosynthetic bacteria have been found capable of photoautotropic growth using $\mathrm{H}_{2}$, though in certain cases trace amounts of specific vitamins or reduced sulfur compounds may be necessary (Pfenning and Truper, 1974).

The initial observation of $\mathrm{H}_{2}$ evolution by photosynthetic bacteria was made by Nakamura (1937). Chromatium species were found to decompose formate into $\mathrm{H}_{2}$ and $\mathrm{CO}_{2}$ in the dark, but not in the light. Dark production of $\mathrm{H}_{2}$ from formate was also noted in $R_{\text {. }}$ rubrum (Gest and Kamen, 1949a). These observations were not pursued further. Instead, the major focus was directed towards lightdriven production of $\mathrm{H}_{2}$ which occurs under particular environmental conditions. When $R_{-}$rubrum was grown photosynthetically on a medium containing certain amino acids as the sole $\mathrm{N}$ source, copious production of $\mathrm{H}_{2}$ was noted (Gest and Kamen, 1949a and 1949b). In the presence of $\mathrm{N}_{2}$ gas or ammonium ion photoevolution of $\mathrm{H}_{2}$ ceased. This relationship led to the 
discovery that $R$. rubrum can fix atmospheric dinitrogen via an inducible enzyme system, nitrogenase (Kamen and Gest, 1949). This capacity was later demonstrated in representative members of the other families of photosynthetic bacteria (Lindstrom et a1., 1951; Evans and Smith, 1971).

The relationship between $\mathrm{H}_{2}$ evolution and the presence of nitrogenase was, however, not understood. Gest et al. (1956) suggested that a pool of low oxidation-reduction (redox) potential electrons was generated from the splitting of water molecules. (At the time it was thought that all photosynthetic organisms split water.) These electrons could then be used for the reduction of $\mathrm{N}_{2}$ or, in its absence, transferred to hydrogenase for proton rcduction and release of $\mathrm{H}_{2}$ gas. Bregoff and Kanin (1952) suggested an alternative mechanism in which $\mathrm{H}_{2}$ was released through reactions of intermediary metabolism and subsequently resorbed, but only when $\mathrm{N}_{2}$ or ammonium ions were present. Losada et al. (1961) and Arnon et al. (1961) subsequently proposed an electron flow theory which at the time received widespread acceptance. Working with Chromatium, they noted that thiosulfate, in the absence of carbonaceous substrates, could support either $\mathrm{N}_{2}$ fixation or $\mathrm{H}_{2}$ photoevolution. In their model, reduced substrates donate electrons into an electron transport pathway coupled to specialized molecules of bacteriochlorophyll (BCh1). Excitation by light was thought to energize electrons to a level sufficient to reduce $\mathrm{N}_{2}$ or evolve $\mathrm{H}_{2}$. Current ideas about this electron flow theory are discussed later.

The photoevolution of $\mathrm{H}_{2}$ in photosynthetic bacteria is now known to be a function of nitrogenase rather than hydrogenase. In the absense of $\mathrm{N}_{2}$ purified preparations of nitrogenase evolve $\mathrm{H}_{2}$ when ATP (adenosine triphosphate) and dithionite are present (Bulen et al., 1965; Burns and Bulen, 1966). Conventional hydrogenases evolve $\mathrm{H}_{2}$ under these conditions as well but are ATP-independent and unaffected by $\mathrm{N}_{2}$. In addition, hydrogenases are inhibited by $\mathrm{CO}$ whereas $\mathrm{H}_{2}$ evolution from nitrogenases or intact photosynthetic bacteria is not (Winter and Burris, 1968; Winter and Arnon, 1970). Furthermore, Rps. capsulata mutants defective in nitrogenase activity do not evolve $\mathrm{H}_{2}$ though no effect is noted in their hydrogenase activity. Revertant or genetic transferent strains regain $\mathrm{N}_{2}$ fixation and $\mathrm{H}_{2}$ photoevolution activities concomitantly (Wall et al., 1975a).

\subsection{GREEN ALGAE}

As early as 1940 Gaffron observed that the green alga Scenedesmus undergoes an "adaptive" process when incubated anaerobically in the presense of $\mathrm{H}_{2}$ for several hours in the dark. Adapted cells take up $\mathrm{H}_{2}$ when $\mathrm{CO}_{2}$ is present. Similar observations were reported for other species of green, red, and brown algae (Frenkel and Rieger, 1951). If the $\mathrm{CO}_{2}$ is replaced by a fermentable substrate such as glucose, the cells evolve $\mathrm{H}_{2}$ (Gaffron and Rubin, 1942). Both $\mathrm{H}_{2}$ uptake and evolution are enhanced by light. Nevertheless, if the light intensity is increased beyond even moderate levels ( $>500$ lux), activity ceases and normal oxygenic photosynthesis resumes. Photoevolution of $\mathrm{H}_{2}$ is distinguishable from dark fermentative $\mathrm{H}_{2}$ metabolism from the action of dinitrophenol, which completely inhibits dark $\mathrm{H}_{2}$ production though it stimulates $\mathrm{H}_{2}$ photoevolution (Gaffron and Rubin, 1942; Gaffron, 1944). 
Kessler (1974) and Bishop et al. (1977) have recently identified numerous species of algae, mostly in the Chlorophycaea class, which also photoevolve $\mathrm{H}_{2}$ under anaerobic conditions.

Apparently hydrogenase alone mediates $\mathrm{H}_{2}$ metabolism in these organisms since they have never been shown to $\mathrm{fix} \mathrm{N}_{2}$, and their $\mathrm{H}_{2}$ exchange reactions are $\mathrm{CO}-$ sensitive, as are those of other hydrogenases (Gaffron, 1942).

\subsection{CYANOBACTERIA}

Certain isolates of cyanobacteria (or blue-green algae as they were formerly designated) also exhibit $\mathrm{H}_{2}$ exchange reactions. Frenkel and Rieger (1951) noted that some strains, though not all, take up $\mathrm{H}_{2}$ in a manner similar to that observed in algae. However, Benemann and Weare (1974) demonstrated recently that Anabaena cylindrica can also undergo a CO-insensitive photoproduction of $\overline{\mathrm{H}_{2}}$ in the absence of $\mathrm{N}_{2}$. It is quite probable that this latter reaction is mediated by nitrogenase, which has long been known in certain species of this group, particularly those of the Anabaena genus (Drewes, 1928; De, 1939; Fogg, 1942; Burris et al., 1943). 
THIS PAGE INTENTIONALLY LEFT BI ANK 
SECTION 3.0

KEY ENZYME AND BIOCHEMICAL SYSTEMS

Before discussing the current status of photobiological $\mathrm{H}_{2}$ production, it is necessary to examine the enzymes that catalyze $\mathrm{H}_{2}$ metabolism, the photosynthetic apparatus that supplies the raw material (reductants and in some cases adenosine triphosphate) for $\mathrm{H}_{2}$ evolution, and the manner in which these two components are coupled in a functional system.

\subsection{PRIMARY ENZYME SYSTEMS}

Two general classes of enzymes, hydrogenase (iron-sulfur proteins) and nitrogenase (protein complexes containing iron, sulfur, and molybdenum), are closely associated with the final $\mathrm{H}_{2}$ evolving act in photosynthetic bacteria, green algae, and cyanobacteria. However, the primary functions of the enzymes are quite different. Nitrogenase normally functions in biological nitrogen fixation whereas hydrogenase (a holdover from the time when organisms were exposed to a reducing primordial atmosphere) catalyzes hydrogen uptake or consuming reactions. However, under certain conditions both can catalyze $\mathrm{H}_{2}$ photoproduction.

\subsubsection{Hydrogenase}

Hydrogenases encompass a number of different proteins whose function in vivo can be summarized by the reaction sequence indicated by Equation (1). If we further stipulate that $\mathrm{H}_{2}$ must be the main and natural product or substrate of the enzyme activity, then nitrogenases are excluded since they produce $\mathrm{H}_{2}$ only in the absence of $\mathrm{N}_{2}$. (It is difficult to envisage a natural environment where $\mathrm{N}_{2}$ would not be present in sufficient concentrations to inhibit hydrogen evolution.)

\subsubsection{Assays}

Hydrogenase is usually detected by observing $\mathrm{H}_{2}$ evolution or uptake using either manometric or amperometric techniques. In these instances the $\mathrm{H}_{2}$ exchange is often coupled to physiological substrates (Section 3.1.1.3); to nonphysiological electron acceptors such as oxidized methylene blue (Gest, 1952); or to electron donors such as dithionite plus reduced methyl viologen (Perk and Gest, 1957b). Colorimetric quantitations can be made on redox dyecoupled systems as well. Finally, isotopic exchange assays using tritium (Gingras et al., 1963; Anand and Krasna, 1965) have been employed. This method has the advantage that the kinetic data obtained are independent of the slow electron transport reactions in coupled assays. For example, $\mathrm{H}_{2}$ activation, which this method assays, is probably not the rate-limiting step in the consumption of $\mathrm{H}_{2}$ coupled to $\mathrm{CO}_{2}$ fixation.

The amperometric technique for measuring hydrogen exchange developed by Wang et al. (1971) has the advantages of speed and sensitivity. Similarly, simultaneous measurements of $\mathrm{H}_{2}$ and $\mathrm{O}_{2}$ exchanges are possible using the apparatus described by Jones and Bishop (1976). However, these electrode 
systems are not appropriate when gases such as $\mathrm{H}_{2} \mathrm{~S}$ or $\mathrm{CO}$ are present (they interfere with the electrode) or for long-term experiments (the concentrations of dissolved gases in the medium reach equilibria).

Since nitrogenase is also capable of evolving $\mathrm{H}_{2}$, assays monitoring the release of $\mathrm{H}_{2}$ must exclude any contribution from nitrogenase. Hydrogenase activity is strongly inhibited by CO (Hoberman and Rittenberg, 1943; Peck et al., 1956) whereas $\mathrm{H}_{2}$ evolution via nitrogenase is not (Winter and Burris, 1968). Thus, $\mathrm{CO}$ is a means for discriminating between the two (except in amperometric assays since $\mathrm{CO}$ is an interfering gas). There are other tests to distinguish between hydrogenase and nitrogenase activity (such as the ATP requirement of the latter), but in practice they are more difficult to use.

\subsubsection{Distribution}

A large number of organisms have been assessed for hydrogenase activity (which is found much more frequently then nitrogenase activity). Representative examples are given in Table 3-1. Nonphotosynthetic organisms are also included since their hydrogenases may prove to be suitable for the in vitro photoconversion systems described in Section 5.2.1. For a more complete listing see Gray and Gest (1965), Mortenson and Chen (1974), Kessler (1974), and the individual bacterial citations in Buchanan and Gibbons (1974).

Hydrogenases have been detected in a diverse group of procaryotes, including obligate and facultative anaerobes, as well as nitrogen fixing and hydrogen oxidizing bacteria. Nearly all photosynthetic bacterla have hydrogenases as do approximately $50 \%$ of the algal strains tested (Kessler, 1974). Hydrogenases have also been reported in a protozoan (Edwards and Mathison, 1970), an animal (Kurata, 1962), and several higher plants (Renwick et al., 1964; Efimstev et al:, 1975). A note of caulion is in order here. Extreme care must be exercised in ascribing a function to an organism that is not free from symbioses, parasitisms, or commensalisms with other organisms. As a pertinent example, Newton (1976) has shown that the water fern Azolla exhibits both $\mathrm{H}_{2}$ evolution and uptake activities. However, the "organism" also contains a cyanobacterial symbiont, which is probably responsible for hydrugenase activity (as well as unidentified bacterla). Other efforts to detect hydrogenase in the chloroplasts of higher plants have been unsuccessful.

\subsubsection{Physiological Types}

A number of different types of hydrogenases have been detected and categorized (Gray and Gest, 1965). Most of the strictly anaerobic bacteria which evolve $\mathrm{H}_{2}$ (e.g., Clostridium) contain a soluble, highly oxygen-labile reversible hydrogenase (Peck and Gest., 1957a). (A "reversible" hydrogenase functions both in the uptake and evolution direction in vivo.) In these types of organisms the oxidative decarboxylation of pyruvate reduces an iron-sulfur carrier, ferredoxin (Mortenson et al., 1962 and 1963), and the reduced ferredoxin in turn reduces hydrogenase (Valentine et al., 1963; Whiteley and McCormick, 1963; Nakos and Mortenson, 1971). The hydrogenase functions as an electron disposal mechanism for reductants generated during fermentation (Gray and Gest, 1965). A similar function has been ascribed to the particulate hydrogenase that is part of the "formate hydrogenlyase" enzyme complex found in facultatively anaerobic bacteria such as coliforms (Peck and Gest, 1957b). 
Table 3-1. REPRESENTATIVE ORGANISMS EXHIBITING HYDROGENASE ACTIVITY

ORGANISM

REFERENCE

Photosynthetic Bacteria

Rhodospirillum rubrum

Rhodopseudomonas capsulata

Rhodomicrobium vannielii

Chromatium vinosum

Thiocapsa roseopersicina

Chlorobium thiosulfatophilum

Cyanobacteria

Anabaena cylindrica

Synechococcus elongatus

Synechocystis sp.

Nostoc muscorum

Euglenoid

Euglena gracilis

Green Algae

Chlamydomonas reinhardtii

Chlorella fusca

Scenedesmus obliquus

Ulva lactuca

Red Algae

Porphyra umbilicalis

Porphyriduim cruentum

Brown Algae

Ascophyllum nodosum

Nonphotosynthetic Bacteria

Escherichia coli

Klebsiella pncumoniae

Alcaligines eutrophus

Dcoulfovibrio vulgaris

Clostridium pasteurianum

Methanobacterium sp.

Rhizobium leguminosarum

Azotobacter vinelandii
Omerod and Gest, 1962

Klemme, 1968

Hoare and Hoare, 1969

Roelofsen, 1934

Gogotov et al., 1976

Pfennig and Trüper, 1974

Hattori, 1963

Frenkel et al., 1950

Frenkel et a1., 1950

Ward, $19 \overline{70}$

Hartman and Krasna, 1963

Hartman and Krasna, 1963

Kessler, 1974

Gaffron and Rubin, 1942

Frenkel and Rieger, 1951

Frenke1 and Rieger, 1951

Frenkel and Rieger, 1951

Frenke1 and Rieger, 1951

Stephenson and Stickland, 1931

Ordal and Halvorson, 1939

Repaske, 1962

Yagi et al., 1968

Peck and Gest, 1954

Bryant et a1., 1967

Dixon, 1967

Hyndman et al., 1953 
Since the $\mathrm{H}_{2}$ molecule contains a considerable amount of chemical energy, a variety of microbes have developed "uptake" hydrogenases which function primarily, if not exclusively, in the direction of $\mathrm{H}_{2}$ oxidation. Two distinct hydrogenases, one soluble and one particulate, function in the oxy-hydrogen metabolism of the chemolithotrophic bacterium, Alcaligines eutrophus (Wittenberger and Repaske, 1961; Schneider and Schlegel, 1977). The soluble enzyme catalyzes the direct reduction of $\mathrm{NAD}^{+}$, while the particulate form uses an as yet unknown high redox potential electron acceptor. Hydrogen consumption can also be the primary source of energy for the anaerobic production of methane (e.g., in Methanobacterium), the anaerobic respiration of nitrate (e.g., in Micrococcus denitrificans), or the anaerobic respiration of sulfate (e.g., in Desulfovibrio). The last example has been studied in some detail, and both soluble and particulate hydrogenases coexist in Desulfovibrio vulgaris (Yagi et al., 1968 and 1976). Both forms are specific for cytochrome $\mathrm{c}_{3}$ which has a relatively high (relative to hydrogenase) redox potential $(-205$ $(\mathrm{mV}$ ) and serves as its electron acceptor (Postgate, 1961)..

More in keeping with the topic of this review, however, are the hydrogenases associated with photosynthetic organisms. Those found in photosynthetic bacteria function primarily in the uptake direction. However, there are exceptional conditions under which $\mathrm{H}_{2}$ evolution may occur as a result of reversible hydrogenase activity. The dark metabolism of Chromatium (Nakamura, 1937 ) and $\underline{R}$. rubrum (Gest and Kamen, 1949a), where $\mathrm{H}_{2}$ production is coupled to formate oxidation, is an example. Also, the dismutation of $\mathrm{CO}$ engenders $\mathrm{H}_{2}$ evolution in Rps. gelatinosa (Uffen, 1976). Both processes appear to be electron disposal mechanisms. Nevertheless, additional data must be accumulated in order to determine the exact physiological significance. of these observations.

'l'he most obvious manifestation of hydrogenase function in photosynthetic. bacteria is autotrophic growth. The ability to fix $\mathrm{CO}_{2}$ in the light with $\mathrm{H}_{2}$ as the sole electron donor has been well established (Ormerod and Gest, 1962; Pfennig, 1967; Klemme, 1968). In addition, a few rhodopseudomonad strains can also couple $\mathrm{H}_{2}$ oxidation to $\mathrm{CO}_{2}$ fixation and aerobic growth in the dark (Weaver, unpublished).

Unlike photosynthetic bacteria, cyanobacteria and algae apparently cannot use $\mathrm{H}_{2}$ as an electron donor for autotrophic growth (Nuhrenberg et al., 1968). However, their hydrogenases are functional in several metabolic pathways. This topic has been reviewed by Bishop (1966) and Kessler (1974).

In those strains containing inducible hydrogenase activity, $\mathrm{H}_{2}$ oxidation can be coupled to $\mathrm{CO}_{2}$ reduction (but not growth) under low light conditions (Gaffron, 1940; Frenkel and Rieger, 1951). Hydrogenase activity is inhibited by high light intensities presumably because the high levels of $\mathrm{O}_{2}$ evolved under these conditions inhibit the enzyme. Hydrogen-coupled reduction of $\operatorname{NAD}(P)^{+}$(Abeles, 1964), nitrite (Kessler, 1957; Stiller, 1966), and sulfite (Kessler and Maifarth, 1960) has also been observed. Kessler (1974) and Kok (1974) suggested that algae containing hydrogenase have an additional survival advantage over those that do not in that they are better suited to recover from periods of extreme anaerobiosis during which the cells can become overreduced. Excess reducing power can be "bled off" via hydrogenase, thereby 
regenerating the oxidized acceptors necessary for photosynthetic electron transport. This function is the basis for hydrogenase-coupled $\mathrm{H}_{2}$ evolution in these organisms. Algae lacking hydrogenase do not evolve $\mathrm{H}_{2}$ and are comparatively slow in resuming normal photosynthesis after being subjected to anaerobiosis.

Another function for hydrogenase has been proposed in the $\mathrm{N}_{2}$-fixing strains of photosynthetic bacteria and cyanobacteria. As previously mentioned, $\mathrm{H}_{2}$ evolution occurs inherently during normal activity of the nitrogenase enzyme complex (Schubert and Evans, 1976). The invariable presence of uptake hydrogenase activity in $\mathrm{N}_{2}$-fixing organisms led Dixon (1972), to propose that the function of the hydrogenase was to act as an "afterburner" to reclaim some of the lost energy by reoxidizing the evolved $\mathrm{H}_{2}$. This model has received some experimental verification from studies on Anabaena (Bothe et al., 1977) and Rps. capsulata (Kelley et al., 1977; Meyer et al., 1978a). It also has been noted that Anabaena cells deprived of reductant use $\mathrm{H}_{2}$ as an electron donor for $\mathrm{N}_{2}$ fixation (Benemann and Weare, 1974).

\subsubsection{Purification and Properties}

Considerable confusion has arisen concerning the solubility and biochemical properties of certain hydrogenases. For example, Chromatium hydrogenase, as assayed by coupled $\mathrm{NAD}^{+}$(nicotinamide adenine dinucleotide) reduction, has been characterized as either fully soluble (Weaver et al., 1965), soluble but requiring a membrane-bound cofactor (Buchanan and Bachofen, 1968), or entirely membrane-bound (Feigenblum and Krasna, 1970). Thiocapsa roseopersicina cultures yield both soluble (Gogotov et al., 1976). and membrane-bound (Serebryakova et a1., 1977) enzymes. Anabaena also contains both soluble (Fujita et al., 1964) and membrane-bound (Fujita and Myers, 1965) hydrogenases. Chlamydomonas (Abeles, 1964), Chlorella (Lee and Stiller, 1967), and Scenedesmus (Ward, 1970) hydrogenases are exclusively membrane-bound and reportedly result from the action of multiple isozymic forms (Ward, 1970). R. rubrum and Rps. sphaeroides hydrogenase activities, along with those from several nonphotosynthetic sources, have also been described as resulting from the cumulative action of different ioosymec (Ackrell et al., 1966). With the exception of A. eutrophus (Schneider and Schlegel, 1977), though, the multiple forms of hydrogenase within a given cell have not been conclusively shown to be physiologically different. However, all these results should be reexamined in light of the observation that hydrogenase from Clostridium pasteurianum readily forms strong complexes with other cellular proteins (Nakos and Mortenson, 1971). Perhaps the binding of hydrogenase to other soluble or membranous components during isolation may explain the discrepancies reported in solubilities, isozymes, and molecular weights (see below). In any case, the difficulties or benefits that this strong inter-molecular binding would create in applied cell-free photoconversion systems are not possible to assess at this time.

Steroids, detergents, and chaotropes have been used successfully to solubilize membrane-bound hydrogenases. After solubilization they are purified by standard techniques (Mortenson and Chen, 1974). Purified hydrogenases have been prepared from photosynthetic bacteria including Chromatium (Gitlitz and Krasna, 1975; Kakuno et al., 1977), T. reseopersicina (Gogotov et al., 1976; Serebryakova et $\underline{a 1} ., \overline{1976)}$, and $\underline{R}$. rubrum (Adams and Hall, 1977). A11 are 
relatively resistant to heat denaturation, a property which has proven useful in the purification procedures. Compared to hydrogenases from other sources, the Chromatium and $\underline{T}$. roseopersicina enzymes are much more stable in air. The first crystalline preparation of hydrogenase has been achieved by $T$. Horio and colleagues (personal communication) from $\underline{R}$. rubrum. They also suggest that the protein from this source is stable in $\overline{1.0 \mathrm{M} \mathrm{NaCl}}$ in air for periods of years. Methods have been devised to stabilize further various hydrogenases in the presence of $\mathrm{O}_{2}$ (Section 6.1 and 6.3.1.).

Hydrogenases, as mentioned before, are iron-sulfur proteins similar to bacterial ferredoxins (Carter et al., 1972). They contain approximately four gram-atoms of both iron and inorganic sulfide per mole of enzyme or multiples thereof. Enzymes 1solated from C. pasteurianum (Nakos and Mortenson, 1971), D. vulgaris (Yagi, 1970), Chromatium (Gitlitz and Krasna, 1975), and $T$. roseopersicina (Gogotov et al., 1976) have been characterized in detail. E $\bar{P} R$ spectra normally show a $\mathrm{g}=1.94$ signal (characteristic of an iron-sulfur cluster) in C. pasteurianum and other hydrogenases (Mortenson and Chen, 1974), though Gititiz and Krasna (1975) did not observe it for Chromatium hydrogenase.

Purified hydrogenases from the above sources appear to have a molecular weight of about 60,000 daltons and are comprised of two subunits of equal size (Yagi, 1970; Nakos and Mortenson, 1971; Le Gal1 et al., 1971). Similar molecular weights have been estimated for hydrogenases from $\mathrm{T}$. roseopersicina (Gogotov, 1978) and R. rubrum (Adams and Hal1, 1977). On the other hand, Gitlitz and Krasna (1975) have reported that Chromatium hydrogenase has a molecular weight of 98,000 daltons whereas Kakuno et al. (1977) maintain that it is only 70,000 daltons. (A possible explanation for this discrepency was discussed earlier,)

Several compounds appear to inhibit hydrogenase activity though most of these data were derived from unpurified enzyme preparations. Both $\mathrm{CO}$ and $\mathrm{O}_{2}$, as previously mentioned, are inhibitory in most systems (Hoberman and Rittenberg, 1943). Cyanide is also inhibitory but apparently only when the enzyme is f1rst aerated (Green and Wilson, 1953). In addition, nitric oxide (Krasna and Rittenberg, 1954), sulfhydryl reagents (Hartman and Krasna, 1964), and acetylene (Smith et al., 1976) suppress hydrogenase activity to various extents:

\subsubsection{Nitrogenase}

The availability of combined nitrogenous compounds (e.g., ammonia, nitrate, and protein) is essential for biosynthetic reactions and cell growth. Most life forms must be fertilized or fed with these compounds. However, a few types of organisms--all procaryotes (bacteria and cyanobacteria)--are able to reduce ("fix") atmospheric $\mathrm{N}_{2}$, to the level of ammonia and are thus an essential link in the biosphere's nitrogen cycle. The process is carried out by a repressible enzyme complex, called nitrogenase, which functions at the most reducing end of the redox potential scale in biological systems. While the presence of the enzyme creates unique capacities for the host, it also poses problems for the cell as well as for the investigators seeking to understand the processes it catalyzes. 
Of prime importance to this review is the fact that nitogenase in the absence of its physiological substrate or product $\left(\mathrm{N}_{2}\right.$ or $\mathrm{NH}_{4}{ }^{+}$, respectively) reduces protons and thereby evolves $\mathrm{H}_{2}$. In fact, it was the observation of $\mathrm{H}_{2}$ photoproduction in a culture of $R$. rubrum that led Kamen and Gest (1949) to discover that photosynthetic bacteria can fix $\mathrm{N}_{2}$. This section describes briefly the distribution and properties of nitrogenase and indicates the feasibility of employing the enzyme in radiant energy conversion systems. Numerous comprehensive reviews on nitrogenase have recently appeared in the literature (Dalton and Mortenson, 1972; San Pietro, 1972; Streicher and Valentine, 1973; Burris and Orme-Johnson, 1974; Quispe1, 1974; Winter and Burris, 1976; Meyer et a1., 1978; Burris et al., 1978).

\subsubsection{Assays}

A culture that increases in cell mass for long periods of time in the absence of combined nitrogen (but in the presense of $\mathrm{N}_{2}$ gas) probably contains nitrogenase, especially if concomitant increases in cellular nitrogen are observed. However, care must be taken to ensure that the organism is in pure culture before $\mathrm{N}_{2}$ fixation capacities are assigned. In complex symbiotic systems such as those found in the root nodules of legumes, though, this is not always feasible in practice. Fortunately, more direct assays for nitrogenase activity have been perfected. Burris (1972) has described many of these techniques which are applicable to both whole cell and cell-free systems.

Mass spectrometric analysis was the first rapid, definitive assay employed, and the technique involves following the incorporation of $15 \mathrm{~N}_{2}$ into cellular constitutents. The isotope is a specific and sensitive tracer for nitrogenase activity. Dilworth (1966) subsequently recognized that nitrogenase can also catalyze the reduction of acetylene to ethylene, and this has provided the basis for a quick and simple assay. The ethylene evolved is detected by gas chromatography. The assay is now the method of choice for quantitatively measuring nitrogenase activity. Manometric or amperometric determinations of $\mathrm{H}_{2}$ evolution can also be used as an assay for nitrogenase activity provided that contributions from hydrogenase are suppressed or otherwise corrected for.

Nitrogenase-mediated ammonia production can be measured by a modifled Conway microdiffusion technique with Nessler's reagent (Bulen et al., 1965), but the commercial availability of ammonia-specific electrodes has recently supplanted this type of measurement. Nevertheless, accurate determinations of ammonia production from crude extracts are difficult or impossible if ammonia assiuilatory enzytues are also present.

Regardless of the assay method used, nitrogenase activity in cell-free extracts is strictly dependent upon the presence of both a strong reductant, usually dithionite, and $\mathrm{Mg}$-ATP (Burns and Bulen, 1965). Thus, the $\mathrm{H}_{2}$ evolution activity of the ATP-dependent, CO-insensitive nitrogenase can be readily discriminated from that of the ATP-independent, CO-sensitive hydrogenase. 


\subsubsection{Distribution}

The capacity for $\mathrm{N}_{2}$ fixation has been detected in isolates of uniquely distinct microorganisms. Table 3-2 lists representative strains of different genera and species exhibiting this property. More complete surveys, especially of the nonphotosynthetic bacteria, can be found elsewhere (Quispel 1974). No examples of $\mathrm{N}_{2}$ fixation in eucaryotes have been discovered as yet. Early reports of growth of yeast and fungi in the presence of $\mathrm{N}_{2}$ gas have not been confirmed when repeated using the $1 \mathrm{~N}_{2}$ or acetylene reduction assays (Postgate, 1971).

Nitrogenase is an extremely common, if not universal, enzyme in photosynthetic bacter1a. Members of all species that have becn examined are capable of growth using $\mathrm{N}_{2}$ as sole nitrogen source (Pfennig and Truper, 1974). Presumably, though this has not been tested specifically in many cases, nearly all photosynthetic bacterial isolates also have the capacity to express nitrogenase activity, either as $\mathrm{N}_{2}$ fixation or as $\mathrm{H}_{2}$ evolution. of 33 strains of Rps. capsulata examined, 30 exhibited good growth with $\mathrm{N}_{2}$ as the sole nitrogen source (Weaver et al., 1975), suggesting that the capacity is extremely widespread. Two of the three negative strains grew poorly even on medium containing combined nitrogen (indicating the necessity of healthy cells for demonstrating the energy-intense process of $\mathrm{N}_{2}$ fixation). The third was a laboratory strain which had been kept in pure culture for more than 40 years with no challenge to nitrogenase, raising the possibility of a mutant (lacking nitrogenase activity) takeover in the intervening years. Finally, a high positive correlation was noted between ability of all strains to photofix $\mathrm{N}_{2}$ and their abllity to photoevolve $\mathrm{H}_{2}$ in the absense of $\mathrm{N}_{2}$. Thus, $\mathrm{N}_{2}$ fixation and $\mathrm{H}_{2}$ production at the expense of radiant energy probably occurs in nearly all strains of photosynthetic bacteria. Although $\mathrm{N}_{2}$ fixation is usually thought to be an anaerobic, light-driven process in these anoxygenic bacteria, it has also been reported under conditions of moderate to low $n_{2}$ rnnrentrations (Gest and Kamen 1949a; Siefert, 1976). Meyer et al.(1978b) could not confirm this, however.

Besides photosynthetic bacteria the other main group of photosynthetic $\mathrm{N}_{2}-$ fixing organisms are the cyanobacteria. It is difficult to ascertain the ubiquity of nitrogenase in all isolates, since oxygenic photosynthesis in these microbes is inherently incompatible with the functioning of the extremely $\mathrm{O}_{2}$-labile nitrogenase enzymes. Certain filamentous cyanobacteria have apparently solved this problem by sequestering the bulk of their nitrogenase into specialized cells called heterocysts. Nn $\mathrm{O}_{2}$ evnlution occurs in these differentiated cells, and they appear to have an anaerobic interior (see Section 3.2.2). Low levels of $\mathrm{N}_{2}$ fixation can be detected also in the associated vegetative cells but only when the $\mathrm{O}_{2}$ concentration is kept low by sparging with $\mathrm{N}_{2}$ or argon (Te1-Or and Packer, 1978). However, most cyanobacteria do not form heterocysts. Nevertheless, two strains of the unicellular Gleothece have been isolated which are also capable of fixing $\mathrm{N}_{2}$ in air (Wyatt and Silvey, 1969; Rippka et al., 1971). Since their nitrogenase, like all others examined so $\mathrm{far}$, is rapidly inactivated in vitro by oxygen (Gallon et al., 1975) the Gleothece cells must have some alternative mechanism for creating anaerobiosis in vivo. Stanier and Cohen-Bazire (1977) reported that of 122 strains of nonheterocystous cyanobacteria, excluding Gleothece strains, 43 synthesized nitrogenase when incubated anaerobically in 
the absence of combined nitrogen. Activity was lost in all cases, however, when the cultures were exposed to air. The functionality of such $\mathrm{O}_{2}$-sensitive systems in natural environs, where even moderate light would raise the $\mathrm{O}_{2}$ concentration to critical levels, has not been determined.

Table 3-2. REPRESENTATIVE ORGANISMS EXHIBITING NITROGENASE ACTIVITY

Photosynthetic Bacteria

Rhodospirillum rubrum Rhodopseudomonas capsulata Rhodomicrobium vannielii

Chromatium sp.

Thiocapsa roseopersicina

Chlorobium sp.

Cyanobacteria

Anabaena cylindrica

Nostoc muscorum

Gleothece sp.

Plectonema boryanum

Nonphotosynthetic Bacteria

K1ebsiella pneumoniae

Clostridium pasteurianum

Rhizobium japnnirum

Azotobacter vinelandi i

Desulfovihrin sp.
Kamen and Gest, 1949

Lindstrom et al., 1951

Lindstrom et a1., 1951

Lindstrom et al., 1950

Gogotov, 1978

Lindstrom et a1,. 1950

Fogg, 1942

Williams and Burris, 1952

Rippka et a1., 1971

Stewart and Lex, 1970

Penga and Wilson, 1958

Rosenblum and Wilson, 1949

Hoch et al., 1960

Burris et al., 1943

Sisler and ZoBel1, 1951 


\subsubsection{Physiology}

The primary reaction catalyzed by nitrogenase is summarized as follows:

$$
\mathrm{N}_{2}+6 \mathrm{e}^{-}+6 \mathrm{H}^{+}+\mathrm{nATP} \longrightarrow 2 \mathrm{NH}_{3}+\mathrm{nADP}+\mathrm{nP}_{i}
$$

The enzyme complex is quite versatile and can also reduce a number of other substrates including nitrous oxide (Lockshin and Burris, 1965), acetylene, and azide (Schollhorn and Burris, 1966). The reduction products are $\mathrm{N}_{2}$, ethylene, and $\mathrm{N}_{2}$ plus $\mathrm{NH}_{3}$, respectively. It also catalyzes the reduction of cyanide to methane plus $\mathrm{NH}_{3}$ (Hardy and Knight, 1967), isocyanides and their derivatives to methane and a1kylamines (Kelly et a1., 1967; Hardy et al., 1971), and protono to $\mathrm{H}_{2}$. Thio laot reaction io

$$
2 \mathrm{H}^{+}+2 \mathrm{e}^{-}+\mathrm{mATP} \longrightarrow \mathrm{H}_{2}+\mathrm{mADP}+\mathrm{mP}_{\mathbf{i}}
$$

The only difference between Equations (1) and (3) is the irreversibility of the latter and its additional requirement for energy in the form of ATP. The number of moles of ATP [ $\mathrm{n}$ in Equation (2)] required to reduce a mole of $\mathrm{N}_{2}$ has been estimated from a comparison of growth yields on $\mathrm{N}_{2}$ and $\mathrm{NH}_{3}$, and ranges from 4 to 5 (Dalton and Postgate, 1969) to 29 (Hi11, 1976). A median value is normally assumed. However, when the equivalent energy of the reductant and the energy needed to synthesize the proteins involved are included in the estimates, the requirement may rise to as high as 35 - 40 moles of ATP per mole of $\mathrm{N}_{2}$ (Shanmugam et al., 1978). Since $\mathrm{H}_{2}$ production is a two-electron process [Équation (3)] it might be expected that the molar ATP requirement (m) would be one-third that for $\mathrm{N}_{2}$ reduction. In fact it may be much less. The process of $\mathrm{N}_{2}$ fixation involves an inherent release of $\mathrm{H}_{2}$ that corresponds to a minimum of $25 \%$ (possibly $40-60 \%$ ) of the electron flow through nitrogenase (Bulen et al., 1965; Schubert and Evans, 1976). 'Thus, determinations of the ATP requirement for $\mathrm{N}_{2}$ fixation include a considerable expenditure of ATP for wasteful $\mathrm{H}_{2}$ evolution. However, it should be mentioned that most $\mathrm{N}_{2}-\mathrm{f}_{\text {ixing }}$ organisms contain an uptake hydrogenase, and it has been suggested (Dixon, 1972) that the hydrogenase recycles some of this expended energy through coupled $\mathrm{H}_{2}$ oxidation (see Section 3.1 .1 .3 ).

\subsubsection{Purification and Properties}

In addition to its $\mathrm{O}_{2}$ sensitivity, nitrogenase in some cases is also coldsensitive (Burns and Bulen, 1965; Mortenson, 1972). These properties create complications in the purification procedures but Mortenson (1972) successfully used modified chromatographic techniques under strictly anaerobic conditions. Thereafter nitrogenases have been purified from Klebsiella pneumoniae (Eady et al., 1972), C. pasteurianum (Tso, 1974), Azotobacter vinelandii (Shah and Brill, 1973), and Azotobacter chroococcum (Yates and Planque, 1975). In addition, partially purified preparations have been obtained from Chromatium (Evans et al., 1973) and Rhizobium japonicum (Israel et a1., 1974).

Nitrogenase is an enzyme complex consisting of two proteins, one containing iron (the $\mathrm{Fe}$ protein) and the other containing both iron and molybdenum (the MoFe protein). Both are necessary for nitrogenase activity and both are ironsulfur proteins with approximately equivalent amounts of iron and acid-labile sulfide (Burris et al., 1978). 
The MoFe proteins from all sources are $\mathrm{O}_{2}$-labile and have molecular weights of approximately 220,000 daltons. They are comprised of one or two types of 50,000 to 60,000 dalton subunits. Approximately two moles of molybdenum and 24 - 32 moles of iron and sulfide are found per mole of protein.

The $\mathrm{Fe}$ proteins are also $0_{2}$-labile, completely inactivated after $1-3 \mathrm{~min}$ exposure to air, and, in the case of $\underline{C}$. pasteurianum, cold labile as well. Molecular weights average about 60,000 daltons and the protein consists of two subunits of equal weight. The presense of four irons and four sulfides per protein molecule and a $g=1.94$ EPR signal suggest that the active site may be similar to that of bacterial ferredoxins; that is, of the $\mathrm{Fe}_{4} \mathrm{~S}_{4}$ configuration.

of the two proteins, only the $\mathrm{Fe}$ protein is reduced by dithionite, and it is also the site of Mg-ATP binding (Walker and Mortenson, 1974). The Mg-ATP-Fe protein complex has a redox midpoint potential below $-400 \mathrm{mV}$ which is sufficient to reduce the MoFe protein (Zumft et al., 1974). Rivera-Ortiz and Burris (1975) suggested that all of the substrates for nitrogenase, including $\mathrm{N}_{2}$ and $\mathrm{H}^{+}$, bind to the MoFe protein (though at different sites) where they compete for the $\mathrm{Mg}-\mathrm{ATP}-$ reduced $\mathrm{Fe}$ protein complex.

Some gaseous compounds are inhibitors of nitrogenase. For example, nitrous oxide is a potent competitive inhibitor of $\mathrm{N}_{2}$ fixation (Lockshin and Burris, 1965). Carbon monoxide inhibits all nitrogenase activity with triple-bonded substrates but does not affect nitrogenase mediated $\mathrm{H}_{2}$-evolution (Hwang et al., 1973). Finally, $\mathrm{H}_{2}$ itself is a competitive inhibitor, but only of $\overline{\mathrm{N}_{2}}$ fixation.

\subsection{IN VIVO COUPLING TO PHOTOSYNTHETIC ELECTRON TRANSPORT}

\subsubsection{Photosynthetic Bacteria}

This section discusses the mechanisms whereby light energy captured by the bacterial photosynthetic apparatus are used to drive the process of $\mathrm{H}_{2}$ evolution in vivo. The coupling to uptake hydrogenase is also addressed to determine the feasibility of reversing the reaction under appropriate conditions.

As mentioned, $\mathrm{H}_{2}$ photoproduction in photosynthetic bacteria is mainly associated with nitrogenase rather than hydrogenase activity. Nitrogenase activity in C. pasteurianum (a nonphotosynthetic organism) is dependent upon the availability of reduced ferredoxin (or flavodoxin) generated from the phosphoroclastic reaction (Mortenson et al., 1963; Knight and Hardy, 1966). Winter and Arnon (1970) and Yoch and Arnon (1970) subsequently demonstrated that ferredoxin (reduced by illuminated chloroplasts in a hybrid system) can donate electrons to Chromatium nitrogenase. Likewise, two separate ferredoxins from R. rubrum (also reduced by illuminated chloroplasts) are known to reduce R. rubrum nitrogenase (Yoch and Arnon, 1975).

Thus, the important question at this point is how photosynthetic bacteria generate reductants at the reduced ferredoxin level to carry out nitrogenasecoupled $\mathrm{H}_{2}$ evolution. The possibilities are threefold: ferredoxin is reduced directly by a light-driven reaction; indirectly by ATP-driven reversed electron transport; or directly by dehydrogenation or oxidative decarboxyla- 
tion reactions of intermediary metabolism not involving electron transport chains. These possibilities are discussed further (Section 3.2.1.2).

\subsubsection{Electron Transport}

Photosynthetic bacteria, in contrast to cyanobacteria, algae, and higher plants (see Section 3.2.2), are thought to contain only one type of cytochrome-associated photoreactive pigment complex (Parson and Case, 1970; Seibert and DeVault, 1970; Seibert and DeVault, 1971) normally referred to as the reaction center or $\mathrm{P} 870$. The function of the reaction center is to convert light energy absorbed by accessory pigments (bacteriochlorophyll and carotenoids) into chemical potential in the form of a charge separation across the reaction center complex. In the natural membrane system, charge separation drives a cyclic electron transport pathway that 1s coupled to photophosphorylation (Frenkel, 1954 and 1956) or the generation of pyrophosphate (Baltscheffsky et al., 1966). These high energy compounds are used to fix carbon and supply the energy required for the various metabolic processes ensuring the survival of the organism. Hydrogen ions and electrons are supplied from organic or inorganic sources in the environment because the organisms cannot utilize water as an electron donor (see Section 3.2.2).

During the past five years, understanding of the primary photochemical processes associated with photosynthesis and the bacterial reaction center has benefited greatly from direct kinetic observations in the picosecond $\left(10^{-12}\right.$ $\mathrm{sec}$ ) time domain (Seibert, 1978). In fact, the picosecond studies of Kaufmann et al. (1975), Rockley et al. (1975), and Dutton et al. (1975) along with the more conventional studies of numerous other groups have led to the model in Figure 3-1 which explains how light is used to generate the primary charge separation (brackets in Figure 3-1) and subsequently to reduce the primary acceptor, $X$. The reduced primary acceptor drives cyclic electron transport. Recent reviews by Seibert (1978) and Holton and Windsor (1978) summarize the sequence of events in Rhodopsendomonas sphaeroides $R-26$ reaction center preparations as follows: light is absorbed by a BCh1 dimer in step (a) leading to the very rapid formation of an excited single state. Excitation transfer from the antenna pigments to drive this step may be rate limiting in Rps. sphaeroides chromatophores though, because the fluorescent lifetime of the antenna pigments is $200 \mathrm{psec}$ in the 1760-I strain (Paschenko et al., 1977) and $300 \mathrm{psec}$ in the $\mathrm{R}-26$ strain (Campillo et al., 1977). The radical cation BChl dimer is formed in step (b) when an electron from the dimer reduces the long wavelength bacteriopheophytin ( $B P h$ ) molecule. In step (c) $X$ is reduced in an electron transfer reaction from the $B P h$ radical anion. Further electron transfer involving cytochromes and secondary acceptors including $X$ occurs after this step in the intact organism. The dotted lines ( 1 ) and (2) represent possible reverse reactions (Dutton et al., 1975; Prince et al., 1976) since electron transfer beyond step (c) is not possible in reaction center preparations. Present evidence strongly favors reaction (1), especially at low temperature (Dutton et al., 1977). Step (d) can occur at room temperature but is kinetically much less favorable than (c). However, under conditions when $X$ is reduced prior to a flash, step (d) can be observed spectrally (Parson et al., 1975) although with a low quantum efficiency. This pathway presumably involves the $\mathrm{BChl}$ dimer as a blradical or spin-polarized triplet state $\left[\mathrm{BCh1}^{+}--\mathrm{BCh} 1^{-}\right]$and is responsible for the ESR triplet signal observed at low temperature (Dutton et al., 1972). 


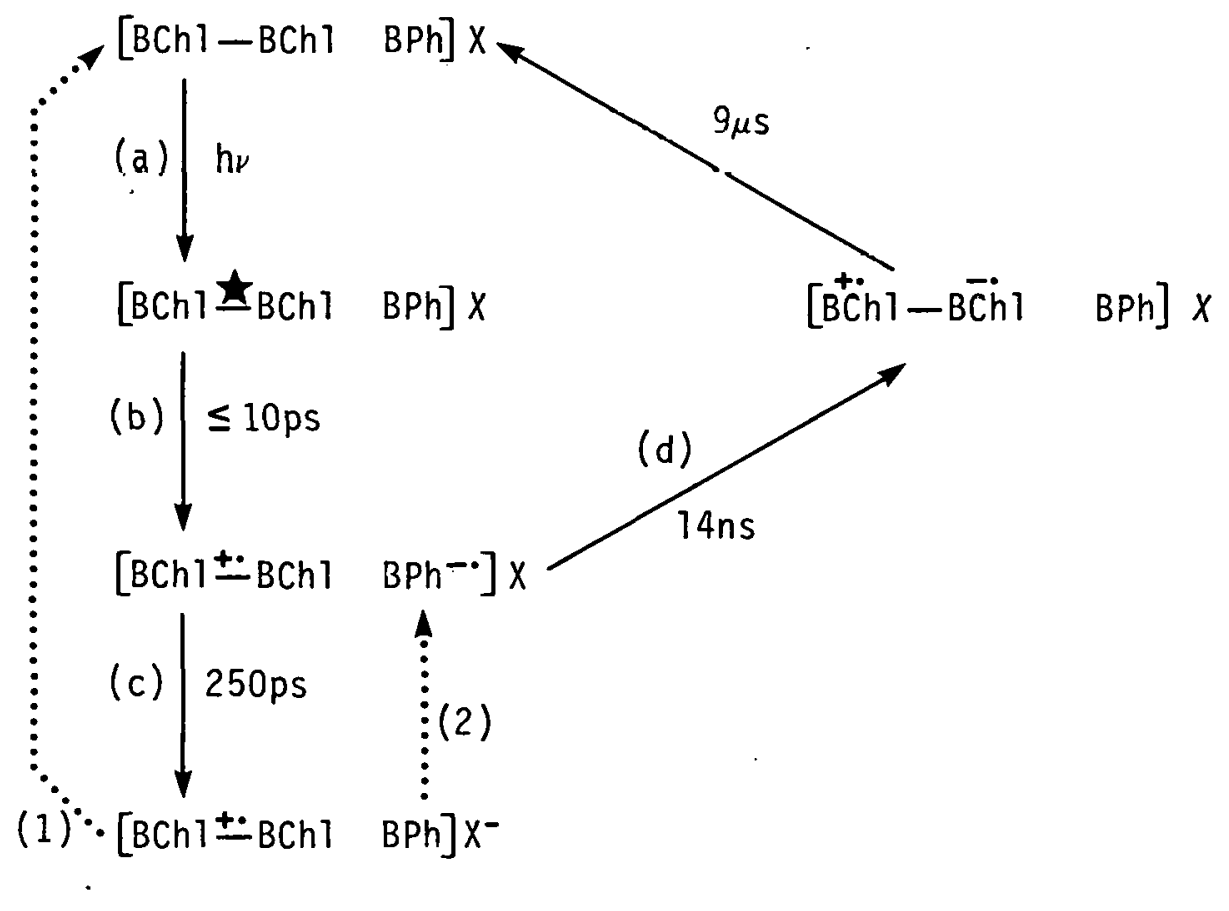

FIGURE 3-7. PRIMARY PHOTOCHEMISTRY IN BACTERIAL PHOTOSYNTHESIS.

The working scheme outlines the room-temperature picosecond time-scale reactions leading to the reduction of $X$ (the classical primary acceptor). The rate at which each step occurs is expressed in terms of its 1/e decay time. Step (d) occurs when $X$ is reduced prior to a flash, since step (c) cannot take place. Steps (1) and (2) are possible back reaction pathways. The identification of $\mathrm{BPh}$ (bacteriopheophytin) in this figure is tentative since I may involve an additional species. See the text for more details. This figure was modified from Figure 4 in Dutton et a1. (1975) and incorporates data taken from Cogdell et al. (1975). BChl is the symbol for bacteriochlorophyl1. 


\subsubsection{Coupling to Hydrogen Evolution}

The primary acceptor $X$ in Rps. sphaeroides reaction center prepärations appears to be an iron-quinone complex with a midpoint potential of about -180 $\mathrm{mV}$ (Feher and Okamura, 1978). Similar potentials have been determined for $X$ in most other photosynthetic bacteria examined (Parson et al., 1975; Dutton, et al.: 1978). Unfortunately, these potentials are too positive to reduce efficiently either ferredoxin $\left(E_{m, 7}=-420 \mathrm{mV}\right)$ or $\operatorname{NAD}(P){ }^{+}\left(E_{m, 7}=-320 \mathrm{mV}\right)$ which might be expected to act as intermediates in hydrogen metabolism.

This raises the question of whether photosynthetic bacteria carry out noncyclic electron transport at all (see reviews by Vernon, 1968; Hind and Olsull, 1969; Ffenkel, 1970; GesL, 1972; Grumel-Éllialla, 1977). Thie cuncepl of noncyclic electron flow, of course, is based on photosystem $I$ in oxygenic organisms (see Section 3.2.2) where the primary acceptor is known to reduce sequentially both ferredoxin and pyridine nucleotides. As a consequence, the source of reductant for $\mathrm{H}_{2}$ evolution remains largely obscure in photosynthetic bacteria. Biochemical studies have not been profitable since $\mathrm{H}_{2}$ evolution and $\mathrm{N}_{2}$ reduction do not occur in cell-free extracts without the addition of nonphysiological reductants. In fact, the mere loss of morphological integrity that occurs during spheroplast formation is sufficient to destroy the coupled light-driven reduction of $\mathrm{N}_{2}$ (Karunairatnam et a1., 1958). This demonstrated lability--even within intact cells--may be important in interpretating data obtained from cell-free extracts.

Nevertheless, there is evidence for direct electron transport in the green sulfur bacterium Chloroblum. Evans er al. (1966) described a reductive carboxylic acid cycle for chlorobial $\mathrm{CO}_{2}$ fixation in which reduced ferredoxin had an essential role. In the presence of ATP, ferredoxin was not reduced in the dark but was in the light, presumably by direct photoreduction (Buchanan and Evans, 1965 and 1969). Furthermore, the primary acceptor in this species. has a redox midpoint potential lower than $-450 \mathrm{mV}$ (Prince and 01son, 1976), a value sufficient to reduce ferredoxin directly. However, whether photosynthetic bacteria other than Chlorobium can also generate strong photoreductants directly remains a moot po1nt.

At several times in the past, various authors have suggested the presence of a second photosystem in photosynthetic bacteria which might generate carriers at a potential low enough to drive $\mathrm{H}_{2}$ evolution. Although the existence of such a system has not been eliminated and the work of Cusanovich et al. (1968) with Chromatium and Okayama et al. (1970) with $\underline{R}$. rubrum indicate the presence of light reactions operative below $-100 \mathrm{mV}$, there is at present no definite evidence substantiating such a second photoact.

In the absence of conclusive data supporting the existence of the noncyclic electron transport pathway in most bacteria, a number of investigators have suggested that the generation of low potential reductants is not the direct product of a photoact. Rather, it occurs by an ATP-driven reversal of electron flow from substrate-reduced cytochromes (Gest, 1966; Keister and Yike, 1967; Jones and Vernon, 1969), similar to that seen in mitochondria (Chance and Hollunger, 1963). The models proposed for such a scheme involve a single reaction center pigment with a cyclic electron transport pathway generating ATP as the sole form of conserved energy (see Figure 3-2). Keister 


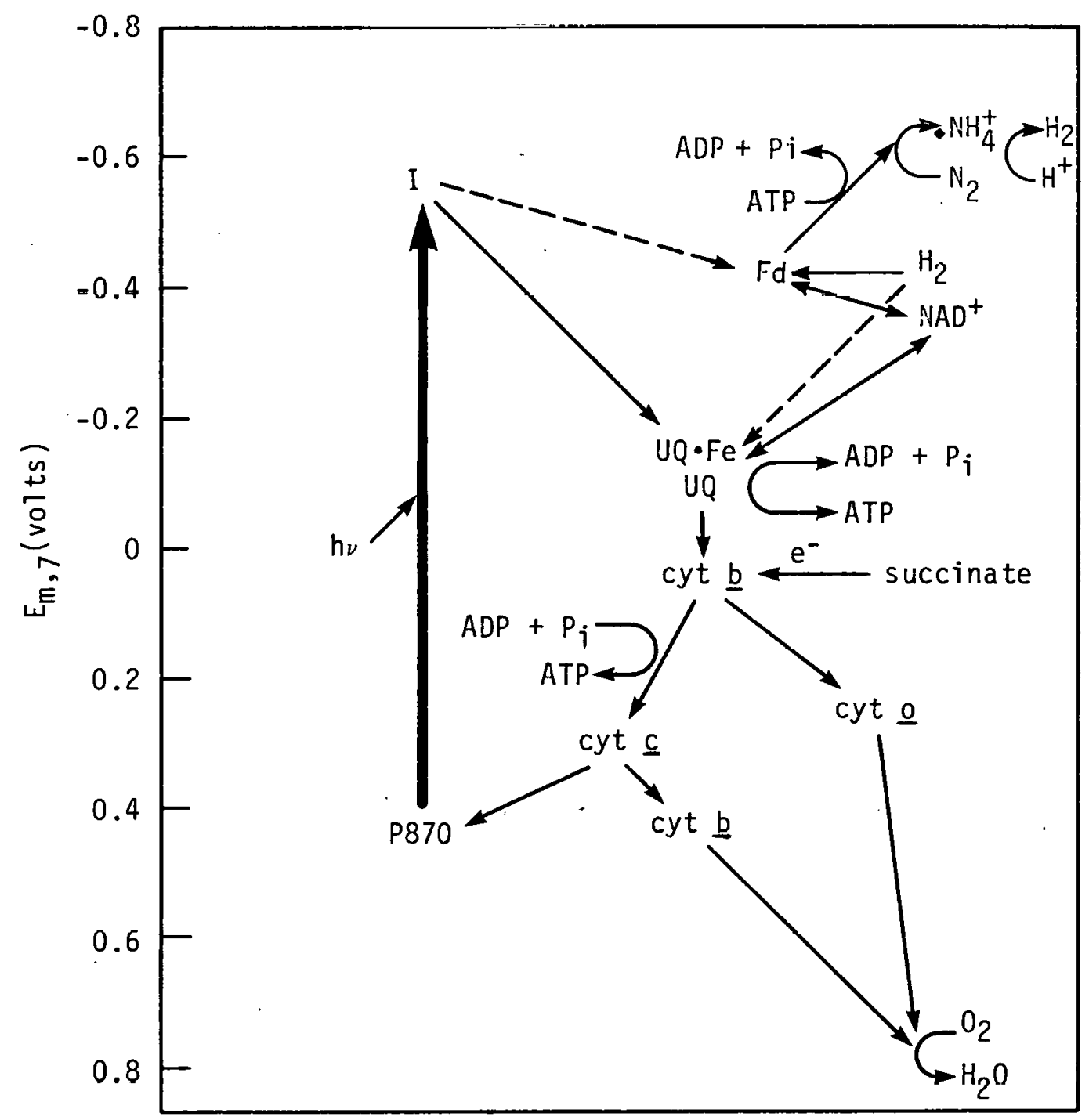

FIGURE 3-2. ELECTRON TRANSPORT IN PHOTOSYNTHETIC BACTERIA AND ITS RELATIONSHIP TO $\mathrm{N}_{2}$ FIXATION AND $\mathrm{H}_{2}$ METABOLISM.

Light excites an electron in $\mathrm{P} 870$, the reaction center bacteriochlorophy11, to a level where it can reduce the acceptor I. Subsequently the electron is transferred sequentially through an iron-quinone moiety (UQ.Fe, or $X$ in Figure 3-1), a pool of ubiquinone (UQ), cytochrome-carriers, and back to oxidized $P 870$. In the process ATP is generated. Noncyclic electron transport to ferredoxin (Fd) is represented by a broken line indicating an uncertain reaction. See text for further discussion. The scheme presented includes aerobic respiratory pathways which reflect data of Marrs and Gest (1973). 
and Yike (1967) demonstrated that in the dark, ATP can provide the necessary energy to drive a reversal of electron flow from succinate to oxidized NAD ${ }^{7}$ (although the rates obtained were only $20 \%$ or less than those observed in the light). However, no evidence for the reduction of ferredoxin via a reversed electron transport mechanism has been obtained.

The third possible mechanism for the generation of reduced ferredoxin was suggested by Bennett et al. (1964) as operative in Chromatium. They proposed that a phosphoroclastic cleavage of pyruvate reduces ferredoxin in a dark reaction analogous to that observed in $\underline{C}$. pasteurianum. In this model the function of light is relegated to that of providing optimal levels of ATP through cyclic photophosphorylation. Anaerobically dark-grown cells of $\underline{R}$. rubrum exhibit the phosphoroclastic reaction as well, though the cells have not been shown capable of $\mathrm{N}_{2}$-fixation or $\mathrm{H}_{2}$ evolution under these conditions (Gorrel and Uffen, 1977). Further confirmation and extension of this model to other photosynthetic organisms is obviously needed.

\subsubsection{Coupling to Uptake Hydrogenase}

Hydrogenases from nonphotosynthetic sources couple specifically to a variety of different electron carriers. Ferredoxin (Mortenson, 1963), flavodoxin (Knight and Hardy, 1966), $\mathrm{NAD}^{+}$(Schneider and Schlegel, 1977), and cytochrome $c_{3}$ (Yagi et al., 1968) are all physiological acceptors or donors for hydrogenase.

As mentioned previously, in vivo photosynthetic bacterial hydrogenases appear to function exclusively in the uptake direction. Hydrogen uptake in the purple sulfur bacterium Chromatium is linked to a sequential reduction of Eerredoxin and of $\mathrm{NAD}^{+}$(Weaver et al., 1965; Buchanan and Bachofen, 1968). A similar mechanism may exist in the green sulfur bacterium Chlorobium (Weaver et a.1., 1965).

The nonsulfur photosynthetic bacteria apparently couple $\mathrm{H}_{2}$ uptake in a manner different from that of the sulfur bacteria. Of those tested, none can use $\mathrm{H}_{2}$ to reduce $\mathrm{NAD}^{+}$anaerobically in the dark (Klemme, 1969; Weaver, unpublished results). Exogenously added flavin mononucleotides become partially reduced by $\dot{\mathrm{H}}_{2}$ in deoxycholate-treated subcellular particles (Bose and Gest, 1962), suggesting a moderately low potential acceptor. It is of interest that many of these organisms contain ferredoxin (Shanmugam et al., 1972), flavodoxin (Cusanovich and Edmonson, 1971), and cytochrome $\underline{c}_{3}$ (Bartsch, 1978), all of which are acceptors or donors to hydrogenase from other sources. No physiological role tor these components in the $\mathrm{H}_{2}$ uptake metabolism of the nonsulfur photosynthetic bacteria has been observed.

There is reason to believe that, with proper reductant supplies and coupling, these hydrogenases can be made to function in the evolution direction. For example, $\mathrm{H}_{2}$ is readily evolved by Chromatium hydrogenase in the presence of reduced methyl viologen (Gitlitz and Krasna, 1975). Chronatium ferredoxin, the normal carrier to this hydrogenase, has a midpoint potential $70 \mathrm{mV}$ more negative than that of the $\mathrm{H}_{2}$ couple (Arnon, 1965). Using in vitro or modified in vivo systems, reduced ferredoxin generated from photometabolism should $\overline{\mathrm{dr}}$ ive the photoevolution of $\mathrm{H}_{2}$ by hydrogenase. 


\subsubsection{Oxygenic Photosynthetic Organisms}

Under appropriate conditions various algae and cyanobacteria evolve $\mathrm{H}_{2}$ gas when illuminated with photosynthetically active light (380 to $720 \mathrm{~nm})$. This implies the existence of a coupling mechanism linking the light-induced redox reactions with the $\mathrm{H}_{2}$-producing dark enzymatic reactions. In order to provide the essential foundation upon which a detailed discussion of the coupling mechanism can be based, a brief description of electron transport in oxygenic photosynthetic organisms is provided. Extensive reviews of the structural, functional, biochemical, and biophysical properties of the photosynthetic electron transport apparatus are available (Trebst, 1974; Junge, 1977; Goldbeck et al., 1977).

\subsubsection{Electron Transport}

Unlike photosynthetic bacteria, in which the primary photochemical process involves a single photosystem, the oxygenic photosynthetic redox reactions of algae and cyanobacteria consist of a more complex form of photosynthetic electron transport which is driven by two sequentially linked photochemical reactions. Both are associated with enzyme-pigment complexes of membranous nature and are called photosystem I (PSI) and photosystem II (PSII). As illustrated in Figure 3-3, the primary photochemical reaction of PSI (which may be similar to that observed in bacterial reaction centers; see Section 3.2.1.1) generates a weak oxidant, $\mathrm{P} 700^{+}$, which subsequently receives electrons from PSII via a series of redox carriers (including a pool of plastoquinones, cytochrome $f$, and plastocyanin). At the same time it also produces a strong reductant $\mathrm{X}^{-}$, which is the reduced form of the primary electron acceptor of PSI. At present, the chemical identity of $X$ is uncertain. It may be a membrane-bound iron-sulfur protein, but alternative possibilities cannot be ruled out (Bolton, 1976; Malkin et a1., 1976; Heathcote et al., 1978; Sauer et al., 1978). Under normal conditions $X^{-}$ donates its electrons to nicotinamide adenine dinucleotide phosphate (NADP ${ }^{+}$, a hydrogen carrier) through another series of redox components including a we11characterized ferredoxin ( $F d$, an iron-sulfur protein) and ferredoxin - NADP ${ }^{+}$ oxidoreductase (FP, a flavoprotein). The reduced form of NADP together with ATP formed by coupled electron flow ultimately reduces $\mathrm{CO}_{2}$ to carbohydrate $\left(\mathrm{CH}_{2} \mathrm{O}\right)_{n}$. However, the redox midpoint potential of $\mathrm{X}^{-}$is thought to be approximately 100 to $200 \mathrm{mV}$ more negative than that of the hydrogen electrode (Goldbeck et al., 1977), and thus the reducing equivalents (which conserve a substantial fraction of the energy input provided by the absorbed photons) generated by PSI are sufficiently energetic to reduce hydrogen ions directly to molecular H..

The primary photochemical reaction of PSII produces a weak reductant, $Q^{-}$ (thought to be a specialized plastoquinone), that donates electrons to PSI through a series of inter-photosystem redox carriers (see Figure 3-3). At the same time PSII generates a strong oxidant, $\mathrm{P} 680^{+}$. Mediated by the watersplitting enzyme complex of PSII, P $680^{+}$eventually oxidizes water to molecular $\mathrm{O}_{2}$ and thereby obtains reducing equivalents (electrons) for the photochemical reduction of $Q$ to $Q^{-}$. The basic redox reaction catalyzed by PSII can be expressed as follows: 


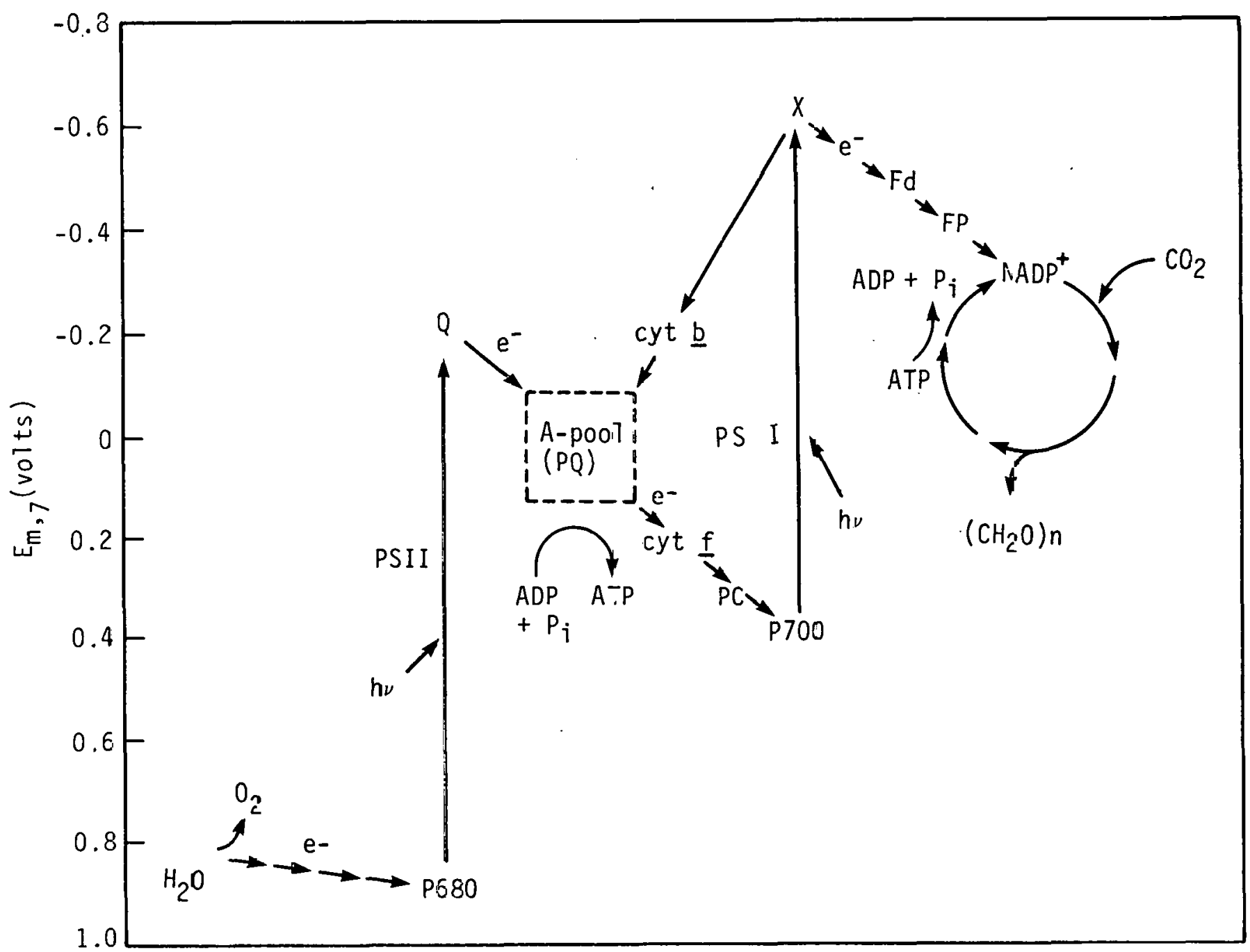

FIGURE 3-3. ELECTRON TRAIISPORT SYSTEMS OF OXYGENIC PHOTOSYNTHETIC ORGANISMS.

Light absorbed by photas rstem II (PSII) excites P680, the reaction center chlorophyll of PSII, and generates a strong oxidant capable of removing electrons from water. Light absorbed by photosystem I (PSI) excites P700, the reaction center choloraphyll of PSI, and generates a strong reductant $X^{-}$ capable of reducing ferredoxin ( $F d)$ and a flavaprotein (FP). Electron transport between the two photosystems is mediated by a pool of plastoquinone ( $P 0$, al so known as A-pool), cytochrome $f$ (cyt $f$ ) and plastacyanin (PC). ATP created in the process is utilized in conjunction with PSI reductants to reduce $\mathrm{CJ}_{2}$ to the level of carbohydrate $\left(\mathrm{CH}_{2} \mathrm{O}\right) \mathbf{n}$. 


$$
2 \mathrm{H}_{2} \mathrm{O} \underset{\mathrm{PSII}}{\mathrm{PSV}} \mathrm{O}_{2} \uparrow+4 \mathrm{H}^{+}+4 \mathrm{e}^{-}
$$

where $e^{-}$represents the reducing equivalent at the level of $\mathrm{Q}^{-}$.

The water oxidation reaction associated with PSII is a unique photochemical process that uses visible light to split water molecules efficiently. Because of the optical absorption properties and highly stable bond structure of water, nonenzymatic photolysis occurs only in the presence of photons with wavelengths shorter than $185 \mathrm{~nm}$ (Calvert and Pitts, 1966; Bolton, 1978). These wavelengths, of course, are not present in the solar spectrum at the surface of earth. Although visible light is poorly absorbed by water and is not sufficiently energetic to decompose water directly, it can split water if a suitable, photochemically active "catalytic system" is present. Such a system would combine the energy of two or more photons absorbed by the "catalyst" in a concerted "multiphoton reaction" or more likely in a sequential photodriven reaction cycle. PSII, in fact, uses visible light to split water in this manner. Briefly, the absorption of four visible photons (in sequential events which can be spaced up to a few seconds apart) results in the accumulation of four positive charges within the water-splitting enzyme complex. At this point, the complex rapidly oxidizes two molecules of water to molecular $\mathrm{O}_{2}$ (for a review see Radmer and Cheniae, 1977) and releases four reducing equivalents.

In summary, reducing equivalents extracted from water by PSII are further activated by PSI. At the level of $\mathrm{X}^{-}$, the electrons are energetically capable of spontaneously driving the various reductive reactions associated with the biosynthetic metabolism of the organism. However, as mentioned earlier, $\mathrm{X}^{-}$is approximately 100 to $200 \mathrm{mV}$ more negative than the hydrogen electrode and therefore is capable of reducing protons (which are also produced in the water-splitting reaction and are present in the aqueous medium) to $\mathrm{H}_{2}$ gas.

At this point, the pertinent questions are: (1) can the reducing equivalents be coupled to the production of $\mathrm{H}_{2}$ in vivo and, if so, (2) are the mechanisms of coupling identical in various $\mathrm{O}_{2}$-evolving photosynthetic organisms? The answer to the first question is yes (see Section 2), although $\mathrm{H}_{2}$ evolution does not necessarily occur under physiological conditions (Bishop et al., 1977; Bothe et a1., 1978). The answer to the second question is no. There are at least two different modes of coupling among the $\mathrm{O}_{2}$-evolving organisms. The first type of coupling involves the enzyme hydrogenase (3.1.1) and is found in green and red algae as well as cyanobacteria. The second type of coupling is found only in particular species of cyanobacteria and, like $\mathrm{H}_{2}$ production in photosynthetic bacteria, involves the catalytic activity of the nitrogen-fixing enzyme complex, nitrogenase (3.1.2).

\subsubsection{Coupling Mechanism in Algae}

In their original study of $\mathrm{H}_{2}$ photoproduction in algae, Gaffron and Rubin (1942) concluded that light-dependent evolution is not simply a lightaccelerated version of the dark, fermentative $\mathrm{H}_{2}$ production process. Rather, the authors provided the following farsighted interpretation of the mechanism: "We assume that the hydrogen originates from water in the photochemical reaction; that it is part of the hydrogen destined to reduce carbon dioxide. 
Unable to reach the substrate, the hydrogen is transferred to the hydrogenase and there transformed into the free gas." Moreover, Frenkel (1952), using anaerobically adapted Chlamydomonas moewsuii which also exhibits $\mathrm{H}_{2}$ production in the light, arrived at a similar conclusion. However, he reported that in the light $\mathrm{H}_{2}$ and $\mathrm{CO}_{2}$ (instead of $\mathrm{H}_{2}$ and $\mathrm{O}_{2}$ ) were produced at a ratio of $1.7: 1$ and concluded that an internal source of reductant (produced via a fermentative process) was also consumed during the photoproduction of $\mathrm{H}_{2}$. The reductant reacted with the oxidants (i.e., $\mathrm{O}_{2}$ or its precursors) generated during the photochemical splitting of water. Questions about the source of reducing power continued for a number of years.

By the early 1960 s most investigators recognized that $\mathrm{O}_{2}$-evolving photosynthetic organisms contained two photosystems operating in series (see Section 3.2.2.1). Consequently, the question arose whether both photosystems were involved in the photoproduction of $\mathrm{H}_{2}$. Healey (1970) observed in $\mathrm{C}$. moewsuii that $\mathrm{H}_{2}$ evolution was completely eliminated by monofluoroacetate (an inhibitor of the tricarboxylic acid or Krebs cycle reactions) but was rather insensitive to 3-(3,4-dichloropheny 1)-1,1-dimethylurea (DCMU, a potent and specific inhibitor of PSII electron transport). Stuart and Kaltwasser (1970), investigating the effects of heating, chemical inhibitors, and specific electron transport mutants on $\mathrm{H}_{2}$ production by Scenedesmus, also raised serious questions about the ultimate source of electrons. However, both groups demonstrated the direct involvement of PSI in $\mathrm{H}_{2}$ photoproduction. For example, PSI-defective mutants of Scenedesmus were unable to evolve $\mathrm{H}_{2}$ (Stuart and Kaltwasser, 1970), and the action spectrum in C. moewsuii was characteristically that of a PSI-catalyzed reaction (Healey, $\overline{1970) . ~ M o r e ~ r e c e n t l y, ~}$ Greenbaum (1977), using a short saturating flash technique, reported a very fast turnover time $(0.1$ to $5 \mathrm{msec})$ for PSI-catalyzed $\mathrm{H}_{2}$ photoproduction in Scenedesmus, Chlamydomonas reinhardi, and Chlorella vulgaris. Efimtsev et al. (1976) also observed that $\mathrm{H}_{2}$ could be detected in Chlorella pyrenoidosa within $1-2 \mathrm{msec}$ of a short-duration $(40 \mu \mathrm{sec})$ flash. These results clearly demonstrated the intimacy of in vivo interaction between PSI and the hydrogenase system. Additional evidence for the absolute requirement of the PSI reactions has been reviewed recently by Bishop et al. (1977).

In contrast to the general agreement on the participation of PSI, the role of PSII in algal $\mathrm{H}_{2}$ photoproduction is a subject of considerable controversy. On the one hand, several groups have concluded that water was the source of reducing equivalents (Gaffron and Rubin, 1942; Frenke1, 1952; Bishop and Gaffron, 1963); and on the other hand, Healey (1970), Stuart and Kaltwasser (1970), and Wang et al. (1971) reported that $\mathrm{H}_{2}$ evolution was either unaffected or only partially sensitive to specific inhibitors of PSII activity. These conflicting observations were caused in part by different species of algae used in the various experiments (Stuart and Gaffron, 1972), by differences in the nutritional condition of the cells during their cultivation, and by differences in the prevailing physiological state of the organisms during assay (Stuart and Gaffron, 1972; Bishop et al., 1977). Given the intrinsic complexity of the various metabolic processes of algal cells, it is likely that in vivo photoproduction of $\mathrm{H}_{2}$ in different organisms under different physiological and experimental conditions may well occur by different metabolic pathways. In any event, the participation of PSII reactions and, therefore, the ultimate utilization of water as a substrate is thermodynamically favorable. In addition, under appropriate experimental 
conditions simultaneous photoproduction of both $\mathrm{H}_{2}$ and $\mathrm{O}_{2}$ gases has been clearly documented by various experimental techniques with different species of algae (Bishop and Gaffron, 1963; Bishop et al., 1977; McBride et al., 1977). Furthermore, in some cases the ratio of $\mathrm{H}_{2}$ to $\mathrm{O}_{2}$ produced in the $\overline{1 \text { ight }}$ approaches the theoretical value of 2.0 as required for the splitting of water (Bishop et al., 1977). Thus, at least under some conditions, water is the ultimate source of reducing power.

In any case, $\mathrm{H}_{2}$ production appears to be catalyzed by an anaerobically adaptable hydrogenase. An anaerobic incubation period of varying duration is a prerequisite, and the adaptation process appears to require energy (Benemann et al., 1978). In all species of algae examined to date, the conditions that lead to activation of photoproduction also lead to the appearance of $\mathrm{H}_{2}-$ utilizing processes, such as reductive $\mathrm{CO}_{2}$ fixation with $\mathrm{H}_{2}$ as electron source (photoreduction and dark $\mathrm{CO}_{2}$ fixation) and the reduction of $\mathrm{O}_{2}$ by $\mathrm{H}_{2}$ (the oxyhydrogen reaction). All observations so far suggest that $\mathrm{H}_{2}^{2}$ photoproduction is catalyzed by an $\mathrm{O}_{2}$-sensitive, CO-inhibitable, ATP-independent reversible hydrogenase which is also responsible for the $\mathrm{H}_{2}$-utilizing reactions of the organism. However, there is evidence that some red algae contain only an uptake hydrogenase (Ben-Amotz et al., 1975). Hydrogen photoproduction in algae is not sensitive to uncouplers of photophosphorylation or oxidative phosphorylation. In fact, the reaction is often stimulated by the uncouplers (Gaffron and Rubin, 1942; Frenke1, 1952; Healey, 1970; and Wang et al., 1971). In contrast, photoproduction of $\mathrm{H}_{2}$ in photosynthetic bacteria and cyanobacteria (see Sections 3.2 .1 and 3.2.2.3) are highly sensitive to uncouplers of phosphorylation. Thus, unlike nitrogenase-catalyzed $\mathrm{H}_{2}$ photoproduction in the procaryotic organisms which require ATP, algal cells involve only redox coupling between the low-potential reductants formed by PSI and hydrogenase. The most probable in vivo coupling reactions between the hydrogenase system and electron transport system of algae are summarized in Figure 3-4.

\subsubsection{Coupling Mechanism in Cyanobacteria}

Cyanobacteria are photosynthetic procaryotes situated between photosynthetic bacteria and green algae, on the evolutionary scale. They derive electrons for $\mathrm{CO}_{2}$ reduction from water (and thus evolve $\mathrm{O}_{2}$ ) as do green algae but some also fix $\mathrm{N}_{2}$ as do photosynthetic bacteria. Of more than a thousand species identified, only a few have been extensively examined in the laboratory. Therefore, any generalized statements concerning the biochemistry and metabolism of these organisms must be accepted with caution.

Photosynthetic electron transport in cyanobacteria (Krogmann, 1973) is quite similar to that in algae and higher plants (see Section 3.2.2.1). Both PSII and PSI operate in series and cover similar redox potential ranges. Most of the electron transport redox carriers are similar or identical to those in eucaryotic photosynthetic organisms (Krogmann, 1977). Since cyanobacteria contain hydrogenase (Packer et al., 1977a; Tel-Or et al., 1978), it might be expected that coupling to $\mathrm{H}_{2}$ production would be similar to that observed in green algae. Unfortunately, the situation is not that simple.

The limited information available on $\mathrm{H}_{2}$ photoproduction in cyanobacteria is restricted to the $\mathrm{N}_{2}$-fixing species, which contain nitrogenase in addition to 


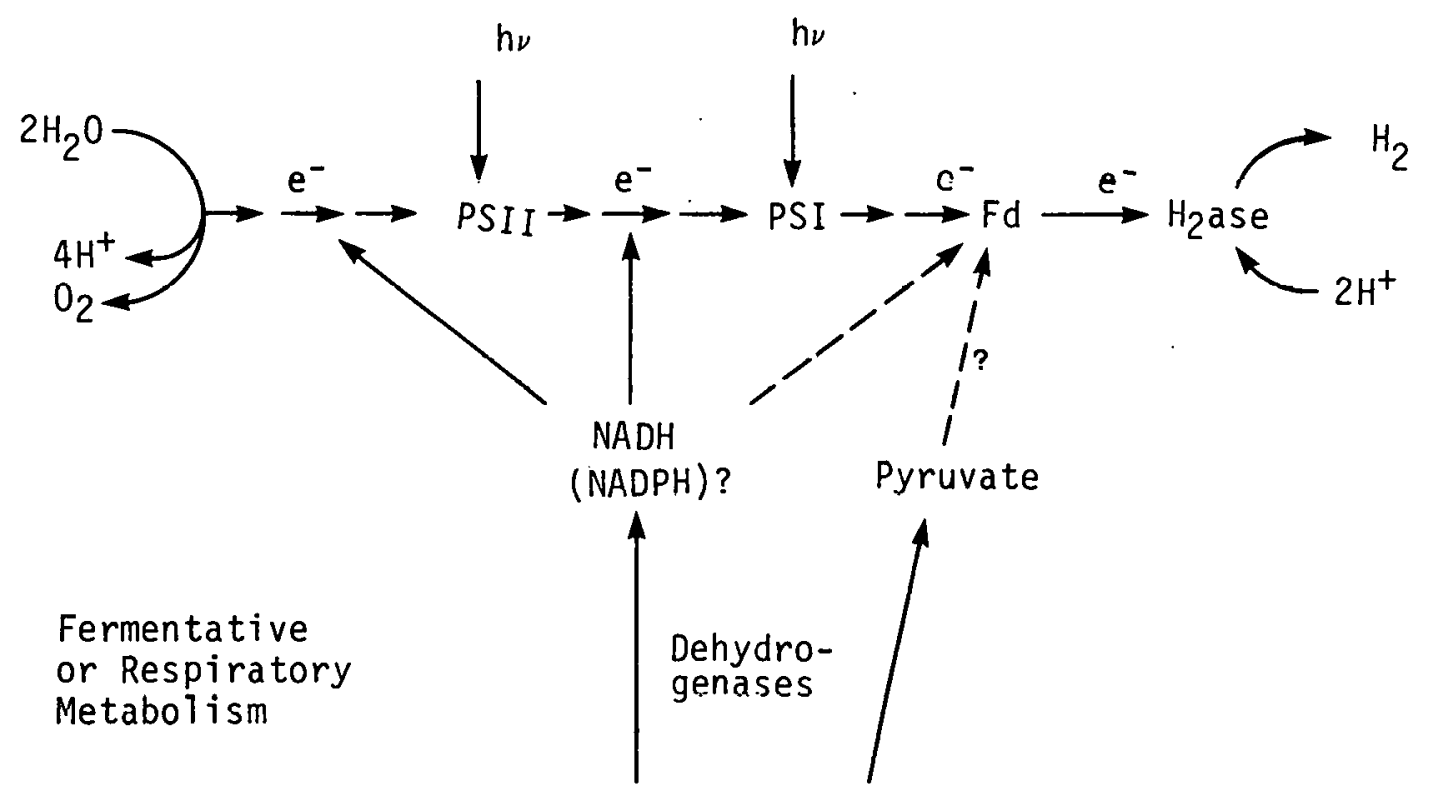

Organic Substrates

FIGURE 3-4. IN VIVO HYDROGEN PRODUCTION IN ALGAE.

The electron transport scheme and symbols are the same as in Fiqure 3-3. Hydrogen evolution is mediated by hydrogenase, which is directly coupled to ferredoxin. The reduced ferredoxin can be supplied by direct liahtdriven reactions or by dark metabolic reactions. 
hydrogenase (Fay et al., 1968). Bothe et al. (1978) have reviewed this area

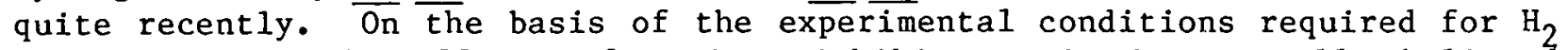
production and the effects of various inhibitors, it is generally believed that in vivo $\mathrm{H}_{2}$ production in these organisms is coupled to CO-resistant, ATPdependent nitrogenase activity (Benemann and Weare, 1974; Jones and Bishop, 1976; Peters et al., 1976; Weissman and Benemann, 1977). COsensitive, ATP-independent hydrogenase activity is not coupled to in vivo $\mathrm{H}_{2}$ production, probably because of poor reactivity with the low potential electron carrier ferredoxin (Fujita and Myers, 1965; Bothe et al., 1978). Thus it appears that the hydrogenases of these organisms function exclusively in $\mathrm{H}_{2}$ uptake reactions (Fujita and Myers, 1965; Benemann and Weare, 1974; Bothe et al., 1978). As discussed in Section 3.1, the organism probably uses this mechanism to recycle $\mathrm{H}_{2}$ leaked during $\mathrm{N}_{2}$ fixation, thereby increasing the efficiency of the latter reaction (Smith et al., 1976; Bothe et al., 1977; Te1-Or et al., 1978; Peterson and Wolk, 1978).

Nitrogenase, even more than hydrogenase in eucaryotic algae, is extremely sensitive to inactivation by $\mathrm{O}_{2}$ (Fay and Cox, 1967; Haystead et al., 1970). Thus an in vivo means of protecting nitrogenase activity from $\overline{\mathrm{O}_{2}}$ inactivation must be an integral part of the overall mechanism of coupling photosynthetic reductants to the nitrogenase system. Some filamentous cyanobacteria (Anabaena, for example) effectively overcome the problem by differentiating specialized cells known as heterocysts which provide an anaerobic cellular environment for nitrogenase in spite of the presence of $\mathrm{O}_{2}$ in the extraheterocystous space. Detailed descriptions of the developmental, metabolic and structural aspects of heterocysts have appeared in recent reviews (Stainer and Cohen-Bazire, 1977; Haselkorn, 1978).

That the heterocyst is the major site of nitrogenase activity in Anabaena has been well documented (Fay et al., 1968; van Gorkom and Donze, 1971; Thomas and David, 1972; Weare and Benemann, 1973). But how do heterocysts provide an anaerobic environment for nitrogenase? The answer is complex. First, Anabaena heterocysts are surrounded by a multilayered cell wall structure and their connections with neighboring vegetative cells are much more restricted than those between two neighboring vegetative cells (Lang and Fay, 1971; Wilcox et al., 1973a and 1973b). These structural modifications provide a diffusion barrier between the interior of the heterocyst and its surrounding environment. Furthermore, the highly reducing nature of the intraheterocystous medium (Stewart et al., 1969) and the very active respiratory process of the heterocysts (Fay and Walsby, 1966) contribute to the maintenance of an anaerobic environment.

Perhaps the most important mechanism for protecting nitrogenase activity from $\mathrm{O}_{2}$ inhibition results from a major modification in the photosynthetic electron transport apparatus. During heterocyst differentiation and development, the PSII complex disappears in a process probably involving proteolytic destruction (Haselkorn, 1978). Thus, mature heterocysts exhibit no detectable PSII activity and are unable to produce $\mathrm{O}_{2}$ (Thomas, 1970; Donze et al., 1972; Te1-Or and Stewart, 1975 and 1977). On the other hand, the heterocysts retain highly active PSI complexes capable of generating ATP in a coupled reaction with light-driven cyclic electron flow (Donze et al., 1972; Lex and Stuart, 1973; Donze et al., 1974; Alberte and Te $\overline{1-0} \bar{r}$ 1977). The modified photosynthetic processes in the heterocyst are best described by Stanier and 
Cohen-Bazire (1977): "...the available information suggests that the mature heterocyst retains a modified photosynthetic apparatus, which is a phenocopy of that of a purple or green (photosynthetic) bacterium."

Lacking the water-splitting function of PSII, sustained $\mathrm{N}_{2}$ fixation or $\mathrm{H}_{2}$ production by nitrogenase in the heterocyst is critically dependent on the supply of reductants imported from the neighboring vegetative cells. In fact, active movement of organic carbon compounds and sugar phosphates from the vegetative cells into heterocysts has been demonstrated by autoradiographic techniques and other tracer analyses (Wo1k, 1968; Weare and Benemann, 1973; Juttner and Carr, 1976; Wolk et al., 1976). The mechanism of intercellular transport of organic carbon and the mode of reductant generation in the heterocysts have been reviewed by Haselkorn (1978). Maltose is the major fixed carbon species transported to the Anabaena heterocyst, wherein it is metabolized to produce NADPH. However, it is not clear whether NADPH is utilized to reduce ferredoxin (the most probable immediate electron donor for nitrogenase) exclusively in a dark reaction catalyzed by NADP $^{+}$-ferredoxin oxidoreductase or whether it is also used as an electron donor for PSI in the photochemical reduction of ferredoxin (Bothe et al., 1978). Reduced ferredoxin can also be generated from pyruvate via pyruvate-ferredoxin oxidoreductase (Bothe et al., 1974).

In summary, the in vivo coupling mechanism employed by the heterocystous

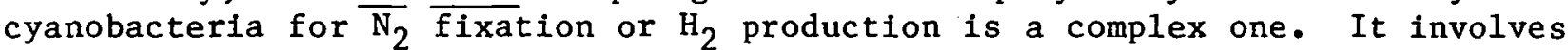
a spatial separation of two mutually incompatible partial processes-- PSIIdependent generation of $\mathrm{O}_{2}$ and fixed carbon in vegetative cells and anaerobic $\mathrm{N}_{2}$ fixation or $\mathrm{H}_{2}$ production by nitrogenase in the heterocysts. The integration of the two partial processes is achieved via intercellular transport of metabolites and reductants. In essence, the coupling mechanism developed by the heterocystous cyanobacteria is equivalent to a two-staged $\mathrm{H}_{2}$ producing scheme (see Section 5.1.4) using oxygenic algae (vegetative cells) to generate reductants for the formation of $\mathrm{H}_{2}$ by anoxygenic photosynthetic bacteria (heterocysts). While the system apparently overcomes the adverse effect of $\mathrm{O}_{2}$, the overall energy efficiency of $\mathrm{H}_{2}$ production is inherently lower than one would expect from a more direct means of coupling.

Hydrogen production by a nonheterocystous, filamentous cyanobacterium (Plectonema boryanum) was reported to paralle1 the nitrogenase activity of the cells (Weare and Benemann, 1974). Photosynthetic activity ( $0_{2}$-evolution) decreased as nitrogenase activity ( $\mathrm{H}_{2}$ production and nitrogen fixation) was induced by anaerobic adaptation. The reductants for $\mathrm{H}_{2}$ production in this case are derived from stored substrates generated by photosynthesis. Apparently, in the absence of heterocysts a temporal separation of these mutually imcompatible reactions is necessary. Among unicellular cyanobacteria, Gleothece exhibits a similar tempora1 separation of nitrogenase activity and photosynthetic $\mathrm{O}_{2}$ evolution activity (Gallon et al., 1975). However, $\mathrm{H}_{2}$ production in this organism has not been reported.

\subsection{CONTROL MECHANISMS}

Light intensity and $\mathrm{O}_{2}$ tension are the dominant factors in the biosynthetic control of the many components of the bacterial photosynthetic apparatus 
(Oelze and Drews, 1972; Kaplan, 1978, Drews, 1978). However, despite their intimate connection with photosynthesis, hydrogenase and nitrogenase activities are apparently regulated by other mechanisms.

The adaptation of algal hydrogenase (Gaffron, 1940) requires 2 to 30 hours or more of dark, anaerobic incubation (Kessler, 1974). Inhibitors of protein synthesis partially inhibit the process, suggesting that both de novo synthesis and activation of existing hydrogenase occur during the anaerobiosis (Oesterheld, 1971). Additions of glucose or iron-EDTA stimulate the appearance of hydrogenase activity through unknown means (Sasaki, 1966). The BSW8 strain of the photosynthetic bacterium Rps. sulfidophila also exhibits hydrogenase activity that is strongly stimulated by anaerobic, dark incubation (see Table 4-1). However, only cultures interrupted in logarithmic phase of growth showed such large dark-induced increases; fully grown or newly inoculated cultures do not respond with more than a doubling of activity when placed in darkness (Weaver, to be published). Hydrogen itself is not an effector, but the presence of both a reduced carbon source such as glucose or formate and bicarbonate ion is essential for expression of hydrogenase.

In the light, autotrophic growth on $\mathrm{H}_{2}$ also produces high levels of hydrogenase activity. Most photosynthetic bacteria exhibit approximately equivalent levels of hydrogenase activity, whether grown heterotrophically or autotrophically on $\mathrm{H}_{2}$, when assayed during the stationary phase. The enzyme is not constitutive in these organisms, however; samples taken at different times during heterotrophic growth show that logarithmic cultures have little hydrogenase activity. Only when cultures depart from the logarithmic phase of growth does hydrogenase activity appear, and during stationary phase the level of activity equals that of autotrophic cells. It is at this same point of the growth cycle that previous work (Weaver, 1975) indicated that major alterations occur in the physiological (including $\mathrm{H}_{2}$ photoevolution), spectral, and component makeup of the photosynthetic apparatus, apparently attributable to a drop in the redox potential within the cells. Schick (1971b) likewise observed an increase of $\mathrm{H}_{2}$-mediated photoreduction of $\mathrm{CO}_{2}$ at this stage of growth. Winpenny (1969) has suggested that E. coli also initiate hydrogenase biosynthesis when incubated in a reducing environment. In addition, $\mathrm{O}_{2}$ inhibits the biosynthesis of hydrogenase in aerobically grown cultures of photosynthetic bacteria. This finding may also be due to an alteration, this time through an increase, in the redox potential of the medium. The underlying mechanism(s) for these phenomena remains unknown, however.

Lee and Wilson (1943) reported that hydrogenase is coinduced with nitrogenase in some $\mathrm{N}_{2}$-fixing organisms. However, such strict correlations are not always observed in photosynthetic bacteria where nitrogenase-induced logarithmic phase cultures exhibit no demonstrable hydrogenase activity (see Table 4-1). However, the lowered in vivo redox potentials in aged cells that are associated with the initiation of $\mathrm{H}_{2}$ photoevolution from nitrogenase are also coincident with the biosynthesis of hydrogenase.

Small amounts of ammonium ion stimulate the photoreduction of $\mathrm{CO}_{2}$ with $\mathrm{H}_{2}$ (Schick 1971c; Hillmer and Gest, 1977b). The rapidity of the stimulation implies that the regulatory effect is at the enzyme level, but the specific site of $\mathrm{NH}_{4}^{+}$influence in this multistep reaction is presently unclear. 
In contrast to hydrogenase, small amounts of $\mathrm{NH}_{4}^{+}$inhibit nitrogenase-mediated $\mathrm{H}_{2}$ production in photosynthetic bacteria. Furthermore, the inhibition occurs at two levels. First, the biosynthesis of nitrogenase is repressed by $\mathrm{NH}_{4}^{+}$ (Ormerod et al., 1961). This is not altogether surprising since nitrogenase can constitute up to $20 \%$ of the cellular soluble protein (Ludden and Burris, 1978), and its unregulated synthesis under conditions where nitrogenase is not needed would impose an unacceptable metabolic burden on the cell. On the other hand, some forms of combined nitrogen, such as glutamate, support growth yet do not repress nitrogenase synthesis. Most amino acids do not repress nitrogenase in Rps. capsulata (Hillmer and Gest, 1977a), but several do so in R. rubrum (Bregoff and Kamen, 1952). In the latter report a steady-state level of $\mathrm{NH}_{4}^{+}$was observed in culture medium containing repressive amino acids. Presumably the $\mathrm{NH}_{4}^{+}$comes from cellular deamination reactions, causing the inhibition. Very high levels of glutamate inhibit nitrogenase biosynthesis in Rsp. capsulata as well, and this has also been correlated with the release of free $\mathrm{NH}_{4}^{+}$into the medium (Hillmer and Gest, 1977a).

Ammonium ion itself is probably not the repressor of nitrogenase synthesis. Methionine sulfoximine, a glutamate analogue, derepresses A. vinelandii nitrogenase even in the presence of excess $\mathrm{NH}_{4}^{+}$(Gordon and $\overline{\mathrm{Br}} \overline{11}, 1974$ ). Similar results have been obtained with $R_{\text {. }}$ rubrum (Weare and Shanmugam, 1976)

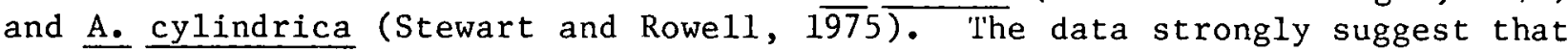
glutamine synthetase, the enzyme responsible for newly fixed ammonia assimilation, plays a critical role in the biosynthetic regulation of nitrogenase in addition to other enzymes of cellular nitrogen metabolism (Brill, 1975; Magasanik et al., 1975).

A second form of $\mathrm{NH}_{4}^{+}$control is exerted at the enzyme level and effects short-term regulation of presynthesized nitrogenase activity. Concentrations as low as $10 \mu \mathrm{M}$ are inhibitory (Meyer et al., 1978a). Inhibition is observed immediately upon addition of $\mathrm{NH}_{4}^{+}$, and total release from inhibition is observed upon its metabolic removal (Schick 1971a; Hillmer and Gest, 1977b). The mechanism of this phenomenon is unknown since purified nitrogenases are inhibited only slightly by much higher concentrations of $\mathrm{NH}_{4}^{+}$(Neilson and Nordlund, 1975). 


\section{SECTION 4.0 \\ COMPARATIVE RATES OF HYDROGEN CONSUMPTION}

Any comparison of the published rates of $\mathrm{H}_{2}$ exchange suffers from variations in both the assay systems and the rate calculation methods employed by different investigators. These variant factors include the conditions for growth of the cells, the type of assay employed, the nature of the reactants and their concentrations, temperature, $\mathrm{pH}$, references used to calculate activity (dry weight, protein, chlorophyll, etc.), calculations based on maximal or steady state rates, and the presence of $\mathrm{O}_{2}$-scavenging or continuous sparging systems. Adequate comparisons can be made only from data accumulated under similar conditions.

Comparative surveys have recently been initiated. A survey of the hydrogenase activities of twelve aerobic $\mathrm{H}_{2}$-consuming nonphotosynthetic bacteria was made by Schneider and Schlegel (1977). Surprisingly, a strain of Pseudomonas exhibited a 20-fold higher activity than A. eutrophus strains though absolute rates were not reported. Additionally, the $\mathrm{H}_{2}$ consumption rates of a large number of photosynthetic bacteria have been determined (Weaver, unpublished results); they commonly vary between 0 and $6 \mu \mathrm{l} \mathrm{H}_{2} \cdot \mathrm{mg} \mathrm{dry} \mathrm{wt}^{-1} \cdot \mathrm{min}^{-1}$ for most strains (see Table 4-1). A notable exception is Rps. sulfidophila BSW8, which under certain environmental conditions (see Section 3.3) expresses a high level of derepressed hydrogenase activity. Examples of nonphotosynthetic bacteria, including a highly active marine strain of Desulfovibrio, are also included in Table 4-1. 
Table 4-1. REPRESENTATIVE COMPARATIVE RATES OF $\mathbf{H}_{2}$ UPTAKE

\begin{tabular}{|c|c|c|}
\hline & & Activity \\
\hline Organism & Growth Conditions & $\left(\right.$,il $\mathrm{H}_{2} \cdot \mathrm{mg}$ dry wt $\left.\mathrm{win}^{-1} \cdot \mathrm{min}^{-1}\right)$ \\
\hline
\end{tabular}

Photosynthetic Bacteria

Chromatium vinosum, Strain D

Rhodospirillum rubrum S-1

Thiocapsa roseopersicina Rhodomicrobium vannielii

Rhodopseudomonas capsulata SP7

Rhodopseudomonas capsulata SCJ

Rhodopseudomonas sulfidophila BSW

\section{Rhodopseudomonas sulfidophila W4}

Nonphotosynthetic Bacteria

Desulfovibrio, marine sp. Clostridium pasteurianum

$\begin{array}{lr}\text { Thiosulfate heterotrophic, light } & 5.82 \\ \text { Heterotrophic, light } & 1.35 \\ \text { Heterotrophic, light } & 0.45 \\ \quad \text { (nitrogenase induced) } & 0.00 \\ \text { Heterotrophic, light } & \\ \quad \text { (early logarithmic phase) } & 0.00 \\ \text { Heterotrophic, dark, aerobic } & 2.09 \\ \mathrm{H}_{2} \text { autotrophic, light } & 3.80 \\ \text { Thiosulfate autotrophic, light } & 0.52 \\ \text { Heterotrophic, light } & 24.95 \\ \mathrm{H}_{2} \text { autotrophic, light } & 2.42 \\ \mathrm{H}_{2} \text { autotrophic, light } & 4.15 \\ \text { Heterotrophic, light } & 6.13 \\ \text { Heterotrophic, light } & \\ \quad \text { (nitrogenase induced) } & 03.1 \\ \text { Heterotrophic, light } & \\ \quad \text { (dark incubated 60 hours) } & 87.46 \\ \mathrm{H}_{2} \text { autotrophic, light } & 4.41 \\ \text { Hetotrophic, light } & \\ \quad \text { Heterotrophic, dark } & 4.42 \\ \text { Heterotrophic, dark } & \end{array}$

All reactions were measured in the dark with Warburg apparatus at $32^{\circ} \mathrm{C}$ and $\mathrm{H}_{2}$ as gas phase. Dultures were in early stationary phase of growth unless otherwise noted ard assayed in spent medium adjusted to $\mathrm{pH} 7.2$. C. pasteurianum cells were previously frozen tc $-20^{\circ} \mathrm{C}$. Reactions were initiated by tipping $0.3 \mathrm{ml}$ of methylene blue solution ( $75 \mathrm{mg} / \mathrm{m} 1$ ) into the reaction vessel. 


\section{SECTION 5.0}

\section{LIGHT-DEPENDENT HYDROGEN PRODUCTION}

Production schemes have been assembled on a laboratory scale to demonstrate the technical feasibility of employing biological systems to produce $\mathrm{H}_{2}$ at the direct expense of light energy. Both whole-cell and cell-free systems are discussed in this section.

\subsection{IN VIVO SYSTEMS}

\subsubsection{Photosynthetic Bacteria}

Intact photosynthetic bacteria offer the best immediate potential for applied photobiological $\mathrm{H}_{2}$ production systems (see Section 8.0 for additional justification of this statement). The technology is probably available now, and functioning systems could be built if suitable low cost, metabolizable substrates were available. Kobayashi and colleagues (1973 and 1976) have described solar pilot plants that use photosynthetic bacteria to purify organic industrial wastes. A 10 -ha pond can treat 100 tons of cfflucnt (30,000 ppm BOD) per day. As yet no attempt has been made to evolve and collect $\mathrm{H}_{2}$ from this process though the bacterial cell mass generated has been used as animal feed supplement and as fertilizer.

Other forms of biomass are plentiful and could be suitable substrates if they could be attacked metabolically by photosynthetic bacteria. Cellulose, lignin, and agar contain low levels of combined nitrogen and, as substrates, would cause the derepression of nitrogenase in bacterial cells. Even if photosynthetic bacteria could not attack these substrates directly, they could utilize the saccharification products generated from preparatory chemical or biological hydrolysis. Obviously, more research is needed in this area.

Reported rates for photoproduction of $\mathrm{H}_{2}$ are invariably made from cells grown on defined medium, usually with glutamate as the sole nitrogen source (to induce nitrogenase) and organic acids as a carbon source. The rates for a given organism (Table 5-1) vary from laboratory to laboratory, probably due to many of the same factors that cause variations in $\mathrm{H}_{2}$ uptake. The procedure of harvesting and washing cells prior to assay invariably results in lowered rates. This is probably attributable at least in part to oxygen inactivation during the preparative procedure, since the rates obtained from growing cultures are normally much higher than those from washed cells. A large number of photosynthetic bacteria in growing cultures have been assayed for $\mathrm{H}_{2}$ evolution activity (Weaver, unpublished data). The extreme examples are included in Table 5-1. Rates can be maintained over several days until the substrate is nearly exhausted. Note also in Table 5-1 that a partially derepressed R. rubrum nitrogenase mutant (Weare, 1978) has twice the $\mathrm{H}_{2}$ evolution rate of the wild-type strain under similar assay conditions.

Bennett and Weetall (1976) have made the first attempt to construct a laboratory-scale $\mathrm{H}_{2}$ photoproduction device (which might be used as a model in future applied systems) using photosynthetic bacteria. The approach was to 
Table 5-1. REPRESENTATIVE RATES OF H, PHOTOEVOLUTION FROM PHOTOSYNTHETIC BAETERIA (LIQUID CULTURE)

\begin{tabular}{|c|c|c|c|}
\hline Organism & Strain & Reference & $\left(\mu \mathrm{H} \mathrm{H}_{2} \cdot \stackrel{\text { Activity }}{\left.\mathrm{mg} \text { dry } \mathrm{wt}^{-1} \cdot \mathrm{hr}^{-1}\right)}\right.$ \\
\hline
\end{tabular}

\section{Chromatium vinsoum}

Ectothiorhodospiria shaposhnikovii

Rhodopseudomonas capsulata

Rhodopseudomonas palustris

Rhodospirillum rubrum
$\mathrm{D}$

$---$

\section{1}

S.L.

$\mathrm{B} 10$

$$
\text { SCJ }
$$

LB2

$---$

S-1

$\mathrm{S}-1$

$\mathrm{S}-1$

$S-1$

$\mathrm{S}-1$

$--$

S-1

$S-1$
---
---

$S-1$

II C31
Arnon et al., 1961

Kondratieva, 1977

Weaver et al., 1975

Hillmer and Gest, 1977a

Kelley et a1., 1977

Meyer et al., 1978

Weaver (unpub1.)

Weaver (unpubl.)

Kondratieva, 1977

Gest and Kamen, 1949a

Gest et al., 1950

Ormerod et a1., 1961

Gest et a1., 1962

Schick, $1971 \mathrm{~b}$

Gogotov and Zorin, 1972

Weaver, 1975

Bennett and Weeta11, 1976*

Kondratieva, 1977

Weare, 1978

Weare, 1978

Kondratieva, 1977

*Data obtained in an immobi-ized spstem. 
encapsulate $R$. rubrum cells in agar and to pass substrates over the entrapped cells. This resulted in $\mathrm{H}_{2}$ evolution which lasted for prolonged periods of time. Unfortunately, the rates reported by the authors are two orders of magnitude less than those obtained for cells in liquid culture (see Table 5-1). This is probably due to the suboptimal temperature used and the fact that $\mathrm{CO}_{2}$ and minerals were not present in the system. The choice between practical liquid or immobilized systems must obviously await further performance and economic analyses.

\subsubsection{Green Algae}

Light-dependent $\mathrm{H}_{2}$ production in single-cell green microalgae has remained a rather esoteric area of research for nearly four decades. Studies have been conducted mainly on a few laboratory-established strains (notably Scenedesmus, Chlamydomonas, and Chlorella genera) readily available from their use as tools in the study of photosynthesis. Only recently has there been any attempt to evaluate the process as a potential vehicle for photobiological solar energy conversion. This effort began a few years ago in the United States with the first attempts to screen for other species of algae better suited to the production of $\mathrm{H}_{2}$ (Gibbs, 1973; Bishop et al., 1977).

$\mathrm{H}_{2}$ evolution in laboratory-cultivated algae occurs only under a stringent set of conditions (Gaffron and Rubin, 1942; Frenke1, 1952; Healey, 1970; Bishop et al., 1977). For example, anaerobiosis is required for the activation of hydrogenase and the partial pressure of $\mathrm{CO}_{2}$ also must be kept low. The process is easily inhibited by light intensity considerably below that required to saturate photosynthesis. Furthermore, even under these rather restrictive laboratory conditions, $\mathrm{H}_{2}$ production remains a highly transitory event, lasting from a few minutes to several hours (Healey, 1970; Bishop et al., 1977; McBride et al., 1977). The maximal transient rates of $\overline{\mathrm{H}_{2}}$ (Bishop et al., 1977; McBride et al., 1977). However, these transient rates are still far below the average rate of steady state photosynthesis (equivalent to approximately $200-300 \mu$ moles of $\mathrm{H}_{2} \cdot \mathrm{mg} \mathrm{Chl}^{-1} \cdot \mathrm{hr}^{-1}$ ) observed in most algal species. Hydrogen production rates measured over an extended period of time are lower yet, amounting to a few $\mu$ moles of $\mathrm{H}_{2} \cdot \mathrm{mg} \mathrm{Ch1} \mathrm{Ch}^{-1} \cdot \mathrm{hr}^{-1}$ (Stuart and Gaffron, 1972). Since the current status of algal $\mathrm{H}_{2}$ photoproduction research is rather embryonic, it would be futile to discuss the environmental and nutritional conditions affecting $\mathrm{H}_{2}$ evolution. Consequently, only the intrinsic metabolic processes that undoubtedly contribute to the low rates of $\mathrm{H}_{2}$ production in these organisms are discussed here.

First, the low rates can be traced largely to the $0_{2}$-sensitivity of hydrogenase (see Sections 3.1 .1 and 6.1 ) and its residence within the same cell that houses the $\mathrm{O}_{2}$-generating PSII complex. When $\mathrm{H}_{2}$ production is coupled to the splitting of water or whenever PSII activity is observed, $\mathrm{O}_{2}$ is produced within the cell. If not rapidly removed, the $\mathrm{O}_{2}$ inactivates the catalytic activity of hydrogenase and abolishes $\mathrm{H}_{2}$ production. This is clearly demonstrated by the fact that $\mathrm{H}_{2}$ production is severely curtailed if a cell suspension is equilibrated with $\sigma_{2}$ at a partial pressure exceeding $0.4 \%$ of one atmosphere (Healey, 1970; McBride et al., 1977). Under moderate illumination, algal cells readily produce $\mathrm{O}_{2}$ at concentrations exceeding this value. As a 
result, $\mathrm{H}_{2}$ production is normally observed only at low light intensity when photosynthetic $\mathrm{O}_{2}$ evolution is not inhibited (Gaffron and Rubin, 1942; Frenkel, 1952; Healey, 1970). In order to utilize more fully the capacity of the photosynthetic apparatus for $\mathrm{H}_{2}$ production, it will be necessary to confer a greater degree of in vivo $\mathrm{O}_{2}$ tolerance upon hydrogenase, perhaps via genetic modification of the enzyme itself (Togasaki, 1973; Monty and Beck, 1973; McBride et al. , 1977).

Second, the complex cellular metabolism of intact algae includes several wasteful processes (in terms of decreasing $\mathrm{H}_{2}$ evolution) which either compete directly for the low potential reductant or consume $\mathrm{H}_{2}$ after its formation. These reactions are: (1) photosynthetic $\mathrm{CO}_{2}$-fixation and other NADPHdependent reductive synthetic processes that competc with the hydrogenase for electrons from ferredoxin via ferredoxin-NADP ${ }^{+}$oxidoreductase (Forti, 1977); (2) photoreduction $\left(\mathrm{CO}_{2}+2 \mathrm{H}_{2} \stackrel{\text { Hydrogenase }}{\longrightarrow} \mathrm{CH}_{2} \mathrm{O}+\mathrm{H}_{2} \mathrm{O}\right)$, or $\mathrm{CO}_{2}$-dependent hydrogen consumption, involving hydrogenase-catalyzed generation of reduced NADP and reductive $\mathrm{CO}_{2}$ fixation via the Calvin cycle of normal photosynthesis (Gaffron, 1940; Gingras et al., 1963); (3) auto-oxidation reactions (i.e., the direct reaction of the primary acceptor of PSI, reduced ferredoxin, or reduced flavoprotein with $0_{2}$ (Mehler, 1941; Heber and French, 1968; Lien and San Pietro, 1978); and (4) the oxy-hydrogen reaction $\left(2 \mathrm{H}_{2}+\mathrm{O}_{2}\right.$ Hydrogenase $\left.\rightarrow 2 \mathrm{H}_{2} \mathrm{O}\right)$ or hydrogenase-catalyzed reduction of oxygen by hydrogen to produce water (Gaffron, 1940; Kessler, 1974). This last reaction may proceed through autooxidation of hydrogenase (reduced by $\mathrm{H}_{2}$ ) or through hydrogenase-catalyzed reduction of ferredoxin followed by reaction (3). More likely, the reaction proceeds through a coupled mechanism involving the hydrogenase-mediated generation of reduced substrates, such as $\mathrm{NAD}(\mathrm{P}) \mathrm{H}$, followed by the respiratory oxidation of the substrate by molecular oxygen. In any case, the net result is equivalent to a reversal of water splitting.

The operation of these reactions in vivo results in a decrease in the rate of net $\mathrm{H}_{2}$ production. Obviously, the development of an efficient algal system for photobiological $\mathrm{H}_{2}$ production requires a clear understanding of the basic biochemical events involved in each of these in vivo metabolic processes as well as elucidation of the detailed mechanisms controlling electron flow from the reducing side of $P S I$ to the various low potential redox reactions within the cell. Unless these fundamental biochemical and metabolic control processes are clearly defined, any attempt to improve the ratd and efficiency of $\mathrm{H}_{2}$ production from intact algae will remain strictly empirical and has low probability of success.

\subsubsection{Cyanobacteria}

1

The use of photosynthetic bacteria or eucaryotic (green and red) algae represents potentially the most direct route to the photoevolution of $\mathrm{H}_{2}$ in intact cellular systems. This is because the nitrogenase and hydrogenase enzymes which respectively catalyze the process in the two types of organisms are rather closely coupled to the reducing power generated by the primary photoprocesses (see Section 3.2). On the other hand, the presence of any $0_{2}$ (including that either leaked into or generated by the system) abolishes hydrogenase and nitrogenase activity in these organisms (Section 3.1). 
With the first reports that cyanobacteria (blue-green algae) were able to generate $\mathrm{H}_{2}$ either in the presence of exogenous organic substrates in the dark (Oshchepkov et al., 1973; Gogotov and Kosyak, 1976) or in nitrate-free media under an atmosphere of argon and $\mathrm{CO}_{2}$ in the light (Benemann and Weare, 1974), came the important observation that atmospheric $\mathrm{O}_{2}$ levels only decreased $\mathrm{H}_{2}$ evolution to a limited extent (Benemann and Weare, 1974). Consequently, the use of intact heterocystous cyanobacteria to produce $\mathrm{H}_{2}$ has been seriously considered as a means of solar energy conversion. According to Benemann (1977) cyanobacteria are the only organisms that partially meet the following minimum requirements for consideration as a biological $\mathrm{H}_{2}$-generating system using water as a substrate: (1) high specific rates of $\mathrm{H}_{2}$ production and photosynthetic efficiencies, (2) sustained $\mathrm{H}_{2}$ and $\mathrm{O}_{2}$ generation (up to months), (3). stoichionetric ratios of $\mathrm{H}_{2}$ and $\mathrm{O}_{2}$ produced from water, (4) no limitations to scale-up, and (5) faclle operation and control.

Although most of the work reviewed in this section was performed using Anabaena cylindrica, other fresh water cyanobacteria reportedly photoevolve $\mathrm{H}_{2}$, including Anabaena azollae, Anabaena variabilis, Plectonema boryanum, Tolypothrix, Nostoc, Chloroglea, Anabaenopsis sp. and Mastigocladus laminosus (Benemann and Weare, 1974; Weare and Benemann, 1974; Efimtsev et al., 1975; Newton, 1976; Peters et al., 1976; Benemann et al., 1977; Benemann et al., 1978). In addition, a number of marine cyanobacteria including Oscillatoria brevis, Calothrix membranacae, Calothrix scopulorum and several Miami BG isolates also evolve $\mathrm{H}_{2}$ in the light (Lamber and Smith, 1977; Mitsui and Kumazawa, 1977).

Weissman and Benemann (1977) recently reported that nitrogen-starved cultures of A. cylindrica 629 photoevolve both $\mathrm{H}_{2}$ and $\mathrm{O}_{2}$ continuously for 7 to 19 days. Under such conditions the cultures turn from green to yellow after a day or two due to a loss of intracellular phycocyanin (Nielson et al., 1971). In addition, the percentage of heterocysts increases (Benemann and Weare, 1974; Jeffries et al., 1978). The maximum rate of $\mathrm{H}_{2}$ production observed by Weissman and Benneman (1977) was $32 \mu \mathrm{l} \cdot \mathrm{mg}$ dry $\mathrm{wt}^{2-\mathrm{l}^{2}} \cdot \mathrm{hr}^{-1}$ or $30 \mathrm{ml} \cdot \mathrm{l}$ culture medium ${ }^{-1} \cdot \mathrm{hr}^{-1}$. These rates were obtained after actively growing cells exposed to an air $/ 0.3 \% \quad \mathrm{CO}_{2}$ atmosphere were transferred to an argon/0.3\% $\quad \mathrm{CO}_{2}$ atmosphere (nitrogen-starved conditions) and represent a $250 \%$ to $350 \%$ increase compared to unstarved cells. Maximum 1aboratory production rates occurred after one to two days of starvation but fell to onehalf the maximum after five to seven days. This decline is probably due to limitations in the supply of reductant to the heterocysts and is accompanied by filament breakage (Weissman and Benemann, 1977). The average thermodynamic conversion efficiencies (incident light energy divided into the free energy of the $\mathrm{H}_{2}$ produced) reported over the lifetime of the experiments (up to 18 days) were around $0.4 \%$, but peak values of $0.8 \%$ were also observed. Jeffries et al. (1978) have reported similar evolution rates and conversion efficiencies but a longer time (six days) to reach a maximum $\mathrm{H}_{2}$ production. Average hydrogen photoevolution rates in the marine cyanobacterium, Miami BG7, (Mitsui and Kumazawa, 1977) are about one-fourth of those reported in A. cylindrica. It should be mentioned that the reported rates and converson efficiencies are not solar values since artificial light sources were used.

Benemann et al. (1977) have subsequently improved upon earlier laboratory results by slightly modifying the nitrogen starvation conditions. The 
addition of a small amount of $\mathrm{N}_{2}$ to the sparging gas (resulting in a $1.0 \%$ $\mathrm{N}_{2} / 0.3 \% \mathrm{CO}_{2} / 98.7 \% \mathrm{Ar} \mathrm{mix}$ ) resulted in maximum $\mathrm{H}_{2}$ evolufion rątes of $40 \mu \mathrm{l} \cdot \mathrm{mg}$ dry $\mathrm{wt}^{-1} \cdot \mathrm{hr}^{-1}$ and average rates of $23 \mu \mathrm{l} \cdot \mathrm{mg}$ dry $\mathrm{wt}^{-1} \cdot \mathrm{hr}^{-1}$ for 18 days in one case (or about a $1.2 \%$ average thermodynamic conversion efficiency). $\mathrm{H}_{2}$ to $\mathrm{O}_{2}$ evolution ratios of about $2: 1$ were also reported. High levels of $\mathrm{N}_{2}$ normally inhibit $\mathrm{H}_{2}$ production (see Section 5.1.3.1). However, $1 \%$ is apparently low enough that the efficiency of $\mathrm{N}_{2}$ reduction remains low but high enough to allow cell maintenance without cell growth (Benemann et al., 1977). Furthermore, filament breakage decreases, but under these conditions the reductant supply from vegetative cells is still limiting.

Benemann et al. (1977 and 1978) have started to develop an outdoor system and have observed $H_{2}$ evolution for 30 days with average solar conversion efficiencies of $0.1 \%$ to $0.2 \%$. They have also noted increased outdoor $\mathrm{H}_{2}$ evolution rates in $\underline{M}$. laminosus (a thermophilic strain) as compared to $\underline{A}$. cylindrica.

$\Lambda$ number of environmental and nutritional conditions affect $\mathrm{H}_{2}$ photoevolution in cyanobacteria and these are discussed in the following sections. Some of these factors may well provide clues for improving future $\mathrm{H}_{2}$ photoevolution rates.

\subsubsection{Nitrogen}

Molecular $\mathrm{N}_{2}$ from the atmosphere inhibits the dark production of $\mathrm{H}_{2}$ in $\underline{A}$. variabilis (Oshchepkov et al., 1973) and photoproduction in A. cylindrica (Benemann and Weare, 1974) and several marine species when the $\mathrm{N}_{2}$ concentration in the gas phase is as low as 15\% (Lambert and Smith, 1977). However, as indicated previously, lower concentrations $\left(-1 \% \mathrm{~N}_{2}\right)$ appear to stimulate. $\mathrm{H}_{2}$ production under nitrogen-starved conditions.

Weissman and Beneman (1977) have reported that small additions of ammonium ion $\left(10^{-4} \mathrm{M}\right)$ to dense cultures of $\mathrm{A}$. cylindrica early in the period of $\mathrm{N}_{2}$ starvation (after one or two days) results in the maintenance of higher $\mathrm{H}_{2}$ production rates than.those observed in unfed cultures. Moreover, the use of small amounts of $\mathrm{NH}_{4} \mathrm{Cl}$ proved to be a tool for controlling the $\mathrm{H}_{2}$ to $\mathrm{O}_{2}$ rates in starved cultures. Ratios of 4:1 were commonly observed at the beginning of an experiment when stored reductant was high. The early addition of $\mathrm{NH}_{4} \mathrm{Cl}$ increased the rate of $\mathrm{O}_{2}$ evolution along with PSII activity in vegetative cells, and ratios of $1.7: 1$ were observed. This is quite close to the ratio of 2 expected if water were the ultimate snurce of reductant. Aging the starved cultures also led to a decrease in the $\mathrm{H}_{2}$ to $\mathrm{O}_{2}$ ratio but in this case at the expense of $\mathrm{H}_{2}$ production. Later additions of $\mathrm{NH}_{4} \mathrm{Cl}$ had no effect. In contrast, Jeffries et al. (1978), using apparently similar conditions, found that small additions of $\mathrm{NH}_{4} \mathrm{Cl}\left(2 \times 10^{-4} \mathrm{M}\right)$ destabilized the system and eventually led to the suppression of $\mathrm{H}_{2}$ photoproduction as compared to controls.

\subsubsection{Carbon Monoxide and Acetylene}

Carbon monoxide is known to inhibit hydrogenase activity in general (Hoberman and Rittenberg, 1943; Peck et al., 1956). However, at a concentration of 2\% in $\mathrm{N}_{2}$ sparging gas, it reverses $\mathrm{N}_{2}$ gas-inhibited $\mathrm{H}_{2}$ production both in 
unstarved cultures of A. cylindrica (Benemann and Weare, 1974), and in A. azollae (Peters et al., 1976). Bothe et al., (1977), also working with unstarved A. cylindrica cultures, observed a considerable increase in $\mathrm{H}_{2}$ evolution when they were exposed to optimal concentrations of both c0 $\left(0.15 \mathrm{mM}\right.$ ) and $\mathrm{C}_{2} \mathrm{H}_{2}$ (concentrations as high as $25 \mathrm{mM}$ were not saturating for $\mathrm{H}_{2}$ evolution under argon). Neither $\mathrm{CO}$ nor $\mathrm{C}_{2} \mathrm{H}_{2}$ alone were promotive under these conditions. The explanation for the increase in hydrogen evolution was that $\mathrm{CO}$ plus $\mathrm{C}_{2} \mathrm{H}_{2}$ unmasked $\mathrm{H}_{2}$ evolution by nitrogenase from the normally faster uptake of the gas by uptake hydrogenase (Bothe et al., 1977). Lambert and Smith (1977) reported simi.lar results in unstarved marine cyanobacteria. Both $2 \% \mathrm{CO}$ and $10 \% \mathrm{C}_{2} \mathrm{H}_{2}$ (in air) promoted $\mathrm{H}_{2}$ photoevolution (compared to cultures exposed to air alone), and the effects of $\mathrm{CO}$ and $\mathrm{C}_{2} \mathrm{H}_{2}$ were additive. On the other hand, acetylene inhibits $\mathrm{H}_{2}$ photoproduction in starved cultures of $\underline{A}$. cylindrica (Weissman and Beneman, 1977) and A. azollae (which lives in a symbiotic relationship with the water fern Azolia (Peters et al., 1976). This is in agreement with the in vitro work of Rivera-Ortiz and Burris (1975) who observed that acetylene suppressed nitrogenase catalyzed $\mathrm{H}_{2}$ production in $A$. vinelandii. Peters et al. (1977) demonstrated furthermore that the ratios of the partial pressures of $\mathrm{N}_{2}$ and $\mathrm{C}_{2} \mathrm{H}_{2}$ control the amount of reductant used in $\mathrm{H}_{2}$ production and $\mathrm{N}_{2}$ fixation by nitrogenase. Obviously, the mechanism of $\mathrm{CO}$ and $\mathrm{C}_{2} \mathrm{H}_{2}$ action needs more study.

\section{1 .3 .3 Iron}

The presence of $\mathrm{Fe}^{3+}$ ions in the culture medium of nitrogen-starved $\mathrm{A}$. cylindrica is essential for $\mathrm{H}_{2}$ photoproduction (Jeffries et al., 1978). Hydrogen evolution was twice as high when $5 \mathrm{mg} / 1$ iron was present as compared to cultures containing $0.5 \mathrm{mg} / \mathrm{l}$. The phenomenon was reportedly related to the iron requirement of nitrogenase and ferredoxin.

\subsubsection{Oxygen}

Although the observed sensitivity of nitrogenase activity to $0_{2}$ in heterocystous algae has not been consistent (Stewart and Pearson, 1970; Weare and Benemann, 1973), high $0_{2}$ concentrations definitely inhibit nitrogenase activity in nitrogen-starved cultures (Weissman and Benemann, 1977). Moreover, the $\mathrm{O}_{2}$ resistance varies among cultures and they become more sensitive with time.

\section{$5.1 .3 .5 \mathrm{pH}$}

Alkaline conditions are more conductive to prolonged $\mathrm{H}_{2}$ evolution. Jeffries et al. (1978) reported that nitrogen-starved cultures evolved $\mathrm{H}_{2}$ at the same initial ratc whether the $\mathrm{pH}$ wac 7.4 or 9.4 . However, at $\mathrm{pH} 9.4$ cultures continued to produce $\mathrm{H}_{2}$ after $\mathrm{CO}_{2}$ deprivation because the alkaline medium contained more dissolved $\mathrm{CO}_{2}$. This allowed the cells to continue scavenging $\mathrm{CO}_{2}$ for as many as ten days after deprivation, and it demonstrated that continuous sparging with $\mathrm{CO}_{2}$ was not necessary.

\subsubsection{Temperature}

Oshchepkov et al. (1973) reported a temperature dependence for dark $\mathrm{H}_{2}$ evolution in A. variabilis using glucose as a substrate. Maximal activity 
occurred at about $40^{\circ} \mathrm{C}$. Benemann et al. (1978) observed a similar response for nitrogenase activity as measured by acetylene reduction (which should be directly related to $\mathrm{H}_{2}$ photoevolution) in nitrogen-starved cultures of $\mathrm{A}$. cylindrica and $\mathrm{M}$. laminosus except the peak avtivities occured at $35^{\circ} \mathrm{C}$ and $45^{\circ} \mathrm{C}$, respective $\overline{1}$.

\subsubsection{Light}

The incident light intensity as well as the concentration of the culture (high cell concentrations lead to self-shading) greatly influence the rate of $\mathrm{H}_{2}$ production. Efimtsev et al. (1975) observed increases in $\mathrm{H}_{2}$ photoevolution (A. varibilis) as the irradiance of $680 \mathrm{~nm}$ light was raised from $<0.001$ to about $0.5 \mathrm{~mW} / \mathrm{cm}^{2}$. Studies with nitrogen-starved cultures of A. cylindrica in the presence of DCMU have shown that "low" light levels (cool white fluorescent light, $1.8 \mathrm{~mW} / \mathrm{cm}^{2}$ ) limit PSI activity in the heterocysts (and thus limit $\mathrm{H}_{2}$ production) and that stored reductants can sustain $\mathrm{H}_{2}$ evolution for a day or two at most (Weissman and Benemann, 1977). Both Weissman and Benemann (1977) and Jeffries et al. (1978) demonstrated that "high" light 1rradiance (respectively, heat filtered incandescent, $39 \mathrm{~mW} / \mathrm{cm}^{2}$; "Naturescent" $\mathrm{flu}-$ orescent light, $3.2 \mathrm{~mW} / \mathrm{cm}^{2}$ ) stimulates $\mathrm{H}_{2}$ evolution rates compared to lower intensities but decreases the time over which $\mathrm{H}_{2}$ is produced. The latter authors, in fact, observed $\mathrm{H}_{2}$ evolution for a period of 30 days at an average conversiop efficiency of $0.35 \%$ when low irradiance light (incandescent, $0.6 \mathrm{~mW} / \mathrm{cm}^{2}$ ) was used. Under these latter conditions filament breakage was not observed, and the authors concluded that $\mathrm{N}_{2}$ deprivation itself could not account for the gradual decline in activity and filament breakage reported by Weissman and Benemann (1977). Perhaps the higher light intensity employed by Weissman and Benemann (1977) led to a photodegradative reaction. Jeffries et al. (1978) also observed that the ratio of $\mathrm{H}_{2}$ evolution to acetylene reduction was greater at higher light intensity, indicating less uptake hydrogenase activity.

Solar illumination $\left(-100 \mathrm{~mW} / \mathrm{cm}^{2}\right)$ in outdoor systems results in higher $\mathrm{H}_{2}$ production rates but lower conversion efficiencies than artificial illumination in laboratory experiments (Benemann et al., 1977). The former is due to the much denser cultures which can be used outdoors and the latter to the low saturation intensity of photosynthesis relative to solar light levels and the fact that over half the solar spectrum is not photoactive.

There are references in the literature reporting the increased efficiency of photosynthesis, growth, etc. (Rabinowitch, 1956; Kuchkarov, 1973) on a per input energy basis when microorganisms are exposed to intermittent versus continuous 11ght. This usually occurs when the continuous light is saturating. Jeffries et al. (1976) postulated that if the rate of ATP generation in the heterocyst exceeds the rate of reductant supply from the vegetative cells, intermittent light should increase the yield of $\mathrm{H}_{2}$ production by allowing the reductant to diffuse into the heterocyst during the dark phase. Jeffries and Leach (1978), in fact, have observed such a phenomenon in both growing and nitrogen-starved A. cylindrica cultures. Using a 5-second-on, 5-second-off cycle, they reported $1.7-$ and 1.35 -fold increases respectively. 


\subsubsection{Two-Stage Systems}

If biological systems are ever to be useful in economical hydrogen production schemes, a number of major problems must be addressed and surmounted. For example, biological $\mathrm{O}_{2}$ and $\mathrm{H}_{2}$ evolution are generally incompatible except in some cyanobacteria (see Sections 3.2.2.3 and 5.1.3), biological materials are inherently unstable, material costs may be limiting unless efficiencies are substantially improved (e.g., large tanks must be covered in order to collect $\mathrm{H}_{2}$ ), and the $\mathrm{H}_{2}$ gas produced must be separated from other gases including $\mathrm{O}_{2}$. Two-stage systems separate $\mathrm{O}_{2}$ evolution and $\mathrm{H}_{2}$ production spatially and thus don't require a covering above the photosynthetic stage. As a consequence, they hold promise for overcoming a number of the problems discussed here (Benemann, 1977). The inherent disadvantage of the two-stage approach is the requirement for pumping between the two stages, but perhaps a well-engineered system taking advantage of diffusion gradients might ultimately overcome this problem.

In any case, two types of two-stage systems have been proposed in the 1iterature. The first combines certain characteristics of the single-stage systems discussed in the earlier parts of Section 5.0 and involves the temporal separation (see Figure 5-1A) of $\mathrm{O}_{2}$ evolution (during the day) and hydrogen production (using stored reductants at night). Benemann and Weissman (1977) suggested the possible use of nonheterocystous, filamentous cyanobacteria, including Plectonema and Oscillatoria, which are known to display a temporal separation of photosynthetic $\mathrm{O}_{2}$ evolution and $\mathrm{N}_{2}$ fixation (Weare and Benemann, 1974; Benemann and Weissman, 1977). Organisms from both genera are known to evolve hydrogen (see Section 5.1.3). The use of green algae in a temporal $\mathrm{H}_{2}$ production scheme has also been suggested (Benemann and Weissman, 1977). However, specific practical results with temporal $\mathrm{H}_{2}$-production systems have not been reported to date.

The second type of two-stage system involves the use of two different organisms. Krampitz (1977) demonstrated an example of such a scheme in which he used the cyanobacterium Anacystis nidulans*, an exogenous redox couple (NADP/NADPH), and a photosynthetic bacterium Rps. capsulata to generate hydrogen in a single vessel (see Figure 5-1B). The cyanobacteria split water (the ultimate source of electrons and hydrogen ions in this system) and photoreduce $\mathrm{NADP}^{+}$to $\mathrm{NADPH}$. Unfortunately, the organism is not permeable to NADP $^{+}$or NADPH so lyophilized A. nidulans were used. This, of course, severely limits the period of water-splitting activity. Since fresh Rps. capsulata cells are also impermeable to NADP and NADPH, both lyophilized and fresh intact cells were used. The lyophilized cells (which do not evolve $\mathrm{H}_{2}$ ) reduce oxalacetate to malate using $\mathrm{NADPH}$ as a reductant. The intact cells (which are permeable to malate and oxalacetate) oxidize the malate to oxalacetate and evolve hydrogen. The differences in the redox midpoint potential of the oxalacetate/malate couple $(-0.16 \mathrm{~V})$ and the hydrogen

\footnotetext{
${ }^{*}$ A. nidulans has been identified both as Synechococcus elongatus and Synechococcus $A N$ in the literature (Stanier et al., 1971; Stanier and CohenBazire, 1977).
} 
A. Temporal
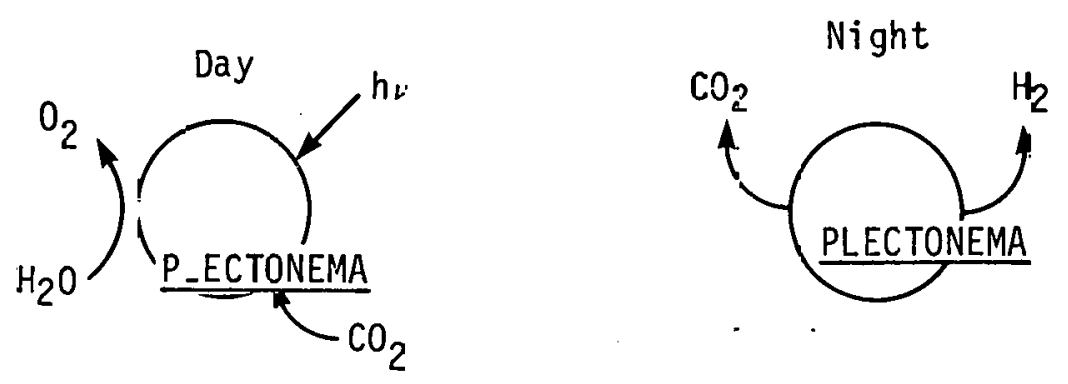

$\stackrel{+}{\infty}$

B. Multiorganism

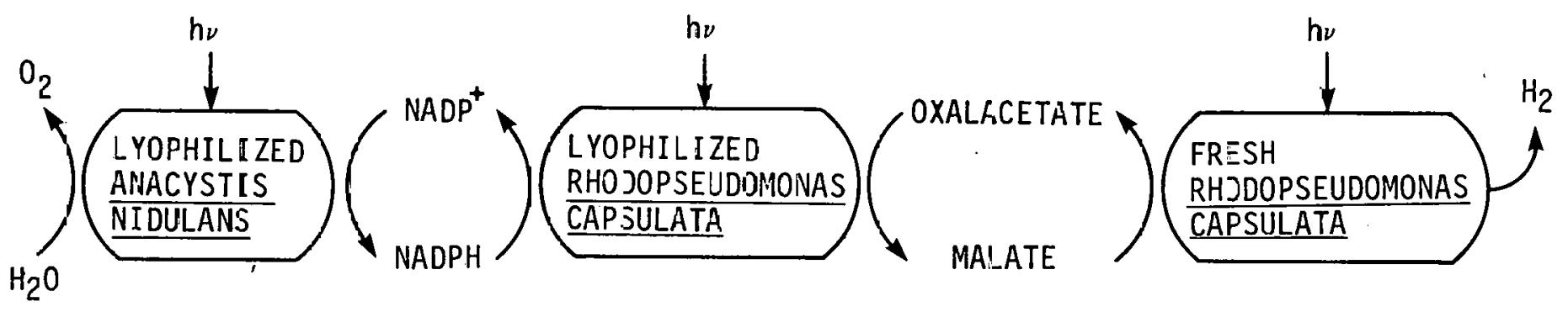

FIGURE 5-1. TWO-STAGE BIOLOGICAL H2 PRODUCTION SYSTEMS USING WHOLE CELLS.

A. Temporal system in which $\mathrm{O}_{2}$ and $\mathrm{H}_{2}$ evolution occur at differert times.

B. Multiorcanism system in which $\mathrm{O}_{2}$ and $\mathrm{H}_{2}$ evolution are separated in space. 
electrode $(-0.42 \mathrm{~V})$ is supplied by the light shining on the photosynthetic bacteria. Apparently, freshly isolated photosynthetic bacterial cells contain an $\mathrm{O}_{2}$ scavenging system which protects the $\mathrm{H}_{2}$ evolving function. In any case Krampitz reported an evolution rate of $2.5 \mu$ moles $\cdot \mathrm{ml}^{-1} \mathrm{hr}^{-1}$ for $30 \mathrm{~min}$.

Weetall and Krampitz (personal communication) have continued this work. However, instead of using a single vessel they immobilized A. nidulans and R. rubrum (instead of Rps. capsulata) in separate transparent reactor vessels. The system is interconnected and a solution containing NADP $^{+}$is cycled between the two vessels. The solution also contains a glucose oxidase/dextrose oxygen-scavenging system and is flushed continuously with argon. When illuminated, the cyanobacteria (which again are lyophilized) reduce exogenous $\mathrm{NADP}^{+}$to NADPH. The photosynthetic bacteria then use the NADPH to evolve $\mathrm{H}_{2}$. As before, light shining on the $\mathrm{R}$. rubrum supplies the difference in energy between the $\mathrm{NADP}^{+} / \mathrm{NADPH}$ couple $(-0.32 \mathrm{~V})$ and the hydrogen electrode. Conversion efficiencies as high as $0.38 \%$ were observed under incandescent light with no attempt to optimize the system.

Obviously, work in this area is just beginning but ideas abound. For example, Krampitz (1977) has proposed that cyanobacteria be modified genetically to produce formate. Formate is a much more stable intermediate than NADPH and in a practical system would be formed in the organism by reducing atmospheric $\mathrm{CO}_{2}$. The biological production of such an intermediate would have considerable advantage over an intermediate added exogenously (at considerable expense) as in the $\mathrm{NADP}^{+}$scheme described above. Photoproduced formate could then be stored for long periods and, when needed, converted to $\mathrm{H}_{2}$ and $\mathrm{CO}_{2}$ in the dark by E. coli.

\subsection{IN VITRO SYSTEMS}

\subsubsection{Ce11-free Photosynthetic Systems}

Photoproduction of $\mathrm{H}_{2}$ in cell-free systems requires the isolation of stable, photochemically active photosynthetic complexes (either in a native form or as a chemically modified derivative) that are capable of generating low potential reducing equivalents using water as a substrate. The 1solated complexes or their derivatives are then coupled to a suitable hydrogen catalyst to produce $\mathrm{H}_{2}$. In principle, only those components essential for the photochemical oxidation of water together with a minimal number of redox carriers for efficient coupling to the hydrogen catalyst would be included. Thus, many of the complexities encountered in the intact cell approaches (due to the unavoidable interaction of the photosynthetic redox carriers and the hydrogenase/nitrogenase enzyme complexes with other intracellular redox systems) can be eliminated. For example, cell-free systems are independent of the energy-consuming metabolic processes of intact cells and should be capable of realizing overall theoretical solar conversion efficiency higher than the $5.8 \%$ calculated for intact plant cells (Bolton, 1977). In fact, it may be feasible to approach a conversion efficiency of $10 \%$, the maximum theoretical value for cellular photosynthesis if dark respiration and photorespiration could be eliminated (Lien and San Pietro, 1975; Ha11, 1976; Bolton, 1977; Radmer and Kok, 1977). In order to approach this high efficiency in a cellfree system, the capacity of the light-driven reactions must be carefully 
matched to the overall capacity of the light-independent reactions, and the maximum quantum efficiency of the overall process must be maintained over the entire dynamic range of solar intensity.

One of the major advantages of cell-free $\mathrm{H}_{2}$ production systems is that the different components used for constructing a functional system need not be derived from a single organism. This allows a greater degree of flexibility for optinizing the performance of the complete system. For example, the photosynthetic apparatus or its components could be obtained from different species of algae or higher plants while the hydrogenases might be extracted from algal or bacterial sources. Synthetic analogues might also be used. In any case, the source for each of the components could be chosen for optimal catalytic activity, stability, and ease of preparation.

\subsubsection{Development of Hydrogen-producing Cell-free Photochemical Systems}

As early as 1961, Arnon and co-workers demonstrated light-dependent production of $\mathrm{H}_{2}$ in a cell-free system consisting of isolated spinach chloroplasts, ferredoxin, and Chromatium hydrogenase. Cysteine (coupled to the chloroplasts by the redox dye DPIP, dichlorophenol indophenol) was the source of reductant, and DCMU was added to inhibit $\mathrm{O}_{2}$-evolution. Yoch and Arnon (1970), using a similar cell-free coupled system, demonstrated that heat-treated chloroplasts could substitute for DCMU-poisoned chloroplasts. In this case, ascorbate-DPIP served as the source of electrons. It is important to emphasize that in these early experiments water was not the source of electrons because PSII activity of the chloroplast was intentionally inactivated. Therefore, only the electron transport components closely assoclated wllh Llie PSI cumplex wete coupled to hydrogenase.

The first indication that the water-splitting activity of PSII could be linked to the photoproduction of hydrogen in a cell-free system (chloroplasts, methyl viologen, and E. coli hydrogenase) was reported by Krampitz (1972) at a workshop on biological energy conversion. Unfortunately, detailed descriptions of the rate and duration of active hydrogen production as well as information about $\mathrm{O}_{2}$ evolution were not available. Shortly afterwards, Benemann et al. (1973) reported $\mathrm{H}_{2}$ photoproduction in a cell-free system consisting of spinach chlorophasts, ferredoxin, and Clustridium kluyveri hydrogenase. No exogenous electron donors were employed. The addition of DCMU reduced the rate of $\mathrm{H}_{2}$ production by $95 \%$, suggesting that water was the source of reductant. Unfortunately, the authors did not demonstrate the simultaneous production of $\mathrm{O}_{2}$ with $\mathrm{H}_{2}$. Nevertheless, the addition of glucose plus glucose oxidase, an $\mathrm{O}_{2}$ scavenger system, stimulated considerably the rate of $\mathrm{H}_{2}$ production. The average rate of $\mathrm{H}_{2}$ production observed by Benemann et al. (1973) in the absence of an $0_{2}$ scavenger was 1 to $2 \mu$ moles of $\frac{\mathrm{H}}{2} \cdot \mathrm{mg} \mathrm{Ch1} \mathrm{C}^{-1} \cdot \mathrm{hr}^{-1}$ but $\mathrm{H}_{2}$ evolution decreased dramatically after $15 \mathrm{~min}$. Much higher rates ( 12.1 and $15.4 \mu$ moles $\mathrm{H}_{2} \cdot \mathrm{mg} \mathrm{Chl}^{-1} \cdot \mathrm{hr}^{-1}$ ) were obtained in the presence of glucose/glucose oxidase and an ascorbate-DPIP electron donor system, respectively. However, the authors did not report any improvement in the duration of operation of their system by the addition of either $\mathrm{O}_{2}$ scavengers or artificial electron donors. Apparently, the instability of PSII and hydrogenase activity limited the overall operating life of the system (Benemann et al., 1.973). 


\subsubsection{Recent Improvements}

Since the report by Benemann et al. (1973), several groups have explored in some detail the factors which affect the performance of the cell-free $\mathrm{H}_{2}$ production systems. Despite this work, cell-free coupled systems are still far from achieving efficient $\mathrm{H}_{2}$ production over a sufficient period of time to warrant practical application in a solar energy conversion scheme. However, some encouraging improvements have been reported since 1973 and are summarized in Table 5-2. In order to convey a realistic picture of the actual advances in this area of research, a conservative view has bccn taken. Only the average rates of $\mathrm{H}_{2}$ production obtained by the investigators over the indicated operating periods are recorded, and the operating period is defined as the time during which a more or less constant rate of $\mathrm{H}_{2}$ production was observed. Whenever possible the rates were obtained from primary data in the report cited. When such data were not available, the rate mentioned by the original authors is cited in parentheses and noted in the last column of the table.

Numerically, the rate of $\mathrm{H}_{2}$ production in water-splitting, in vitro systems has been improved several-fold (from 14 to $94 \mu$ moles $\cdot$ ing $\mathrm{ChI}^{-1} \cdot \frac{\mathrm{hr}}{-1}$ ) since 1973. In addition, the operating duration has increased from less than 15 min to about $6 \mathrm{hr}$. Although encouraging, these improvements represent only a very modest step toward the development of an efficient, practical cell-free system. Furthermore, the improvements were obtained only when an effective $\mathrm{O}_{2}$-scavenging system (glucose and glucose oxidase) and an $\mathrm{H}_{2} \mathrm{O}_{2}$-trap (ethanol and catalase) were included in the reaction mixtures. From the point of view of energy (and cost), the inclusion of these trapping systems is selfdefeating because each mole of $\mathrm{O}_{2}$ trapped by the system (which theoretically would be equivalent to 2 moles of $\mathrm{H}_{2}$ produced) is accompanied by the conversion of one mole of glucose into gluconate and $\mathrm{H}_{2} \mathrm{O}_{2}$ (Fry et al., 1977). Similarly for each mole of $\mathrm{H}_{2} \mathrm{O}_{2}$ converted into $\mathrm{H}_{2} \mathrm{O}$, one mole of ethanol is oxidized to acetaldehyde (Fry et al., 1977; Packer and Cullingford, 1978). Therefore, in the presence of trapping systems water-coupled $\mathrm{H}_{2}$ production is actually an indirect coupling to the photooxidation of these organic substitutes. However, the real significance of these experiments lies in the fact that they firmly demonstrate the technical feasibility of in vitro coupling of the reducing power generated by the water-splitting reactions of PSII to hydrogenase. In addition, the results also focus on the fact that one of the most critical problems faced by the in vitro approaches is identical to that of the in vivo algal system; namely, inactivation of the $\mathrm{H}_{2}$ catalyst by molecular $\mathrm{O}_{2}$ - This problem will be discussed in greater detail in Sections 6.1 and 7.3 .1 .

Finally, both the numerical data of Table 5-2 and the critical but realistic remarks concerning the inclusion of $\mathrm{O}_{2}$ and $\mathrm{H}_{2} \mathrm{O}_{2}$ traps in cell-free systems fail to highlight a very significant aspect of recent research; that is, various investigators are exploring a wide variety of source materials from which different components used in the construction of cell-free systems can be isolated. The photosynthetic membranes for generating reductants from water are no longer limited to spinach or pea chloroplasts (Reeves et al., 1976; Rao et al., 1978). In addition, a large number of hydrogenases from bacterial species and some algae are being explored. Even synthetic compounds mimicking the active site of the hydrogenase are being examined as potential 


\begin{tabular}{|c|c|c|c|c|c|c|}
\hline References & Ma jor Cemponents & $\begin{array}{l}\text { F.lectron } \\
\text { Sources }\end{array}$ & $\begin{array}{l}\text { Oxygen } \\
\text { Trapa }\end{array}$ & $\begin{array}{c}\text { Average Rates } \\
\left(\mu \text { moles } \mathrm{H}_{2} \text { - mg }\right. \\
\left.\text { Ch.l }-\mathrm{hr}^{-1}\right)\end{array}$ & $\begin{array}{l}\text { Operating } \\
\text { Duration } \\
\quad(\text { IIr) }\end{array}$ & Comments \\
\hline $\begin{array}{l}\text { 1. Benemann et al. } \\
\text { (1973) }\end{array}$ & $C p+F d+H_{2}$ ase (c. kluyveri $)$ & $\begin{array}{l}\mathrm{H}_{2} \mathrm{a} \\
\mathrm{H}_{2}^{\mathrm{O}} \\
\mathrm{ASC}+\mathrm{DPIP}\end{array}$ & $\begin{array}{l}- \\
+ \\
-\end{array}$ & $\begin{array}{cc}1- & 2 \\
12- & 14 \\
15.4\end{array}$ & $\begin{array}{l}<0.25 \\
? \\
?\end{array}$ & $\begin{array}{l}\text { Rate falls off to } 25 \% \text { after } 15 \\
\text { min. Stability of the system not } \\
\text { investlgated with } n_{2} \text { trap or donor } \\
\text { system. }\end{array}$ \\
\hline $\begin{array}{l}\text { 2. Ben-Amotz and Gibbs } \\
(1975)\end{array}$ & $\begin{array}{l}\text { Cell-free prep (Chlamydomonas) } \\
\text { Cel1-frez prep (Scenedesmus) } \\
\text { Cp }+\mathrm{H}_{2} \text { Ese (Chiamydomonas: } \\
\text { Crude) }\end{array}$ & $\begin{array}{l}\text { DIT or NADII } \\
\text { DTT } \\
\text { DTT }\end{array}$ & $\begin{array}{l}- \\
- \\
-\end{array}$ & $\begin{array}{l}2 \\
3.6 \\
4.3\end{array}$ & $\begin{array}{c}1-1.5 \\
1 \\
1\end{array}$ & Rate falls off after 60 to $90 \mathrm{~min}$. \\
\hline $\begin{array}{l}\text { 3. Krasnovsk11 et a1. } \\
\text { (i } 975)\end{array}$ & 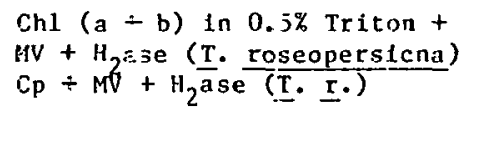 & $\begin{array}{l}\text { NAI:H } \\
\text { NATH }\end{array}$ & - & $\begin{array}{r}11.5 \\
8.2\end{array}$ & $?$ & $\begin{array}{l}\text { The rate value of } 11.5 \text { was esti- } \\
\text { mated from the absorbance rcading } \\
\text { of Chl }(a+b) \text { given by the } \\
\text { authors. }\end{array}$ \\
\hline 4. Rao et $\frac{\text { et }}{(1976)}$ & 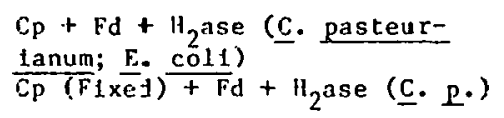 & $\begin{array}{l}\mathrm{H}_{2} \mathrm{C} \\
\mathrm{H}_{2}^{2} \mathrm{C} \\
\mathrm{H}_{2}^{2} \mathrm{C}\end{array}$ & $\begin{array}{l}+ \\
+\end{array}$ & $\begin{array}{r}19-i 15.5 \\
2.8 \\
11.5\end{array}$ & $\begin{array}{r}3-6 \\
3 \\
3\end{array}$ & $\begin{array}{l}\text { Cp (Fixed) represents chloroplasts } \\
\text { fixed tn } 0.05 \% \text { glutaraldehyde. }\end{array}$ \\
\hline $\begin{array}{l}\text { Secves et al. } \\
(1976)\end{array}$ & $\mathrm{Cp}+\mathrm{Fd}+\mathrm{H}_{2} a \mathrm{ae}^{\mathrm{b}}$ & $\mathrm{H}_{2} \mathrm{C}$ & + & $20-(40)$ & 3 & $\begin{array}{l}\text { The rate value of } 40 \text { is the maxi.num } \\
\text { value given by authors. No primary } \\
\text { data was presented. }\end{array}$ \\
\hline $\begin{array}{l}\text { 6. Fry et al. } \\
(1977)\end{array}$ & $\begin{array}{l}\mathrm{Cp}+\mathrm{Fd}+\mathrm{H}_{2} \text { ase (C. pasteur }- \\
\underline{\text { 1anum }}\end{array}$ & $\mathrm{H}_{2} \mathrm{Cl}^{\prime}$ & + & $7-13$ & $2-6$ & $\iota$ \\
\hline $\begin{array}{l}\text { 7. Hoffmann et al. } \\
\text { (1977) }\end{array}$ & $\begin{array}{l}C_{p}+M V \text { or Fd or Triquat }+ \\
H_{2} \text { ase (‥ pasteurlanum) }\end{array}$ & DAF: or TMPI) & - & $50-125$ & 0.1 & $\begin{array}{l}\text { Stabllity of the system was not } \\
\text { Invest igated. }\end{array}$ \\
\hline $\begin{array}{l}\text { 8. } \operatorname{Ran} \frac{\mathrm{et}}{\mathrm{a} 1} \text {. } \\
(1978)\end{array}$ & $\begin{array}{l}C p+F d+H_{2} a s e b \\
C p(\text { Cheozpodium })+F d+H_{2} \text {;se } \\
\text { (C. Pasteurtanum) }\end{array}$ & $\begin{array}{l}\mathrm{H}_{2} \mathrm{CO} \\
\mathrm{H}_{2} \mathrm{C}\end{array}$ & + & $\begin{array}{r}30-(50) \\
(94)\end{array}$ & $\begin{array}{l}2 \\
2\end{array}$ & $\begin{array}{l}\text { The rate values } 50 \text { and } 94 \text { were } \\
\text { maximum values mentioned by } \\
\text { authors. No primary data was } \\
\text { presented. }\end{array}$ \\
\hline
\end{tabular}

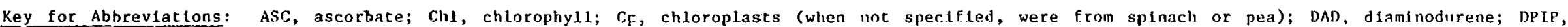

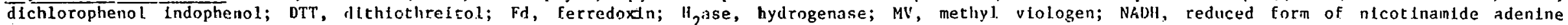
df nucleotide; TMPD, N-tetramethyl-p-phenylened lamine.

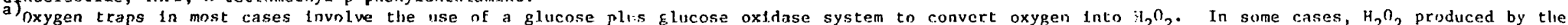

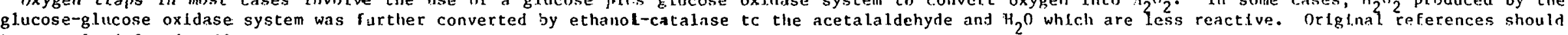
glucose-glucose oxidase

bf consulted for detalls. 
candidates for $\mathrm{H}_{2}$-evolving catalysts (Reeves et al., 1976). Similarly, in addition to spinach and clostridial ferredoxins, other low-potential ironsulfur proteins from bacterial and algal sources, cytochromes, NADH, and synthetic redox carriers (such as viologen dyes) are being investigated with respect to stability and effectiveness as coupling agents in the transfer of reductants from the photosynthetic membrane system to hydrogenase (Rao et al., 1978). The future success of the in vitro approach will undoubtedly rest on a vigorous, long-term research commitment that takes advantage of the flexibility of the cell-free systems.

\subsubsection{Cel1-free Purp1e Memhrane Systems}

The halophilic bacterium Halobacterium halobium, found in natural salt lakes and salterns, has attracted a great deal of interest over the past few years (Schreckenback, 1978). It contains a membrane-bound, retinal-containing protein call bacteriorhodopsin (the so-called "purple membrane") which act's as a proton pump and establishes a proton gradient across the cell membrane of the organism. The energy for proton transport is supplied by light absorbed in the chromophore of the bacteriorhodopsin molecule. Although the organism contains a respiratory chain, evolution of this independent bioenergetic system apparently allowed it to survive at high salt concentrations where respiration is inhibited due to the low solubility of oxygen. Under such conditions, the bacterium uses the bacteriorhodopsin photosystem to store energy in a two-step process. Protons ejected out of the organism by light build up a transmembrane potential which, in turn, drives the protons back into the organism. The returning protons are coupled to an ATPase that synthesizes ATP used by the bacterium as an energy source for ion transport and cellular metabolism.

It has been suggested that the purple membrane isolated from $\mathrm{H}$. halobium might be used in a $\mathrm{H}_{2}$-producing photobiological system because it is stable to both physical and biological degradation, is easy to prepare, and large amounts of membrane are obtainable (Schlegel and Barnes, 1977). However, to the authors' knowledge no one has demonstrated purple membrane-coupled hydrogen evolution, probably because the photo-induced proton gradient would have to be coupled to a redox reaction. On the other hand, a number of reports have appeared in which purple membrane systems have been used to generate photopotentials and photocurrents (Skulachev, 1976; Shieh and Packer, 1976; Eisenback et al., 1977 ; Packer et al., 1977a). 
THIS PAGE INTENTIONALLY LEFT BLANK 


\section{SECTION 6.0}

\section{TECHNICAL PROBLEMS IN PHOTOBIOLOGICAL HYDROGEN PRODUCTION}

Although certain photobiological $\mathrm{H}_{2}$ production schemes, including those employing intact photosynthetic bacteria and cyanobacteria, appear promising at the moment, there are many problems to be surmounted before the technical feasibility of photobiological solar energy conversion can be demonstrated.

\subsection{OXYGEN SENSITIVITY}

One of the more difficult problems in considering photobiological $\mathrm{H}_{2}$ production as a feasible solar conversion process is the (in most instances) extreme $\mathrm{O}_{2}$-sensitivity of $\mathrm{H}_{2}$-evolving enzymes both in vivo and in vitro. As mentioned earlier (Sections 3 and 5 ), whenever water is the ultimate source of reductant for $\mathrm{H}_{2}$ production, molecular $\mathrm{O}_{2}$ is liberated as an obligatory byproduct and in most cases strongly inhibits the rate of $\mathrm{H}_{2}$ production. The primary cause of the inhibition is the susceptibility of both hydrogenase and nitrogenase to $\mathrm{O}_{2}$. In vivo hydrogenase $\mathrm{O}_{2}$-sensitivity was first illustrated by the anaerobic adaptation and aerobic deadaptation processes observed in the $\mathrm{H}_{2}$ metabolism of green algae (Gaffron and Rubin, 1942; Frenke1, 1952). (The adaptation process probably involves a reductive activation of existing inactive hydrogenase during short periods of anaerobic incubation and is followed by the adaptive formation of additional enzyme upon prolonged anaerobiosis.) Deadaptation of $\mathrm{H}_{2}$ production activity in anaerobic algae occurs within a few minutes after exposure to low concentrations of $\mathrm{O}_{2}$ (about $0.4 \%$; McBride et al., 1977). In the case of C. reinhardi, hydrogenase appears to be the primary site of inactivation during the aerobic deadaptation process because, along with the loss of $\mathrm{H}_{2}$-evolving activity, the rate of the oxy-hydrogen reaction is also severely inhibited. Furthermore, deadapted cells retain full capacity for respiration and photosynthetic $\mathrm{O}_{2}$-evolution (McBride et a1., 1977). In the in vitro case, hydrogenases from algal and bacterial sources are inactivated by both reversible and irreversible reactions (Abeles, 1964; Nakos and Mortenson, 1971; Mortenson and Chen, 1974). Bacterial and cyanobacterial nitrogenases are even more sensitive to $O_{2}$ than hydrogenases and, of course, organisms which evolve $\mathrm{H}_{2}$ from nitrogenase activity lose the ability if the enzyme is inactivated (see Sections 3 and 5 ). In cyanobacteria $\mathrm{O}_{2}$-inactivated nitrogenase cannot be reactivated and is subsequently degraded by the action of proteases (Haselkorn, 1978).

In addition to the direct inhibition of hydrogenase and nitrogenase, $\mathrm{O}_{2}$ also interferes with photobiological $\mathrm{H}_{2}$ production through a number of secondary reactions (see also Section 5.1 .2 ) including (1) competition with hydrogenase or nitrogenase for low potential reducing equivalents at the reducing side of PSI, i.e., auto-oxidation of the reduced form of primary electron acceptor and ferredoxin (Heber and French, 1968; Asada et al., 1974; Lien and San Pietro, 1978a); (2) inactivation of ferredoxin and other iron-sulfur proteins (Petering et al., 1971; Hall and Rao, 1977); and (3) the reaction of $\mathrm{O}_{2}$ with enzymatically produced $\mathrm{H}_{2}$ (the oxy-hydrogen reaction). 
The situation is not hopeless, however, since heterocystous cyanobacteria do evolve $\mathrm{H}_{2}$ in the presence of $\mathrm{O}_{2}$ (although the rate is higher in its absence). This fact makes these organisms quite attractive in energy conversion applications, as shown in section 5.1.3. In addition, there has been some progress in selecting for $0_{2}$-tolerant mutants of green algae (McBride et al., 1977). Naturally stable hydrogenase enzymes are also available from nonphotosynthetic sources (Section 3.1.2.4). Klibanov et al. (1978) have reported some impressive improvements in the stabilization of highly $\mathrm{O}_{2}$-labile $\mathrm{C}$. pasteurianum hydrogenase by exploiting the "salting out" effect of $\mathrm{O}_{2}$ from the local microenvironment of the enzyme (see Section 7.3.1).

\subsection{STABILITY}

\subsubsection{Whole-ce11 Cultures}

Intact photosynthetic cells offer much potential for use in photoconversion systems. No major technological breakthrough is needed to advance these systems, and expenses would be minimal. Using mixed cultures of photosynthetic organisms, it is possible to capture all wavelengths of radiant energy from $350 \mathrm{~nm}$ to $1050 \mathrm{~nm}$. However, the population stability of such mixtures has not been tested. Photosynthetic bacteria (Guest, 1974; Wall et al., 1975a), cyanobacteria, and green algae (Porter, 1977) all produce bacteriocin-like toxins that may alter the ratio of the organisms within mixed cultures. In applications where cell growth does not occur, the effect of these toxins may not be critical. Likcwisc, the effect of invading lytic viruses may be negligible under nongrowing conditions. Imposed genetic selection procedures could also decrease these mutual intolerances. Prolonged maintenance of cultures in near stationary phase conditions is an unexplored area in need of further research.

As previously described, photosynthetic bacteria can photoconvert reduced carbonaceous substrates into $\mathrm{H}_{2}$ (plus $\mathrm{CO}_{2}$ ). Some form of waste biomass material is the logical substrate choice since it is readily available and inexpensive. Additionally, most forms of biomass are naturally low in combined nitrogen, which would facilitate the derepression of nitrogenase. Unfortunately, little control can be maintained over the introduction of foreign microorganisms indigenous to added waste material short of heat sterilizing, which is expensive, or adding anti-microbial chemicals, which is unwise. However, the replication of contaminating organisms can be inhibited by manipulating environmental conditions (e.g., controlling dissolved $\dot{U}_{2}$, limiting $C, P$, or coinbined $N$ ). Use of fully-grown stationary phase photosynthetic cultures should prevent the massive development of nonphotosynthetic organisms. Periodic flushing and reinoculation of holding tanks would reestablish the inital photosynthetic population as needed. In this regard, certian strains of photosynthetic microbes readily aggregate, making them easy to harvest. Secondary use of this harvested material as a protein supplement or in high-nitrogen "green manure" applications is desirable economically and in fact has been done (Kobayashi and Tchan, 1973), though the presence of pathogens and concentrated toxic materials must be closely monitored (Katzenelson et al., 1976). 
An applied system using intact cells for the photoproduction of $\mathrm{H}_{2}$ would more than likely employ mutants with altered electron transport reactions (Section 7.2). Deletion mutations are totally stable in the absence of genetic exchange from wild-type donors; hence culture stability would not present a problem. However, a temperature-sensitive mutant is by nature unstable and, when put into nonpermissive conditions, wild-type revertants will grow and readily take over the culture. For those organisms whose metabolism will not permit deletion mutations, functionally stable temperature-sensitive mutant populations can be achieved by maintaining them in fully-grown or growthlimited cultures where revertants cannot replicate. Alternatively, the creation of multiple temperature-sensitive mutations within the same cell would exponentially decrease the frequency of reversion to wild type, causing the mutant and thus the culture to remain stable.

\subsubsection{Cel1-free Systems}

Due to the self-regenerative nature of living systems, the photosynthetic apparatus of intact organisms is stable within the normal physiological temperature range. On the other hand, isolated chloroplast membrane preparations and other enzyme systems (including hydrogenases) lose activity rather rapidly at all temperatures above freezing. Thus, cell-free $\mathrm{H}_{2}$ production systems will require the preparation of stable components capable of withstanding numerous adverse environmental conditions, including severe temperature fluctuations, high light intensity, bacterial attack, and chemical degradation for long periods of time. The maintenance of both the catalytic activity of hydrogenase and the overall rate of electron transfer from water to the primary acceptor of PSI in isolated chloroplast membranes will be of major concern in the cell-free systems. The underlying mechanisms governing the structural and functional integrity of these components are treated in this section.

\subsubsection{Enzymes}

Excluding the possibility of synthetic complexes yet to be developed, the ATPindependent hydrogenases from algal and bacterial sources appear to be the best available $\mathrm{H}_{2}$ catalysts capable of interacting effectively with the redox systems of photosynthesis. Although nitrogenases can also catalyze the evolution of $\mathrm{H}_{2}$ gas, they are dependent on additional energy input in the form of ATP and thus are of limited value in cell-free $\mathrm{H}_{2}$ production systems. Therefore, only the stability problems associated with the ATP-independent hydrogenases are considered here.

Hydrogenases are readily inactivated by extreme values of $\mathrm{pH}$ (Nakos and Mortenson, 1971; Ben Amotz et al., 1975), and, at acidic pH, inactivation probably involves the loss of the iron-sulfur cluster (Mortenson and Chen, 1974). As mentioned in earlier sections (3.1.1 and 6.1), hydrogenases are highly sensitive to $\mathrm{O}_{2}$ at concentrations greater than $0.4 \%$ (McBride et al., 1977). Furthermore, like most proteins isolated from biological sources, hydrogenase is susceptible to hydrolytic degradation by microorganisms in nonsterile environments. Practical cell-free $\mathrm{H}_{2}$-evolving systems must incorporate the means to protect hydrogenase from these and other degradative forces; the current approach is to immobilize the enzyme (Section 6.3). 


\subsubsection{Electron Transport Components}

The stability problems associated with in vitro photosynthetic membranes are quite serious. For example, isolated chloroplast membranes function (split water) for only a few hours at most. Photochemical activity of the photosynthetic electron transport system is affected by many physical and chemical parameters which can be classified either as dark thermal inactivation or photochemical degradation.

6.2.2.2.1 Dark Thermal Inactivation. Dark thermal inactivation of photosynthetic electron transport activity in vitro involves the loss (or denaturation) of the soluble, loosely bound cofactors and redox carriers as well as the dissolution of the highly organized structural arrangement associated with electron transport. For example, ferredoxin (and thus electrons from PSI) is lost under most chloroplast preparation procedures (Buchanan and Arnon, 1971). Storage of chloroplasts in hypotonic media results in the partial loss of plastucyanin (Katoh and Takamiya, 1963). Mechanical disruption (sonication) of chloroplasts causes rapid and extensive solubilization of plastocyanin (Katoh and San Pletro, 1966; Lien and Bannister, 1971). Removal of plastocyanin, of course, leads to cessation of electron transfer between PSII and PSI. Under proper conditions the addition of catalytic amounts of plastocyanin to depleted chloroplast preparations restores the flow of electrons to PSI (Katoh and San Pietro, 1966; Lien and San Pietro, 1978b). Fortunately, the other known redox carriers linking the two photosystems appear to be tightly associated with the membranes, and disruption requires drastic procedures employing organic solvents or other membrane degrading agents (Bendall et al., 1971; Barr and Crane, 1971). Under normal laboratory conditions the loss or inactivation of these membrane-bound components is probably not the main cause of the decay in chloroplast electron transport activity. More likely, inactivation is associated with the dissolution of the membrane structure per se.

Other readily extractable cofactors and components are specifically involved in PSII-dependent phenomena. A chloride requirement for the Hill reaction in isolated chloroplasts was recognized some years ago. The site of chloride action has recently been localized on the oxidizing side of PSII (Hind et al., 1969; Izawa et al., 1969). The exact mechanism of chloride action is not known, but the effect of chloride depletion can be reversed readily by its addition to the medium. Manganese is also involved in PSIl activity (Diner and Joliot, 1977; Radmer and Cheniae, 1977). We11-washed chloroplast preparations from photosynthetically competent plant and algal sources contained approximately 5- 8 atoms of manganese per 400 chlorophyll molecules (Radmer and Cheniae, 1977). These "bound" Mn atoms are neither readily released upon washing with metal-complexing agents nor do they exchange readily in the dark with $\mathrm{Mn}^{+}$or $\mathrm{MnO}_{4}^{-}$. $\Lambda$ variety of treatments, including mild thermal shock $\left(50^{\circ} \mathrm{C}\right.$ for a few minutes), washing with $\operatorname{Tris}$ at alkaline $\mathrm{pH}$, washing with chaotropic agents, and extracting with hydroxylamine are known to inactivate the oxidizing side of PSII preferentially. These treatments also result in various degrees of $M n$ depletion, and in some cases it is possible to reactivate the $\mathrm{O}_{2}$-evolving capacity of the treated preparation (for a review see Radmer and Cheniae, 1977). These studies revealed that: 
- The residual $\mathrm{O}_{2}$-evolving activity is not related linearly to the amount of Mn retained by the chloroplasts (Yamashita et al., 1971; Yamashita and Tomita, 1974);

- As much as one-third of the Mn in chloroplasts is not essential for the water-splitting reaction. Chloroplasts inactivated by standard Tris-washing can regain $\mathrm{O}_{2}$-evolving activity at a rate approaching that of control chloroplasts after dark incubation with reduced DPIP, although up to one-third of the total $\mathrm{Mn}$ is lost in the process (Yamashita et a1., 1971; Blankenship et al., 1975);

- The rest of the chloroplast $\mathrm{Mn}$ ( $4-5 \mathrm{Mn} / 400 \mathrm{Ch} 1)$, which appears to be essential for the oxygen evolution, can exist in EPR-detectable and EPR-nondetectable forms. Conversion of the EPR-nondetectable form into the EPR-detectable form is associated with the loss of activity. Upon reactivation by the described procedure, Mn returns to the EPR nondetectable (and probably more tightly bound) form (Blankenship et al., 1975); and

- More exhaustive extraction of Mn by Tris/acetone treatment results in a preparation which cannot be reactivated by incubation with reduced DPIP. Under these conditions, light, and externally added $\mathrm{Mn}^{++}$, together with other agents such as $\mathrm{Ca}^{++}$, dithiothreitol, and bovine serum albumin (BSA) are required for effective reactivation of oxygen evolution (Yamashita and Tomita, 1974).

On the basis of these in vitro Mn extraction and reinsertion experiments, Blankenship et al. (1975) concluded that "the incorporation of $\mathrm{Mn}^{++}$is a twostep process; a light-driven transport of $M n$ into the thylakoid and a dark binding to the site responsible for activity." A detailed elucidation of the mode of incorporation and catalytic reactions associated with the manganoproteins of PSII would contribute not only to the solution of the stability problem of PSII but also to the eventual synthesis of an artificial watersplitting catalyst.

Another important aspect of the stability of in vitro electron transport is directly related to the structural integrity of the thylakoid membrane (Gressel and Avron, 1965). Certain physicochemical parameters, including temperature, $\mathrm{pH}$, and ionic strength, directly influence the thermodynamic equilibrium associated with the structural organization of chloroplast membranes. The effect of these parameters may also be indirect through the modulation of the catalytic activity and substrate accessibility of hydrolytic enzymes present in or contaminating the chloroplast preparation. Since proteins and lipids are the two major constituents of these membrane systems, the consequences of proteolytic and lipolytic activity on photochemical activity has been a subject of considerable interest and investigation.

Limited digestion of chloroplasts with trypsin preferentially inactivates the segment of the electron transport chain located on the oxidizing side of PSII (see the review by Giaquinta and Dilley, 1977). In contrast, PSI-dependent reactions such as the photoreduction of methyl viologen using ascorbate-DPIP as electron donor are only slightly affected (Mantai, 1970; Selman and Bannister, 1971). Extensive treatment of chloroplasts with pronase, a non- 
specific protease from Streptomyces griseus, results in a $60 \%$ loss of total chloroplast protein, a blue spectral shift of the red chlorophyll absorption band, and total inactivation of the DPIP-mediated Hill reaction (Bamberger and Park, 1966). Prior to the complete loss of Hill activity during the early stage of pronase digestion, the quantum efficiency of the reaction decreases dramatically and becomes increasingly dependent on light intensity. These data suggest an impairment of energy transfer from the light-harvesting chlorophyll to the reaction center of PSII and/or inactivation of the reaction center itself. Furthermore, the authors noted a pronounced change in the ORD spectrum in the $700 \mathrm{~nm}$ region as well as some loss of chloroplyll absorbance between 690 and $720 \mathrm{~nm}$. Unfortunately, they did not report the effect, if any, of pronase treatment on PSI-dependent partial reactions.

The effects of exogenous and endogenous lipases on the photochemical activity of chloroplast preparations have been studied widely (McCarty and Jagendorf, 1965; Bamberger and Park, 1966; Helmsing, 1967; Nintermans et al., 1969; Okayama et al., 1971; Heise and Jacobi, 1973; Anderson et a1., 1974). These studies, together with the reported effects of free fatty acids on the photochemical activity of chloroplasts (Krogmann and Jagendorf, 1959; Cohen et al., 1969; Seigenthaler, 1972; Seigenthaler and Havakova, 1975; Seigenthaler and Rawley, 1977), allow the following general statements about the destabilizing effects of lipolytic enzymes:

- Digestion of chloroplasts with lipases results in the transformation of membrane lipids and the release of free fatty acids. There are also changes in light-scattering properties and alterations in the membrane features of the thylakoids;

- Free fatty acids, especially long-chain, unsaturated ones such as linolenic and linoleic acid, are potent uncouplers of photophosphorylation and powerful inhibitors of PSII-dependent activity (Krogmann and Jagendorf, 1959; McCarty and Jagendorf, 1965; Cohen et al., 1969; Okayama et al., 1971; Okamoto and Katoh, 1977); and

- The thermal destabilization of in vitro electron transport during long storage of isolated chloroplasts in the dark can be correlated with lipid transformation and liberation of free fatty acids catalyzed by endogenous or contaminating lipolytic exzymes (McCarty and Jagendorf, 1965; Wintermans et al. 1969; Heise and Jacobi, 1973; Seigenthalor and Rawley, 1977).

It is not yet clear whether the degradative action of the lipolytic enzymes on electron transport is due exclusively to their attack on the structural integrity of membrane systems or to secondary processes involving the inhibitory action of free fatty acids released by these enzymes. Most likely, the actual mode of action is dependent on the particular photochemical reaction affected and also, to some extent, the type of lipase and the degree of digestion. Thus, it is interesting to note that upon treating subchloroplast particles with a partially purified galactolipase isolated from bean leaf chloroplasts, the rates of both PSI- and PSII-dependent electron flow at saturating light intensity were not significantly affected if BSA (a free fatty acid scavenger) was included in the incubation medium. Under the same conditions nearly all the galactolipids associated with the subchlor- 
oplast particles were hydrolyzed (Anderson et al, 1974). On the other hand, incubation of chloroplasts with a crude lipase preparation (a protein fraction of Ricinus leaf extract) resulted in the loss of Hill activity even when as much as $30 \mathrm{mg} / \mathrm{ml}$ of BSA was included (Cohen et al., 1969).

6.2.2.2.2 Photochemical Degradation. Like most photoactive devices, the photosynthetic apparatus may be damaged when photons are absorbed at a rate much higher than that which can be utilized by the apparatus or dissipated by the system. Myers and Burr (1940) carried out an extensive study on this phenomenon known in photosynthetic research as "photoinhibition." Using Chlorella, these authors found that the extent of $\mathrm{O}_{2}$ evolution is a function of both visible light intensity and duration of exposure. Under strong illumination, normal photosynthetic $\mathrm{O}_{2}$ evolution was replaced by net $\mathrm{O}_{2}$ uptake at rates two to three times higher than that of normal dark respiration. This phenomenon is frequently referred to as "photo-oxidation" and is stimulated both by carbon dioxide starvation and by a high partial pressure of oxygen (Franck and French, 1941). In whole cells, photooxidation can proceed for a limited time at a constant rate without inflicting irreversible injury. However, sustained intense illumination causes a decrease in the rate of photooxidation and permanent damage to the photosynthetic apparatus. This irreversible photoinhibition is frequently accompanied by bleaching of the photosynthetic pigments (Myers and Burr, 1940; Franck and French, 1941).

Similarly, kinetic analysis of photoinhibition by Kok (1956) using a "microsample" of Chlorella suspension, as well as the measurement of the time course of pigment bleaching by Sironval and Kandler (1958), led to the conclusion that the initial stage of photochemical damage is associated with the visible light-induced inactivation of the trapping or reaction centers. They also demonstrated that photooxidative bleaching of pigment molecules occurs during the latter stage of damage. Nevertheless, there are several mechanisms that protect against in vivo photoinhibition, including: (1) the dissipation of excitation energy by normal photosynthetic electron flow and, perhaps under some circumstances, by cyclic electron flow (Arnon, 1977); (2) protection by intracellular reductants and carotenoids (Heath and Packer, 1968a; Ridley, 1977); and (3) other in vivo repair reaction(s) of unknown mechanism (Myers and Burr, 1940).

Since the extent of the contribution by these in vivo mechanisms is uncertain, a quantitative analysis of photoinhibition is greatly hindered. However, the complications associated with most of the above mentioned processes can be eliminated to a great extent by in vitro experiments using isolated chloropilast preparations. Such studies (Kok et al., 1965; Jones and Kok, $1966 \mathrm{a}$ and 1966b; Malkin and Jones, 1968), have shown that:

- The same pigments (chlorophylls and carotenoids) that sensitize photosynthesis are also responsible for photoinhibition;

- Photoinhibition involves inactivation of both PSII- and PSI-dependent reactions. Inactivation of PSI-dependent activity is accompanied by locc of light-induced bleaching of P700. When the response of PSII to photoinhibitory illumination was studied, a linear relation between the decay of $\mathrm{O}_{2}$ evolution activity and the loss of variable fluorescence was observed. The damage to PSI is probably located 
very close to the trapping center. In contrast, the locus (or loci) of photoinhibition in PSII with respect to the trapping center, the oxidizing side (i.e., the water-splitting enzyme), or the reducing side of the trap is not clearly established. In view of the extremely labile nature of the water-splitting enzyme system, its inactivation or dissociation from the trapping center might be among the early events induced by photoinhibitory irradiation;

- In the absence of active electron transport, such as observed in isolated chloroplasts when exogenous electron acceptors are not present, the irreversible decline of $\mathrm{O}_{2}$-evolving activity as a function of exposure time to inactivating illumination can be exprecced ac:

$$
R_{t}=R_{0} e^{-\phi a I t}
$$

where $R_{0}$ is the initial rate; $R_{t}$ is the rate after exposure time $t ; \phi$ is the quantum yield of photolnhibition; $\alpha$ is the fractional absorption of incident light; and $I$ is the intensity of incident illumination. Thus, the photoinhibition process affecting the evolution activity of isolated chloroplasts appears to be dependent on the total number of photons received (by a functional photosynthetic unit) rather than the rate at which photons are received;

- As in the in vivo case, loss of photochemical activity precedes the massive destruction of pigment molecules. However, due to the lack of protective and repair mechanisms, the photoinhibitory action in vitro is more rapid and severe than that observed in vivo.

'l'he exact nature and mechanism of reactions leading to photochemical degradation of the photosynthetic apparatus is yet to he clarified. In this respect, the experiments of Heath and Packer (1965; 1968a and 1968b) on the light-induced peroxidation of lipids and chlorophy11 in isolated chloroplasts should be noted. These authors reported that:

- The cyclic peroxidative reactions of isolated chloroplasts are initiated by light absorbed by chlorophyll;

- Photoperoxidation probably involves chlorophyll-sensitized production of free radicals and dark peroxidative destruction of tri-unsaturated fatty acids and chlorophyll accompanied by the uptake of oxygen and the release of malondialdehyde;

- The presence of electron acceptors and cyclic electron flow cofactors, such as ferricyanide, DPIP, phenazine methosulfate, etc., inhibits the photoperoxidative reactions probably via a more efficient dissipation of the absorbed quanta through electron transport reactions; and

- Antioxidants (butylated hydroxytoluene, sodium ascorbate, etc.), as well as an active water-splitting PSII system, tend to stabilize the chloroplasts against photoperoxidation. These characteristics of the cyclic photoperoxidative reactions in isolated chloroplasts indicate 
that they are intimately related to and involved in (at least) the terminal destructive phase of photochemical degradation in photosynthetic membranes.

Another likely mechanlsm of photoinhibition is the generation of the superoxide anion $\left(\mathrm{O}_{2}^{-}\right)$by chloroplasts which, in turn, can be oxidized by the electron transport components to yield singlet $\mathrm{O}_{2}$ (Takahama and Nishimura, 1976). Singlet $\mathrm{O}_{2}$ is highly reactive and can attack membrane lipids and initiate cyclic peroxidation reactions (Halliwel1, 1978). On the other hand, Morris et al. (1978) failed to demonstrate a protective effect of superoxide dismutase. This result may indicate that either superoxide dismutase cannot reach the site of free-radical formation or that photoinhibition does not involve free-radical (superoxide) damage.

Similar phenomena are observed in photosynthetic bacteria although at higher light intensities, since the size of the photosynthetic unit is smaller in these organisms than in algae. In any case, the mechanism of photoinhibition requires further study so that effective means can be devised for countering the undesirable effects of high photon fluxes.

\subsection{COUPLING}

Efficient utilization of the reducing equivalents generated by the photosynthetic apparatus for $\mathrm{H}_{2}$ production requires that the light-driven redox reactions be coupled tightly to hydrogenase or nitrogenase. In whole cells, the efficiency of coupling depends on both the amount of active hydrogenase or nitrogenase present in the organism and the control mechanisms governing the flow of the reductants to the various reductive metabolic pathways (see Section 3.3). Thus, $\mathrm{H}_{2}$ production might be increased by genetically derepressing the biosynthesis of hydrogenase (in algae) or nitrogenase (in photosynthetic bacteria and cyanobacteria; Weare, 1978) and by suppressing the synthesis or action of the $\mathrm{H}_{2}$-uptake enzymes. The system might be further improved by using chemical inhibitors or genetically manipulating cellular metabolism to suppress all other competing reductant-utilizing processes except $\mathrm{H}_{2}$ production.

In the cell-free approach where the isolated photosynthetic apparatus is combined with hydrogenase preparations, the efficiency of coupling depends not only on the ratio of hydrogenase (nitrogenase would not be useful in a cellfree system; Section 5.3.1) to photochemically active chloroplast membrane but also on the specific reactivities of the components chosen for use in the reconstituted system. The reactivity between the photochemical apparatus and hydrogenase depends to a great extent on the type of redox mediator used to link the two systems; the mediator is necessary because hydrogenase by itself does not react directly with the membrane-bound low potential PSI electron acceptors (Benemann et al., 1973; Reeves et al., 1976). Methyl viologen or ferredoxin are commonly employed as redox-mediators in various cell-free $\mathrm{H}_{2}-$ production systems (Benemann et al., 1973; Krasnovskii et al., 1975; Rao et al., 1976; Fry et a1., 1977; Hoffmann et al., 1977). Using spinach

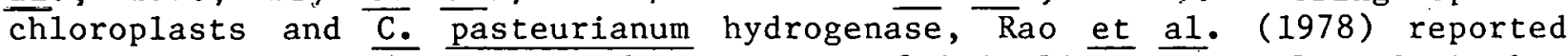
active $\mathrm{H}_{2}$ photoproduction in the presence of Spirulina maxima ferredoxin but little evolution in the presence of $D_{0}$ chloropseudomonas ferredoxin. 
Furthermore, they found that $\mathrm{H}_{2}$ production was extremely sluggish in a system consisting of spinach chloroplasts plus hydrogenase and ferredoxin from $D$. chloropseudomonas unless cytochrome $\underline{c}_{3}$ from the same bacterial source was also included. These findings illustrate the complexity of redox-coupling in cellfree systems.

Another very important but largely unexplored aspect of redox-coupling in cell-free systems is the physical means by which the components are assembled. All cell-free $\mathrm{H}_{2}$ production systems reported to date are liquid systems, and thus the overall rate of $\mathrm{H}_{2}$ production is governed by random diffusion contact of the components. A much higher rate of $\mathrm{H}_{2}$ production might be obtained if a well-organized arrangement of photosynthetic electron transport carriers, redox mediator(s), and hydrogenase were located on a suitable solid support. Candidates for such supports might be artificial membranes, the surface of colloidal particles, or the micropore matrix of various porous materials where the reliance on diffusion interaction would be minimized. To this end, the tendency of biological macromolecules (e.g., hydrogenase) to form highly specific and stable complexes should be further explored.

\subsection{ENVIRONMENTAL IMPACT}

For the most part, solar energy conversion technologies are rather benign with respect to environmental effects and competition for land. Biological $\mathrm{H}_{2}$ photoproduction schemes are no exception. Both in vivo and in vitro systems are applicable in either distributed or centralized systems and could be placed on marginal or nonarable land. Neither would necessarily compete for prime farm or residential land. Waste materials at least in the case of in vivo systems, could be used as fertilizer. Small $\mathrm{H}_{2}$ production devices could conceivably be placed on roof tops of large industrial buildings. Marine systems (employing marine photosynthetic bacteria or cyanobacteria, for example) would avoid the problem of land costs altogether, and would provide cooling, agitation, and a source for most nutrients (assuming that the logistical problems surrounding such a venture could be overcome).

Safety and efficiency considerations in handling and transporting $\mathrm{H}_{2}$ produced are probably the most serious problems at the present time. 


\section{SECTION 7.0}

\section{PROSPECTS FOR ENHANCED PHOTOPRODUCTION OF HYDROGEN}

Previous sections have reviewed the types of photobiological $\mathrm{H}_{2}$ production systems currently under investigation and the technical problems in their use. This section discusses a number of approaches to some of the problems.

\subsection{IGOLATION OF NATURALLY ADEPT STRAIN3}

It is apparent from Tables $3-3$ and 5-1 that different species and isolates of photosynthetic organisms exhibit different levels of hydrogenase and nitrogenase activities. Thus either or both enzyme complexes can limit $\mathrm{H}_{2}$ metabolism. Obviously, it would be desirable to isolate strains having even greater enzyme activities. The availability of such high-producing strains would enhance photoconversion processes in whole-cell applications as well as facilitate the isolation and increase the yield of pertinent proteins for use in coupled cell-free systems.

of the myriad inhabitants of natural water and soil samples a unique wild type strain with a particular quality can often be isolated selectively if that quality confers a growth or survival advantage. The presence of nitrogenase and hydrogenase certainly confers advantages to a host, though these particular survival properties are not utilized routinely in isolation of photosynthetic microorganisms. However, the BSW8 strain of Rps. sulfidophila (Table 3-3) was selected for its capacity for rapid autotrophic growth on $\mathrm{H}_{2}$ (it dominates $\mathrm{H}_{2}$ autotrophic enrichment cultures even when incubated aerobically in the dark). The very high level of hydrogenase activity in this strain demonstrates that wild-type strains can be isolated that exhibit considerably higher activities than those found in an average population. Similar selections for high nitrogenase activity may prove to be equally productive. Likewise, selection for resistance to $\mathrm{O}_{2}, \mathrm{pH}$, extreme high temperature, salinity, etc., can also bc attempted using samples from approprlate environments. These sources may well prove to contain organisms having more suitable properties for solar energy conversion.

\subsection{GENETIC ENGINEERING}

The normal function of photosynthetic organisms, as well as most other life forms, is to capture as much energy as possible and to convert it rapidly and efficiently into stored chemical energy in the form of more cellular constituents. This process can in theory be circumvented--though obviously to the detriment of the host--by specific genetic manipulation that would force the major portion of photosynthetic metabolism exclusively into the photoproduction of $\mathrm{H}_{2}$. Mutational blocks at appropriate points in the electron transport chain can be created to direct photosynthetic electron flow exclusively onto low potential carriers where the reducing power can be used by nitrogenase or hydrogenase. The potential advantage of using such mutants for solar energy conversion is obvious. 
The feasibility of this concept depends on the mutant cells having an alternative mechanism for growth. Obligate phototrophs such as algae have no alternate mode of growth and would probably require the use of temperaturesensitive mutations. Most photosynthetic bacteria, on the other hand, have many alternate modes of growth. Besides photosynthesis and aerobic respiration, many isolates can derive energy from fermentation (Uffen and Wolfe, 1970) and anaerobic respiration (Satoh et al., 1974 and 1976; Yen and Marrs, 1977; Madigan and Gest, 1978). Thus, strains with stable deletion mutations in specific photosynthetic electron transport carriers can survive and replicate under other environmental conditions.

The isolation of mutants constitutive for biosynthesis of nitrogenase, hydrogenase, and reaction center proteins would also be of value in both in vivo and in vitro applications. A mutant strain of K. pneumoniae tunctionally derepressed in nitrogenase activity has been created by Shanmugam and Valentine (1975) by inhibiting the two major enzymes of ammonia assimilation, glutamate dehydrogenase and glutamine synthase. The former enzyme has not been detected in R. rubrum (Weare and Shanmugam, 1976), Rps. capsulata (Johannson and Gest, $\overline{1976) \text {, or Anabaena (Stewart and Rowell, 1975), which }}$ leaves glutamate synthase as the dominant ammonia assimilatory pathway in these organisms. A glutamate auxotroph of $\mathrm{R}$. rubrum has been isolated that exhibits lowered glutamate synthase activity (Weare, 1978). It is characterized by a partial derepression of nitrogenase even in the presence of excess ammonium ion. The strain exhibits nearly twice the $\mathrm{H}_{2}$ evolution rate of its conventionally derepressed wild-type parent; additionally, it is about tenfold less sensitive to ammonia inhibition than the wild-type. The mutant enzyme appears to be somewhat "leaky," but the fact that the strain exists increases the prospects for obtaining fully constitutive mutants of nitrogenase. Strains of $R$. rubrum that conditionally synthesize up to eight times the normal level of reaction centers have also been isolated (Weaver, 1975). of potential benefit to in vitro work as well, these strains are also genetically void of carotenoids and light-harvesting bacteriochlorophyll.

Mutant strain construction in Rps. capsulata has been simplified by the discovery of a "gene transfer agent" by Marrs (1974). This novel genetic vector is common amongst 1solates of this species, but no similar system has so far been detected in any other species of photosynthetic bacteria (Wall et al., 1975a). Solle initial successes with a transducing bacteriophage for Rps. sphaeroides, discussed by Marrs (1978), offer considerable promise for expanding the methods and organisms available for genetic engineering. Conjugative transfer of chromosomal genes of Rps. sphaeroides and Rps. gelatinosa has been achieved by Sistrom (1977) using a promiscuous sex factor. This work may permit further genetic transfcr bctween widely divergent gram-negative bacteria.

Finally, with applications of recombinant DNA techniques to photosynthetic organisms, selected genes can be introduced from foreign sources, or native proteins can be amplified to greatly elevated levels. The introduction of cellulases, lignases, and agarases into photosynthetic bacteria would give their hosts the ability to photoconvert most biomass into $\mathrm{H}_{2}$, or the insertion of an $\mathrm{O}_{2}$-stable bacterial hydrogenase into an alga might permit prolonged rates of $\mathrm{H}_{2}$ production from water. 


\subsection{BIOENGINEERING}

\subsubsection{Protection from Oxygen}

In photobiological $\mathrm{H}_{2}$-producing systems that split water, most of the complications arising from the presence of $\mathrm{O}_{2}$ can be eliminated if the gas can be removed from the reaction medium. Unfortunately, this requires a substantial input of mechanical or chemical energy so that the overall system may become rather uneconomical from an energy standpoint.

An alternative solution to the problem of $\mathrm{O}_{2}$-inhibition is to separate the oxygenic photosynthetic electron transport reactions from the $\mathrm{H}_{2}$-producing reactions either spatially or temporally. The best example of in vivo spatial separation is found in heterocystous cyanobacteria (see sections 3.2 and $5.1 .3)$.

Since both the oxygenic photosynthetic apparatus and the $\mathrm{H}_{2}$ catalysts are found within the same cell, the possibility of spatial separation is precluded in algae and nonheterocystous cyanobacteria. However, it may be possible to devise a scheme that allows for a temporal separation of oxygenic photosynthetic reductant formation and storage from anoxygenic $\mathrm{H}_{2}$ production (see Sections 3.2 and 5.1 .3 ). In principle, this can be approached by introducing a conditional (i.e., temperature sensitive) mutation blocking the $\mathrm{O}_{2}$-evolution activity (at the oxidizing side of PSI). Through a simple shift of the temperature by a few degrees, $\mathrm{O}_{2}$ evolution could be effectively shut down as long as the nonpermissive temperature is maintained. The respiratory activity of the organism would rapidly decrease the $\mathrm{O}_{2}$ tension in the medium (in an enclosed bioreactor) and an anaerobic environment could be generated. Thus, anoxygenic $\mathrm{H}_{2}$ production could be initiated and maintained until the stored reductants were exhausted. Another cycle of reductant generation would be triggered by shifting the temperature back to the permissive range. Another possibility might involve photosynthesis during the day and $\mathrm{H}_{2}$ evolution at night as mentioned in Section 5.1.3. Both schemes are equivalent to the twostage $\mathrm{H}_{2}$ production system described in Section 5.1 .4 , except that both stages of the reaction are accomplished with the same organism.

In cell-free systems, two ways of separating the $\mathrm{O}_{2}-$ and $\mathrm{H}_{2}$-evolving reactions have been proposed. Egan and Scott (1978) explored the basic bioengineering and enzymatic parameters of a two-stage device consisting of immobilized chloroplasts and immobilized hydrogenase located in separate bioreactors with ferredoxin solution (the redox carrier) linking the two. The circulation of ferredoxin solution on a large scale through the two reactors, however, might prove to be very costly. Furthermore, auto-oxidation of reduced ferredoxin by chloroplast-generated $\mathrm{O}_{2}$ in the first reactor remains a major problem. Yagi (1976) attempted to separate hydrogenase-catalyzed $\mathrm{H}_{2}$ evolution from the electron-donating system by means of an enzymatic electric cell technique. This method is not a successful solution to the problem since electrons were supplied by a zinc electrode. Linkup of the electric cell system to a chloroplast reductant-generating system was not attempted.

Ubviously, research involving novel approaches is warranted. In particular, microscopic separation of the reductant-generating and $\mathrm{H}_{2}$-evolving components might be achieved by means of an organized arrangement of the two systems on 
an artificial $\mathrm{O}_{2}$-impermeable membrane. This would limit the presence of $\mathrm{O}_{2}$ to one side of the membrane where it would not interfere with the $\mathrm{H}_{2}$-evolving catalysts.

\subsubsection{Stabilization of Biological Components}

The instability of in vitro biological components is a critical problem in cell-free $\mathrm{H}_{2}$-photoproduction systems. The rapid decline of the catalytic activity of most hydrogenase preparations in the presence of $\mathrm{O}_{2}$ has been a major concern. Currently there is no effective means to counter the $\mathrm{O}_{2}-$ sensitivity of free, unmodified hydrogenase in solution except by exhaustive removal of $\mathrm{O}_{2}$ from the medium. On the other hand, Klibanov et al. (Iy/8) have exploited the principle of "salting out" of gases and postulated that the $\mathrm{O}_{2}$ solubility in the microenvironment of highiy charged surfaces of polyionic solid adsorbants may be sufficiently low to protect hydrogenase from $\mathrm{O}_{2}$ even though the bulk liquid medium is in equilibrlum with a1r. In fact, the authors demonstrated that the half-1ife of clostridial hydrogenase ( $4 \mathrm{~min}$ in air) increases by a factor of 3,000 to 8.3 days when the enzyme is immobilized on a polyethyleneimine cellulose support. Furthermore, the immobilized hydrogenase preparations not only retain over $50 \%$ of the initial enzyme activity, but are also capable of utilizing both reduced methyl viologen and reduced ferredoxin as electron donors for $\mathrm{H}_{2}$ evolution. Yagi (1977) has also immobilized hydrogenase by entrapment on polyacrylamide gel thereby improving its stability.

Another significant advance in the area of hydrogenase $\mathrm{O}_{2}$ sensitivity was achieved through an extensive survey of microbial sources for enzymes having high intrinsic $\mathrm{O}_{2}$-tolerance (McBride et al., 1977; Schneider and Schlegel, 1977; van der Western et a1., 1978). The most stable enzymes yet found have been isolated from Chromatium (Gitlitz and Krasna, 1975), A. encrophus (Schneider and Schlege1, 1977) and D. vulgaris, (van der western et al., 1978). In these cases, the active hydrogenases were obtained using aerobic preparative procedures. Preparations can be stored in air and retain $40 \%$ or more of the initial activity for a period of several weeks (Schneider and Schlege1, 1977; van der Western et al., 1978). Appllcation of the stabilizing technique of Klibanov et al., ( $\overline{197} \overline{8)}$ to these and other naturally $\mathrm{O}_{2}$-tolerant enzymes may result in preparations sufficiently stable for use as a component in practical cell-free $\mathrm{H}_{2}$ production systems.

Ever since the discovery of the Hill reaction in isolated chloroplasts nearly four decades ago, the instability of in vitro chloroplast activity has been a continuing problem in photosynthesis research. In the past, efforts to improve the stability of the isolated photosynthetic apparatus were limited to empirical attempts to minimize only the instability associated with certain partial reactions of special interest to the investigator. A systematic endeavor designed to produce highly stable chloroplast preparations for longterm $\mathrm{H}_{2}$ production has not been actively pursued until very recently (Morris et a1., 1978).

Preservation of the photochemical activity of chloroplast preparations against thermal degradative processes (Section 4.2 .2 ) has been partially successful through empirical variation of the osmolarity, $\mathrm{pH}$, ion composition, and ionic strength in the suspension medium. In general, the electron transport 
activity of chloroplast preparations are better preserved in slightly hypertonic (equivalent to $0.4 \mathrm{M}$ sucrose) medium buffered at near neutral $\mathrm{pH}$ (6.5-8). Inclusion of various "protective" agents such as polyethylene glycol (Krogmann and Jagendorf, 1959; Oquist et al., 1974), glycerol (Packer and Barnard, 1966; Wassermann and Fleisher, 1968), and BSA (Wassermann and Fleisher, 1968; Wintermans et al., 1969; Anderson et al., 1974; Morris, et al, 1978) usually improve the stability of photochemical activity under a variety of storage conditions. Among these "protective" agents, BSA appears to be the most effective against destabilization associated with the inhibitory actions of fatty acids and other products of lipid degradation. However, the use of BSA in large quantity may not be economically feasible. Furthermore, BSA and other "protective agents" only appear effective for storage conditions under which the photosynthetic apparatus is functionally dormant (Morris et al., 1978). Presumably, these "protective agents" are not effective against photochemical degradation of the photosynthetic apparatus.

In recent years, several novel approaches toward stabilization of chloroplast structure and function have been attempted. These include chemical modification of the thykaloid membranes using bifunctional cross-linking agents such as glutaraldehyde and imidoesters (Park et al., 1966; Hallier and Park 1969, Packer, 1976; Hardt and Kok, 1976; Rao et al., 1976); microencapsulation of choroplast particles in artiflcial membranes (Kitajima and Butler, 1976); immobilization of chloroplasts in polyacrylamide gel (Ochiai et al., 1977); and entrapment of choroplasts into the porous matrix of specially treated glass beads (Nugent, 1972). With the limited amount of work reported to date, it is difficult to predict the outcome of these stabilization approaches. Apparently, some of the methods are successful against dark thermal inactivation, but stabilization against photochemical inactivation of the electron transport reations has yet to be demonstrated (Rao et al., 1976; Morris et al., 1978).

In any event, stabilization of the photochemical activity of the photosynthetic apparatus in vitro requires a better understanding of both thermal and photochemical inactivation processes as well as a better characterization of the structure and function of the thylakoid membranes. Such knowledge is a prerequisite for a systematic approach to the solution of the problem and must be solved if cell-free biological $\mathrm{H}_{2}$-evolving systems are ever to contribute to our energy supply. 
THIS PAGE INTENTIONALLY LEFT BLANK 


\section{SECTION 8.0}

\section{COMMENTS AND FUTURE RESEARCH DIRECTIONS}

None of the currently identified photobiological $\mathrm{H}_{2}$-producing systems have reached the development point at which pilot plant operations would be of benefit. However, progress during the past few years has turned a laboratory curiosity into a phenomenon that may be applicable in future solar energy conversion applications. Conversion efficiencies in whole-cell biophotolysis systems (algae and cyanobacteria) might approach $4 \%$ to $5 \%$ while those in cellfree systems could reach $10 \%$. Conversion efficiencies in $\mathrm{H}_{2}$ photoproduction systems utilizing photosynthetic bacteria might be much higher since both the substrates and sunlight contribute energy to the process. In comparison, biomass production schemes presently exhibit maximal solar conversion efficiencies of $1 \%$ to $1.5 \%$ (on an annual basis) and the product (wood, etc.) is not as convenient a fuel or chemical as $\mathrm{H}_{2}$.

Before substantive recommendations are made for dealing with near- to longterm research and development, however, it must be pointed out once again that there is considerable variation in how $\mathrm{H}_{2}$ evolution rates are reported. This has caused confusion and in many cases prevented the direct comparison of results obtained by different investigators with different organisms. Consequently, there is a need for a standard assay to relate $\mathrm{H}_{2}$ production rates in different organisms or systems. Such an assay should measure the effective yield of $\mathrm{H}_{2}$ evolution in an organism exposed to well-defined conditions. In addition, when reporting rates of $\mathrm{H}_{2}$ production enough information should be given (i.e., chlorophyll concentration, dry weight, volume of material, etc.) so that comparison with previous results is possible.

Current prospects for near- to mid-term applications rest mainly with the whole cell systems, including those using cyanobacteria or photosynthetic bacteria. Biophotolysis has received a great deal of recent attention because water is the substrate for the photoproduced $\mathrm{H}_{2}$. Cyanobacteria are probably the most promising organisms that carry out this process because they $f i x$ their own nitrogen (and thus are inexpensive to grow and mainta1n), evolve $\mathrm{H}_{2}$ for extended periods of time $\left(>1\right.$ month), and are not sensitive to $\mathrm{O}_{2}$ degrada tion. On the negative side, the field conversion efficiencies are only a few tenths of a percent and the $\mathrm{H}_{2}$ produced must be separated from other gases. Photosynthetic bacteria may photoconvert organic substrates in such wastes as sewage, crop- and food-processing residues, and cellulosic materials. Their $\mathrm{H}_{2}$ photoevolution rates (on defined media) are much higher than rates observed for other types of photosynthetir organisms. Probleme aesociatcd with $\mathrm{O}_{2}$ inactivation of $\mathrm{H}_{2}$ evolution and with the separation of $\mathrm{H}_{2}$ from other gases are minimized since these organisms do not evolve $\mathrm{O}_{2}$. In addition, the organisms are easily manipulated genetically, thus increasing the probability of obtaining increased $\mathrm{H}_{2}$ photoproduction rates. As yet they have received little serious attention as a basis of applied systems. Since no major technological breakthroughs are needed, they represent the greatest. area nf promise for near-term applications. 
Consequently, research with both procaryotic classes of organisms should continue, emphasizing:

- surveys of naturally occurring strains including marine and thermophilic organisms to identify those having the most active $\mathrm{H}_{2}$ metabolism;

- selection of mutant organisms with constitutive derepression of hydrogenase and nitrogenase (which would result in higher evolution rates and a good source of enzyme for cell-free systems);

- genetic manipulation of cellular metabolism to maximize $\mathrm{H}_{2}$ photoproduction; and

- studies identifying the environmental conditions leading to optimal $\mathrm{H}_{2}$ production.

Long-range applications should emphasize cell-free systems based on the $\mathrm{H}_{2}$ photoproduction pathway found in green algae. Green algae employ a rather direct electron pathway between water and $\mathrm{H}_{2}$ and do not have the metabolic complications associated with $\mathrm{N}_{2}$ fixation. Furthermore, they represent an energetically feasible model system and use water as a substrate. Specific research directions in this area should emphasize:

- detailed studies of the active site(s) of hydrogenase (and also of nitrogenase) which would aid in the synthesis of stable, active analogues for use ln applied systentis;

- stabilization of hydrogenase;

- stabilization of the photosynthetic membrane and in particular PSIIassociated $\mathrm{O}_{2}$ evolution; and

- biochemical and biophysical studies of water splitting and reaction center mechanisms that may give insight into the development of chemical analogues. 


\section{REFERENCES}

Abeles, F.B. 1964. Cell-free hydrogenase from Chlamydomonas. Plant Physiol. 39: $169-176$.

Ackre11, B.A.C., R.N. Asato and H.F. Mower. 1966. Multiple forms of bacterial hydrogenases. J. Bacteriol. 92:828.

Adams, M.W.W. and D.0. Hall. 1977. Isolation of the membrane-bound hydrogenase from Rhodospirillum rubrum. Biochem. Biophys. Res. Comm. 77:730-737.

Adams, M.W.W., S.G. Reeves and D.O. Ha11. 1977. Biological activity of synthetic tetranuclear iron-sulfur analogues of the active sites of ferredoxins. Biochem. Biophys. Res. Commun. 79:1184-1191.

Alberte, R.S. and E. Te1-Or. 1977. Characteristics of the photosynthetic apparatus of heterocyst and vegetative cells of Nostoc and Anabaena. Plant Physiol. 59:129.

Anand, S.R. and A.I. Krasna. 1965. Catalysis of the $\mathrm{H}_{2}-\mathrm{HTO}$ exchange by hydrogenase: A new assay for hydrogenase. Biochem. 4:2747-2753.

Anderson, M.M., R.E. McCarty and E.A. Zimmer. 1974. The role of galactolipids in spinach chloroplast lamellar membranes: I. Partial purification of bean leaf galactolipid lipases and its action on subchloroplast particles. Plant Physio1. 53:699-704.

Arnon, D.I. 1965. Ferredoxin and photosynthesis. Science 149:1460-1470.

Arnon, D.I. 1977. Photosynthesis 1950-75: Changing concepts and perspectives. In A. Trebst and M. Avron (editors), Encyclopedia of Plant Physiology, New Series, Vol. 5. Springer-Verlag, Berlin-Heidelberg-New York, pp. 7-56.

Arnon, D.I., M. Losada, M. Nozak1 and K. Tagawa. 1961. Photoproduction of hydrogen, photofixation of nitrogen and a unified concept of photosynthesis. Nature 190:601-610.

Arnon, D., A. Mitsui and A. Paneque. 1961. Photoproduction of hydrogen gas coupled with photosynthetic phosphorylation. Science 134:1425.

Arnon, D.I., H.U. Tsa.jimoto and B.D. McSwain. 1967. Ferredoxins and photosynthetic phosphorylation. Nature 214:562-566.

Asada, K., K. Kiso and K. Yoshikawa. 1974. Univalent reduction of molecular oxygen by spinach chloroplasts on illumination. J. Biol. Chem. 249:2175-2181.

Baltscheffsky, H., L. von Stedingk, H. Heldt and M. Klingenberg. 1966. Inorganic pyrophosphate: Formation in bacterial photophosphorylation. Science 153:1120-1122. 
Bamberger E.S. and R.B. Park. 1966. Effect of hydrolytic enzymes on the photosynthetic efficiency of chloroplasts. Plant Physiol. 41:1591-1600.

Barr, R. and F.L. Crane. 1971. Quinones in algae and higher plants. In S.P. Colowick and N.0. Kaplan (editors), Methods in Enzymology, Vol. XXIII. Academic Press, New York, pp. 372-405.

Bartsch, R.G. 1978. Cytochromes. In R.K. Clayton and W.R. Sistrom (editors), The Photosynthetic Bacteria. Plenum, New York.

Ben-Amotz, A., D.L. Eribes, M.A. Riedeser-Henderson, D.G. Peavey and M. Gibbs. 1975. $\mathrm{H}_{2}$-metabolism in photosynthetic organisms: I. Dark $\mathrm{H}_{2}$ evolution and uptake by algae mosses. Plant Physiol 56: $72-77$.

Ben-Amotz A. and M. Gibbs. 1975. $\mathrm{H}_{2}$-metabolism in photosynthetic organisms: 11. Light-dependent $\mathrm{H}_{2}$ evolution by preparations from Chlamydomonas, Scenedesmus, and spinach. Biochem. Biophys. Res. Commun. 64:355-359.

Bendall, D.S., H.E. Davenport and K. Hill. 1971. Cytochrome components in chloroplasts of the higher plants. In S.P. Colowick and N.O. Kaplan (editors), Methods in Enzymology, Vol. XXIII. Academic Press, New York, pp. $327-344$.

Benemann, J. 1977. Hydrogen and methane production through microbial photosynthesis. In R. Buvet, M.J. Allen and J.P. Massue (editors), Living Systems as Energy Converters. Elsevier/North-Holland Biomedical Press, Amstcrdam, pp. 285-297.

Benemann, J.R., J.A. Berenson, N.0. Kaplan and M. D. Kamen. 1973. Hydrogen evolution by a chloroplast-ferredoxin hydrogenase system. Proc. National Acad. Sci. 70:2317-2329.

Benemann, J.R. and N.M. Weare. 1974. Hydrogen evolution by nitrogen-fixing Anabaena cylindrica cultures. Science 184:174-175.

Benemann, J.R., P.C. Hallenbeck; J.C. Weissman, L.V. Kochian, P.J. Kostel and W.J. Oswald. 1977. Solar energy conversion with hydrogen producing algae. UCB-SERL Report No. 78-2.

Benemann, J.R., P.C. Hallenbeck, M.A. Murry, L.V. Kochian, K. Miyamoto, P.J. Kostel and W.J. Oswald. 1978. Solar energy conversion through biophotolysis. UCB-SERL Report No. $78-8$.

Benemann, J.R. and J.C. Weissman. 1977. Biophotolysis: Problems and prospects. In H.G. Schlegel and J. Barnea (editors). Microbial Energy Conversion. Perganom Press, Oxford, pp. 413-426.

Benemann, J.R., P.C. Hallenbeck, M.A. Murry, L.V. Miyamoto, P.J. Kostel and W.J. Oswald. 1978. Solar energy conversion through biophotolysis. UCB - SERL Report No. 78-8. 
Bennett, R., N. Rigopoulos and R.C. Fuller. 1964. The pyruvate phosphoroclastic reaction and light-dependent nitrogen fixation in bacterial photosynthesis. Proc. Nat'1. Acad. Sci. 52:762-8.

Bennett, M.A. and H.H. Weetal. 1976. Production of hydrogen using immobilized Rhodospirillum rubrum. J. Solid-Phase Biochem. $1: 137-142$.

Bishop, N.I. 1966. Partial reactions of photosynthesis and photoreduction. Ann. Rev. Plant Physiol. 17:185-208.

Bishop, N.I., M. Frick and L.W. Jones. 1977. Photohydrogen production in green algae: Water serves as the primary substrate for hydrogen and oxygen production. In A. Mitsui, S. Miyachi, A. San Pietro and S. Tamura (editors), Biological Solar Energy Conversion. Academic Press, New York, pp. 3-22.

Bishop, N.I. and H. Gaffron. 1963. On the interrelation of the mechanism for oxygen and hydrogen evolution in adapted algae. In B. Kok and A.T. Jagendorf (editors), Photosynthetic mechanisms in green plants. N.A.S.-N.R.C., Washington, D.C., Pp. 441-451.

Blankenship, R.E., G.T. Babcock and K. Sauer. 1975. Kinetic study of oxygen evolution parameters in Tris-washed, reactivated chloroplasts. Biochim. Biophys. Acta 387:165.

Bockris, J.0'M. 1975. Energy: The Solar-Hydrogen Alternative. John Wiley and Sons, New York.

Bolton, J.R. 1976. Paramagnetic intermediates in photosynthesis. Ann. Rev. Plant Physiol. $27: 375-383$.

Bolton, J.R. 1977. Solar energy conversion efficiency in photosynthesis-or-Why two photosystems? In Proc. of the $4 \mathrm{th}$ International Congress on Photosynthesis, pp. $62 \overline{1-634}$

Bolton, J.R. 1978. Solar fuels produced by the photochemical conversion and storage of solar energy. Science, in press.

Bose, S.K. and H. Gest. 1962. Electron transport systems in purple bacteria: II. Hydrogenase and light-stimulated electron transfer reactions in photosynthetic bacteria. Nature 195:1168-1171.

Bothe, H., B. Falkenberg and U. Nolteernsting. 1974. Properties and functions of pyruvate: ferredoxin oxidoreductase from blue-green algae Anabaena cylindrica. Arch. Mir.rnhin1. 96:291-304.

Bothe, H., E. Distler and G. Eisbrenner. 1978. Hydrogen metabolism in bluegreen algae. Biochimie 60:277-289.

Bothe, H., J. Tennigkeit, G. Eisbrenner and M.G. Yates. 1977. The hydrogenase-nitrogenase relationship in the blue-green algae Anabaena cylindrica. Planta 133:237-242. 
Bregoff, H.M. and M.P. Kamen. 1952a. Photohydrogen production in Chromatium. J. Bacteriol. 63:147-149.

Bregoff, H.M. and M.D. Kamen. 1952b. Quantitative relations between malate dissimilation, photoproduction of hydrogen and nitrogen metabolism in Rhodospirillum rubrum. Arch. Biochem. Biophys. 36:202-220.

Brill, W.J. 1975. Regulation and genetics of bacterial nitrogen fixation. Ann. Rev. Microbiol. 29:109-129.

Buchanan, B.B. and D.I. Arnon. 1970. Ferredoxins: Chemistry and function in photosynthesis, nitrogen fixation and fermentative metabolism. Advan. Enzymo1. 33:119-176.

Buchanan, B.B. and D.I. Arnon. 1971. Ferredoxins from photosynthetic bacteria, algae, and higher plants. Methods in Enzymology, Vol. XXIIIA. Academic Press, New York, pp. 413-440.

Buchanan, B. and R. Bachofen. 1968. Ferredoxin-dependent reduction of nicotinamide-adenine dinucleotides with hydrogen gas by subcellular preparations from the photosynthetic bacterium Chromatium. Biochem. Biophys. Acta $162: 607-610$.

Buchanan, B.B. and M.C.W. Evans. 1965. Synthesis of a-oxoglutarate from succinate and carbon dioxide by a subcellular preparation of a photosynthetic bacterium. Proc. Nat1. Acad. Sci. 54:1212-1218.

Buchanan, B. and M.C.W. Evans. 1969. Photoreduction of ferredoxin and its use in $N A D(P)$ reduction by a subcellular preparation from the photosynthetic bacterium, Chlorobium thiosulfatophilum. Biochem. Biophys. Acta 180:123-129.

Buchanan, R.E. and N.E. Gibbons. 1974. Bergey's Manual of Determinative Bacteriology. Williams and Wilkins, Baltimore.

Bulen, W.A., R.C. Burns and J.R. LeComte. 1965. Nitrogen fixation. Hydrosulfate as electron donor with cell-free preparations of $\underline{A}$. vinelandi1 and $\underline{R}$. rubrum. Proc. Nat'1. Acad. Sci. 53:532-539.

Burns, R.C. and W.A. Bulen. 1965. ATP-dependent hydrogen evolution by cellfree preparations of Azotobacter vinelandii. Biochim. Biophys. Acta 105:437145 .

Burns, R.C. and W.A. Bulen. 1966. A procedure for the preparation of extracts from Rhodospirillum rubrum catalyzing $\mathrm{N}_{2}$ reduction and ATP-dependent $\mathrm{H}_{2}$ evolution. Arch. Biochem. Biophys. 113:461-463.

Burris, R.H. 1972. Nitrogen fixation: Assay methods and techniques. In A. San Pietro (editor), Methods in Enzymology, Vol. XXIV. Academic Press, New York, pp. 415-431.

Burris, R.H., E.J. Eppling, H.B. Wahlin and P.W. Wilson. 1943. Detection of nitrogen fixation with isotopic nitrogen. J. Biol. Chem. 148:349-357. 
Burris, R.H., T. Ljones and D.W. Emerich. 1978. Nitrogenase Systems. In J. Dobereiner, R.H. Burns, and A. Hollaender (editors), Limitations and Potentials for Biological Nitrogen Fixation in the Tropics. Plenum Press, New York, pp.191-207.

Burris, R.H. and W.H. Orme-Johnson. 1974. Survey of nitrogenase and its EPR properties. In J. Nielands (editor), Microbial Iron Metabolism. Academic Press, New York, Pp. 187-209.

Burwe11, C.C. 1978. Solar biomass energy: An overview of U.S. potential. Science 199:1041-1048.

C\&E News Staff. 1978. Facts and Figures. C\&E News, $\underline{56}(24): 45-79$.

Calvert, J.G. and J.N. Pitts. 1966. Photochemistry. John Wiley and Sons, Inc., New York-London-Sydney, p. 200.

Campillo, A.J., R.C. Hyer, T.G. Monger, W.W. Parson and S.L. Shapiro. 1977. Light collection and harvesting processes in bacterial photosynthesis investigated on a picosecond time scale. Proc. Nat1. Acad. Sci. 74:1997-2001.

Carter, C.W., J. Kraut, S.T. Ereer., R.A. Alden., L.C. Sieker, E. Adman and L.H. Jensen. 1972. Comparison of $\mathrm{Fe}_{4} \mathrm{~S}_{4} *$ clusters in high-potential iron protein and in ferredoxin. Proc. Nat'l Acad. Sci. 69:3526-3529.

Chance, B. and G. Hollunger. 1963. Inhibition of electron and energy transfer in mitochondria: II. The site and the mechanism of guanidine action. J. Biol. Chem. 238:431-438.

Cogdell, R.J., T.G. Monger and W.W. Parson. 1975. Carotenoid triplet states in reaction centers from Rhodopseudomonas sphaeroides and Rhodospirillum rubrum. Biochim. Biophys. Acta 408:189-199.

Cohen, W.S., B. Nathanson, J. White and M. Brody. 1969. Fatty acids as model systems for the action of Ricinus leaf extract on higher plant chloroplasts and algae. Arch. Biochem. Biophys. 135:21-27.

Cox, K.E. and 0.D. Williamson (editors). 1977. Hydrogen: Its technology and implications, Vol. I-V. CRC Press, Cleveland.

Cusanovich, M.A., R.G. Bartsch and M.D. Kamen. 1968. Light-induced absorbance changcs in Chromatium chromatophores. Biochim. Biophys. Acta $153: 397-417$.

Cusanovich, M.A. and D.E. Edmondson. 1971. Isolation and characterization of Rhodospirillum rubrum flavodoxin. Biochem. Biophys. Res. Comm. 45:327-336.

Dalton, $\mathrm{H}$. and L.E. Mortenson. 1972. Dinitrogen $\left(\mathrm{N}_{2}\right)$ fixation (with a biochemical emphasis). Bacteriol. Rev. 36:231-260.

Dalton, H. and J.R. Postgate. 1969. Growth and Physiology of Azotobacter chroococcum in continuous culture. J. Gen. Microbiol. 56:307-319. 
De, P.K. 1939. Role of blue-green algae in nitrogen fixation in rice fields. Proc. R. Soc. London Ser. B. 127:121-139.

Dilworth, M.J. 1966. Acetylene reduction by nitrogen-fixing preparations from Clostridium pasteurianum. Biochim. Biophys. Acta 127:285-294.

Diner, B.A. and P. Joliot. 1977. Oxygen Evolution dud Manganese. In A. Trebst and M. Avron (editors), Encyclopedia of Plant Physiology, New Series, Vo1. 5, Springer-Verlag, Berlin-Heidelberg-New York, pp. 187-205.

Dixon, R.0.D. 1967. Hydrogen uptake and exchange by pea root nodules. Ann. Bot. $31: 179-188$.

Dixon, R.O.D. 1972. Hydrogenase in legume root nodule bacteroids: Occurrence and properties. Arch. Microbiol. 85:193-201.

Donze, M., J. Haveman and P. Scherick. 1972. Absense of photosystem 2 in heterocysts of the blue-green algae Anabaena. Biochem. Biophys. Acta 25b:157161.

Donze, M., A.J.P. Rast and H.J. Van Gorkom. 1974. Supply of ATP; and reductant to nitrogenase in the blue-green alga Anabaena cylindrica. Plant Sci. Letter 3: 35-41.

Drewes, K. 1928. The assimilation of atmospheric nitrogen by blue algae. Zentralbl. Bakteriol. Parasitenk 76:88-101.

Drews, G. 1978. Structure and development of the membrane system of photosynthetic bacteria. Curr. Topics in Bioenergetics 8:161-207.

Dutton, P.L., J.G. Leigh and M. Seibert. 1972. Primary processes in photosynthesis: In situ ESR studies on the light induced oxidized and triplet state of reaction center bacteriochlorophyll. Biochem. Biophys. Res. Commun. 46:406-413.

Dutton, P.L., K.J. Kaufmann, B. Chance and P.M. Rentzepis. 1975. Picosecond kinetics of the $1250 \mathrm{~nm}$ band of the Rps. sphaeroides reaction center. FEBS Letters 60:275-280.

Dutton, P.L., R.C. Prince, D.M. Tiede, K.M. Petty, K.J. Kaufmann, T.L. Netzel and P.M. Rentzepis. 1977. Electron transfer in the photosynthetic reaction center. Brookhaven Symp. Biol. 28:213-237.

Dutton, P.L., R.C. Prince and D.M. Tiede. 1978. The reaction center of photosynthetic bacteria. Photochem. Yhotobiol., in press.

Eady, R.R., B.E. Smith, K.A. Cook and J.R. Postgate. 1972. Nitrogenase of Klebsiella pneumoniae: Purification and properties of the component proteins. Biochem. J. 128:655-675.

Edwards, D.I. and G.E. Mathison. 1970. Mode of action of metronidozole against T. vaginalis. J. Gen. Microbiol. 63:297-302. 
Efimtsev, E.I., V.A. Boichenko and F.F. Litvin. 1975. Photoinduced hydrogen evolution by bacteria, algae, and higher plants. Dokl Biophys. Nauk. SSSR 220:986-989 (Eng. transl. Dok1. Bot. Sci., pp. 6-8).

Efimtsev, E.I., V.A. Boichenko, N.E. Zatolokin, and F.F. Litvin. 1976. Investigation of primary processes of photoinduced hydrogen evolution by Chlorella in flashing light. Dokl. Biophys. Akad. Nauk. SSSR 226/228:45-48.

Egan, B.Z. and C.D. Scott. 1978. Use of cell-free biological systems for hydrogen production. Symposium on Biotechnology in Energy Production and Conservation. May 10-12, 1978, at Gatlinburg, Tennessee.

Eisenbach, M., C. Weissmann, G. Tanny and R.S. Caplan. 1977. Bacteriorhodopsin-loaded charged synthetic membranes: Ut1lization of light energy to generate electrical current. FEBS Letters 81:77-80.

Evans, M.C.W., B.B. Buchanan and D.I. Arnon. 1966. A new ferredoxindependent carbon reductant cycle in a photosynthetic bacterium. Proc. Natl. Acad. Sci. 55:928-934.

Evans, M.C.W. and R.V. Smith. 1971. Nitrogen fixation by the green photosynthetic bacterium, C. ethylicum. J. Gen. Microbiol. 65:95-98.

Evans, M.C.W., A. Telfer and R.V. Smith. 1973. Purfication and some properties of the molybdenum-iron protein of Chromatium nitrogenase. Biochim. Biophys. Acta 310:344-352.

Fay, P. and R.M. Cox. 1967. Oxygen inhibition of nitrogen fixation in cel1free preparations of blue green algae. Biochem. Biophys. Acta 143:562-569.

Fay, P., W.D.P. Stewart, A.E. Walsby, and G.E. Fogg. 1968. Is the heterocyst the site of nitrogen fixation in the blue-green algae? Nature 220:810-812.

Fay, P. and A.E. Walshy. 1966. Metabolic activities of isolated heterocysts of the blue-green alga Anabaena cylindrica. Naturc 209:94-95.

Feher, G. and M.Y. Okanura. 1978. Chemfcal composition and properties of reaction centers. In R.K. Clayton and W.R. Sistrom (editors), The Photosynthetic Bacteria. Plenum, New York.

Feigenblum, E. and A. Krasna. 1970. Solubilization and properties of the hydrogenase of Chromatium. Biochem. Diuphys. Acta 198:157-164.

Fogg, G.E. 19/12. Studies on nitrogen fixation by bluc-green algae. J. Expt1. Biol. 19:78-87.

Forti, G. 1977. Flavoproteins. In A. Trebst and M. Avron (editors), Encyclopedia of Plant Physiology, New Series, Vol. 5. Springer-Verlag, Berlin-Heidelberg-New York, pp. 222-226.

Franck, J. and C.S. French. 1941. Photooxidation processes in plants. J. Gen. Physiol. 25:309-324. 
Frenke1, A.W. 1952. Hydrogen evolution by the flagellate green algae, Chamydomonas moewusii. Arch. Biochem. Biophys. 38:219-230.

Frenkel, A.W. 1954. Light-induced phosphorylation by cell-free preparations of photosynthetic bacteria. J. Amer. Chem. Soc. 76:5568.

Frenkel, A.W. 1956. Phosphorylation of adenine nucleotides by cell-free preparations of purple bacteria. J. Biol. Chem. 222:823-834.

Frenkel, A.W. 1970. Multiplicity of electron transport reactions in bacterial photosynthesis. Biol. Rev. 45:569-616.

Frenkel, A., H. Gaffron and E.H. Battley. 1950. Photosynthesis and photoreduction by the blue-green algae, Synechococcus elongatus. Biol. Bull. 99: 157-162.

Frenkel, A.W. and C. Rieger. 1951. Photoreduction in algae. Nature $167: 1.030$.

Fry, I., G. Papageorgion, E. Tel-Or and L. Packer. 19977. Keconstiturion of a system for $\mathrm{H}_{2}$ evolution with chloroplasts, ferredoxin and hydrogenase. $\underline{Z}$. Naturforsch. $32 \mathrm{c}: 110-117$.

Fujita, Y. and J. Myers. 1965. Hydrogenase and NADP-reduction reactions by a ccll-free preparation of Anabaena cylindrica. Arch. Biochem. and Biophys. $111: 619-625$.

Fujita, Y., H. Ohama and A. Hattori. 1964. Hydrogenase activity of cell-free preparation obtained from the blue-green alga, Anabaena cylindrica. P1. Cell Physiol. $5: 305-3 i 1$.

Gaffron, H. 1940a. Carbon dioxide reduction with molecular hydrogen in green algae. Am. J. Bot. 27:273-283.

Gaffron, H. 1940b. The oxyhydrogen reaction in green algae and the reduction of carbon dioxide in the dark. Science 91:529-530.

Gattron, H. 1942. Reduction of carbun dluxide cuupled with the oxyhydrogen reaction in algae. J. Gen. Physiol. 26:241-267.

Gaffron, H. 1944. Photosynthesis, photoreduction and dark reduction of carbon dioxide in certain algae. Biol. Rev. Cambridge Phil. Soc. 19:1-20.

Gaffron, H. and J. Rubin. 1942. Fermentative and photochemical production of hydrogen in algae. J. Gen. Physiol. 26:219-240.

Gallon, J.R., T.A. Lakue and W.G.W. Kurz. 1974. Photosynthesis and nitrogenase activity in the blue-green algae Gleocapsa. Can. J. Microbiol. $20: 1633-1637$.

Gallon, J.R., W.G. Kurz and T.A. Larue. 1975. In W.D.P. Stewart (editor), Nitrogen fixation by free-living microorganisms. Cambridge Univ. Press, Cambridge, pp. 159-173. 
Gest, H. 1952. Properties of cell-free hydrogenase of Escherichia coli and Rhodospirillum rubrum. J. Bacteriol. 63:111-121.

Gest, H. 1966. Comparative biochemistry of photosynthetic processes. Nature 209: 879-882.

Gest, H. 1972. Energy conversion and generation of reducing power in bacterial photosynthesis. Adv. in Microb. Physiol. 7:243-282.

Gest, H., J. Judis and H. Peck. 1956. Reduction of molecular nitrogen and relationships with photosynthesis and hydrogen metabolism. In W.D. McElroy and B. Glass (editors), Inorganic Nitrogen Metabolism. Johns Hopkins Univ. Press, Baltimore, pp. 298-315.

Gest, H. and M.D. Kamen. 1949a. Photoproduction of molecular hydrogen by Rhodospirillum rubrum. Science 109:558-559.

Gest, H. and M.D. Kamen. 1949b. Photochemical production of molecular hydrogen by growing cultures of photosynthetic bacteria. J. Bacteriol. 58:239-245.

Gest, H., M.D. Kamen and H.M. Bregoff. 1950. Photoproduction of hydrogen and nitrogen fixation by Rhodospirillum rubrum. J. Biol. Chem. 182:153-170.

Gest, H., J.G. Ormerod and K.S. Ormerod. 1962. Photometabolism of Rhodospirillum rubrum: Light dependent dissimilation of organic compounds to carbon dioxide and molecular hydrogen by an anaerobic citric acid cycle. Arch. Biochem. Biophys. 97:21-33.

Gest, H. and H.D. Peck. 1955. A study of the hydrogenlyase reaction with systems derived from normal and anaerogenic coli-aerogenes bacteria. J. Bacteriol.

Giaquinta, R. and R.A. Dilley, 1977. Chemical modification of Chloroplast Membranes. In A. Trebst and M. Avron (editors), Encyclopedia of Plant Physiology, New Series, Vol. 5. Springer-Verlag, Berlin-Heidelberg-New York, pp. 297-303.

Gibbs, M. 1973. Reactions of molecular hydrogen in micro algae. In M. Gibbs, A. Hallaender, B. Kok, L.D. Krampitz and A. San Pietro (editors), Proceedings of the Workshop on Bio-Solar Conversion. NSF/RANN Report. NSF/RANN Reports.

Gingras, G., R.A. Goldsby and M. Calvin. 1963. Carbon dioxide metabolism in hydrogen-adapted Scenedesmus. Arch. Biochem. Biophys. 100:178-184.

Gitlitz, P.H. and A.I. Krasna. 1975. Structural and catalytic properties of hydrogenase from Chromatium. Biochemistry 14:2561-2567.

Gogotov, I.N. 1978. Relationships in hydrogen metabolism between hydrogenase and nitrogenase in phototrophic bacteria. Biochimie 60:267-275. 
Gogotov, I.N. and A.V. Kosyak. 1966. Hydrogen metabolism in Anabaena variabilis in the dark. Microbiologiya 45:586-591.

Gogotov, I.N. and N.A. Zorin. 1972. Hydrogen metabolism and hydrogenase activity of Rhodospirillum rubrum. Mikrobiol. 41:947-952.

Gogotov, I.N., N. Zorin and E. Kondratieva. 1976. Purification and properties of hydrogenase from the photosynthetic bacterium Thiocapsa roseopersicina. Biokhimiya 41:836.

Goldbeck, J.H., S. Lien and A. San Pietro. 1977. Electron transport in chloroplasts. In A. Trebst and M. Avron (editors), Encyclopedia of Plant Physiology, New Scries, Vul. 5. Springer-Verlag, Berlin-Heidelbcrg-New York, pp. 94-116.

Gordon, J.K. and W.J. Brill. 1974. Derepression of nitrogenase synthes1s in the presence of excess $\mathrm{NH}_{4}^{+}$. Biochem. Biophys. Kes. Comm. 59:967-971.

Gorrel1, T.E. and R.L. Uffen. 1978. Light-dependent and light-independent production of hydrogen gas by photosynthesizing Rhodospirillum rubrum mutant C. Photochem. Photobiol. 27:351-358.

Gray, C.J. and H. Gest. 1965. Biological formation of molecular hydrogen. Science 148: 186-192.

Green, M. and P.W. W11son. 1953. Hydrogenase and nitrogenase in Azotobacter. J. Bacteriol. 65:511-517.

Greenbaum, E. 1977a. The molecular mechanisms of photosynthetic hydrogen and oxygen production. In A. Mitsiu, S. Miyachi, A. San Pietro and S. Tamura (editors), Biological Solar Energy Conversion. Academic Press, New York, pp. 101-107.

Greenbaum, E. 1977b. The photosynthetic unit of hydrogen evolution. Science $196: 878-879$.

Gregory, D.P. 1973. The hydrogen economy. Scientific American 228:13-21.

Gregory, D.P. and J.B. Pangborn. 1976. Hydrogen energy. In J.M. Hollander and M.K. Simmons (editors), Ann. Rev. of Energy, Vol. 1. Annual Reviews Inc., Palo Alto, pp. 279-310.

Gressel, J. and M. Avron. 1965. The effects of structural degradation on the coupled photochemical activities of isolated chloroplasts. Biochem. Biophys. Acta $94: 31-41$.

Gromet-E1hanan, Z. 1977. Electron transport and photophosphorylation in photosynthetic bacteria. In A. Trebst and M. Avron (editors). Encyclopedia of Plant Physiology, New Series, Vol. 5. Springer-Verlag, Berlin-HeidelbergNew York, pp. 637-662.

Guest, J.R. 1974. Bacteriocinogeny in the Athiorhodaceae. J. Gen. Microbiol. $81: 513$. 
Ha11, D.0. 1976. Photobiological energy conversion. FEBS Letters 64:6-16.

Ha11, D.0. 1978. Solar energy conversion through biology: Could it be a practical energy source? Fuel 57:322-333.

Ha11, D.0. and K.K. Rao. 1977. Ferredoxin. In A. Trebst and M. Avron (editors), Encyclopedia of Plant Physiology, New Series, Vol. 5. SpringerVerlag, Berlin-Heidelberg-New York, pp. 206-216.

Hallier, U.W. and R.B. Park. 1969. Photosynthetic light reactions in chemically fixed spinach thylakoids. Plant Physiol. 44:544-546.

Ha11iwe11, B. 1978. The chloroplast at work: A review of modern developments in our understanding of chloroplast metabolism. Prog. Biophys. Molec. Biol. 33:1-54.

Hardt, H. and B. Kok. 1976. Stabilization by glutaraldehyde of high-rate electron transport in isolated chloroplasts. Biochem. Biophys. Acta 449:125135.

Hardy, R.W.F. and E. Knight, Jr. 1967. ATP-dependent reduction of azide and HCN by $\mathrm{N}_{2}$-fixing enzymes of Azotobacter vinelandii and Clostridium pasteruianum. Biochim. Biophys. Acta 139:69-90.

Hartman, H. and A. Krasna. 1963. Studies on the "adaptation" of hydrogenase in Scenedesmus. J. Biol. Chem. 238:749-757.

Hartman, H. and A.I. Krasna. 1964. Properties of the hydrogenase of Scenedesmus. Biochim. Biophys. Acta 92:52-58.

llaselkorn, R. 1978. Heterocysts. Ann. Rev. Plant Physiol. 29:319-344.

Hattori, A. 1963. Effect of hydrogen on nitrite reduction by Anabaena cylindrica. In Studies on Microalgae and Photosynthetic Bacteria. University Press, Tokyo, pp. 485-492.

Haystead, A., R. Robinson and W.D.P. Stewart. 1970. Nitrogenase activity in extracts of heterocystous and non-heterocystous blue-green algae. Arch. Mikrobiol. 74:235-243.

Healey, F.P. 1970. The mechanism of hydrogen evolution by Chlamydomonas moewusii. Plant Physiol. 45:153-159.

Heath, R.L. and L. Packer. 1965. Effect of light on lipid reoxidation of chloroplasts. Biochem. Biophys. Res. Comm. 19:716-720.

Heath, R.L. and L. Packer. 1968a. Photoperoxidation in isolated chluroplasts: I. Kinetics and stoichiometry of fatty acid peroxidation. Arch. Biochem. Biophys. 125:180-198.

Heath, R.L. and L. Hacker. 1968b. P̈hotoperoxidation in isolated chloroplasts: II. Role of electron transfer. Arch. Biochem. Biophys. 125:850857. 
Heathcote, P., D.L. Williams-Smith, C.K. Sihra and M.C.W. Evans. 1978. The role of the membrane-bound iron-sulfur centers $A$ and $B$ in the photosystem: I. Reaction center of spinach chloroplasts. Biochem. Biophys. Acta 503:333-342.

Heber, U. and C.S. French. 1968. Effect of oxygen on the electron transport chain of photosynthesis. Planta 79:99-112.

Heise, K.P. and G. Jacobi. 1973. The correlation of lipid release and photochemcial activities in isolated spinach chloroplasts. $\underline{Z}$. Naturforsch. $28: 120-127$.

Helmsing, P.J. 1967. Hydrolysis of galactolipids by enzymes in spinach leaves. Biochem. Biophys. Acta 1/44:470-472.

Hil1, S. 1976. The apparent ATP requirement for nitrogen fixation in growing Klebsiella pnuemoniae. J. Gen. Microbiol 95:297-312.

Hillmer, P. and H. Gest. 1977a. $\mathrm{H}_{2}$ metabolism in the photosynthetic bacterium Rhodopseudomonas capsulata: $\mathrm{H}_{2}$ production by growing cultures. J. Bacteriol. 129:724-731.

Hillmer, P. and H. Gest. 1977b. $\mathrm{H}_{2}$ metabolism in the photosynthetic bacterium Rhodopseudomonas capsulata: Production and utilization of $\mathrm{H}_{2}$ by resting cells. J. Bacteriol. 129:732-739.

Hind, G. and J.M. Olson. 1968. Electron transport pathways in photosynthesis. Ann. Kev. Plant Physiul. 19:249281.

Hind, G., H.Y. Nakatani and S. Izawa. 1969. Role of chloride in photosynthesis: I. Chlorlde leyuiltulut of electron tranoport. Biochlm. Biophys. Acta 172:277.

Hoare, D.S. and L. Hoare. 1969. Hydrogen metabolism by Rhodomicrobium vanniellii. J. Bacteriol. 100:1124.

Hoberman, H.D. and D. Rittenberg. 1943. Biological catalysis of the exchange reaction between water and hydrogen. J. Biol. Chem. 147:211-227.

Hoch, G.E., K.C. Schneider and R.H. Burris. 1960. $\mathrm{H}_{2}$ evolution and exchange and conversion of $\mathrm{N}_{2} \mathrm{O}$ to $\mathrm{N}_{2}$ by soybean root nodules. Biochim. Biophys. Acta $\underline{37}: 273$.

Hoffmann, D., R. Thauer and A. Trebst. 1977. Photosynthetic hydrogen evolution by spinach chloroplasts coupled to a Clostridium hydrogenase. $Z$. Naturforsch. 32C:257-262.

Holton, D. and M.W. Windsor. 1978. Picosecond flash photolysis in biology and biophysics. Ann. Rev. Biophys. Bioeng. 7: 189-227.

Huang, T.C., W.G. Zumft and L.E. Mortenson. 1973. Structure of the molybdoferredoxin complex from Clostridium pasteurianum and isolation of its subunits. J. Bacteriol. $113: 884-890$. 
Hwang, J.C., C.H. Chen and R.H. Burris. 1973. Inhibition of nitrogenasecatalyzed reductions. Biochim. Biophys. Acta 292:256-270.

Hyndman, L.A., R.H. Burris and P.W. Wilson. 1953. Properties of hydrogenase from Azotobacter vinelandii. I. Bacteriol. 65:522-523.

Israel, D.W., R.L. Howard, H.J. Evans and S.A. Russell. 1974. Purification and characterization of the molybdenum-iron protein component of nitrogenase from soybean nodule bacteriods. J. Biol. Chem. 249:500-508.

Izawa, S., R.L. Heath and G. Hind. 1969. Role of chloride ion in photosynthesis: III. Effect of artificial electron donors upon electron transport. Biochim. Biophys. Acta 180:338.

Jeffries, T.W. and K.L. Leach. 1978. Intermittent illumination increases biophotolytic hydrogen yield by Anabaena cylindrica. Appl. Environ. Microbiol. 35:1228-1230.

Jeffries, T.W., P.H. Moulthrop, H. Timourian, R.L. Ward and B.J. Berger. 1976. Biosolar production of fuels from algae. Lawrence Livermore Laboratory. Report UCRL-52177.

Jeffries, T.W., H. Timowian and R.L. Ward. 1978. Hydrogen production by Anabaena cylindrica. Appl. Environ. Microbiol. 35:704-710.

Johansson, B.C. and H. Gest. 1976. Inorganic nitrogen assimilation by the photosynthetic bacterium Rhodospeudomonas capsulata. J. Bacteriol. 128:683.

Jones, C.W. and L.P. Vernon. 1969. Nicotinamide adenine dinucleotide photoreduction in Rhodospirillum rubrum chromatophores. Biochim. Biophys. Acta. 180:149-164.

Jones, L.W. and N.I. Bishop. 1976. Simultaneous measurement of oxygen and hydrogen exchange from the blue-green alga Anabaena. Plant Physiol. 57:659665.

Jones, L.W. and B. Kok. 1966a. Photolnhibition of chloroplast reactions: I. Kinetics and action spectra. Plant Physiol. 41:1037-1043.

Jones, L.W. and B. Kok. 1966b. Photoinhibition of chloroplast reactions: II. Multiple effects. Plant Physiol. 41:1044-1049.

Junge, W. 1977. Physical aspects of light harvesting electron transport and electrochemical potential generation in photosynthesis of green plants. In A. Trebst and M. Avron (editors), Encyclopedia of Plant Physiology, New Series, Vol. 5. Springer-Verlag, Berlin-Heidelberg-New York, pp. 59-93.

Juttner, F. and N.G. Carr. 1976. The movement of organic molecules from vegetative cells into the heterocysts of Anabaena cylindrica. In G.A. Codd and W.D.P. Stewart (editors), Proc. 2nd Int. Symp. Photosynth. Prokaryotes., Univ. Dundee, Scotland, pp. 121-123. 
Kakuno, T., N. Kaplan and M.D. Kamen. 1977. Chromatium hydrogenase. Proc. Nat1 Acad. Sci. $14: 861$.

Kamen, M.D. and H. Gest. 1949. Evidence Eor a nitrogenase system in the photosynthetic bacterium Rhodospirillum rubrum. Science 109:560.

Kaplan, S. 1978. Control and kinetics of photosynthetic membrane development. In R.K. Clayton and W.R. Sistrom (editors), The Photosynthetic Bacteria. Plenum, New York.

Karunairatnam, M.C., J. Spizizen and H. Gest. 1958. Preparation and properties of protoplasts of Rhodospirillum rubrum. Biochim. Biophys. Acta $29: 649$.

Katoh, S., and A. San Pietro, 1966. In J. Peisach, P. Aisen and W.E. Blumberg (editors), Biochemistry of Copper, Acadellic Press, New York, pp. 407-422.

Katoh, S. and A. Takamiya. 1963. Light-induced reduction and oxidation of plastocyanin by chloroplast preparations. Plant Cell Physiol. 4:335-347.

Katzenelson, E., I. Buium and H. Schuval. 1976. Risk of communicable disease infection associated with wastewater irrigation in agricultural settlements. Science 194:944-946.

Kaufmann, K.J., P.L. Dutton, T.L. Netzel, J.S. Leigh and P.M. Rentzepis. 1975. Picosecond kinetics of events leading to reaction center bacteriochlorophy11 oxidation. Science .188:1301-1304.

Keister, D.L. and N.J. Yike. 1967. Succinate-1inked ATP-driven NAD ${ }^{+}$ reduction by Rhodospirillum rubrum chromatophores. Arch. Blochill. Biophys. $121 ; 415-422$.

Kelley, B.C., C. Meyer, C. Gandy and P. Vignais. 1977. Hydrogen recycling by Rhodopseudomonas capsulata. FEBS Letters 81:281-285.

Kel1y, M., J.R. Postgate and R.L. Richards. 1967. Reduction of cyanide and isocyanide by nitrogenase of Azotobacter chroococcum. Biochim. J. 102:1C-3C.

Kessler, E. 1957. Stoffwechselphysiologische Untersuchungen an Hydrogenase enthaltenden Grualgen. II. Dunkel-Reduction von Nitrat und Nitrit mit molekularen Wasserstoff. Arch. Mikrobiol. $27: 166-181$.

Kessler, E. 1974. Hydrogenase, photoreduction, and anaerobic growth of algae. In W.D.P. Stewart (editor), Algal Physiology and Biochemistry. Blackwe11, Oxford, pp. 454-473.

Kessler, E. and H. Maifarth. 1960. Vorkommen und Leistungsfahigkeit von Hydrogenase bei einigen Grunalgen. Arch. Mikrobiol. 37:215-225.

King, D., D.L. Erbes, A. Ben-Amotz and M. Gibbs. 1977. The mechanism of hydrogen photoevolution in photosynthetic organisms. In A. Mitsui, S. Miyachi, A. San Pietro and S. Tamura (editors), Biological Solar Energy Conversion. Academic Press, New York, pp. 69-75. 
Kitajima, M. and W.L. Butler. 1976. Microencapsulation of chloroplast particles. Plant Physiol. 57:746-750.

Klemme, J.H. 1968. Photoautotrophic growth of new isolated nonsulfur purple bacteria at the expense of molecular hydrogen. Arch. Mikrobiol. 64:29.

Klemme, J.H. 1969. Reactions of hydrogenase from Rhodopseudomonas capsulata in particulate-bound and dissolved states. $\underline{Z}$. Naturforsch. 24:603.

Klibanov, A.M., N.0. Kaplan and M.D. Kamen. 1978. A rationale for stabilization of oxygen-labile enzymes: Application to a clostridial hydrogenase. Proc. Nat1 Acad. Sci. $75: 3640-3643$.

Knight, E. and R.W.F. Hardy. 1966. Isolation and characteristics of flavodoxin from nitrogen-fixlng Clostridium pasteurianum. J. Biol. Chem. 241:2752-2756.

Kobayashi, M. and Y. Tchan. 1973. Treatment of industrial waste solutions and production of useful byproducts using a photosynthetic bacterial method. Water Res. $\underline{7}: 1219$.

Kobayashi, M., N. Ae, M. Kishimoto, S. Kinoshita, Y. Torigai, E. Takahasi and Z. Kasai. 1976. Purification and use of waste solution discharged from wool washing. Nippon Nogei Kagaku 50:157.

Kok, B. 1956. On the inhibition of photosynthesis by intense light. Biochim. Biophys. Acta 21:234-244.

Kok, B. 1974. Photosynthesis. In Proceedings of the Workshop on Bio-solar Conversion. NSF/RANN Report, pp. 22-30.

Kok, B., B.E. Gassner and H.J. Rurainski. 1965. Photoinhibition of chloroplast reactions. Photochem. Photobiol. 4:215-227.

Kondratieva, E.N. 1977. Phototrophic microorganisms as source of hydrogen and hydrogenase formation. In H.G. Schlegel and J. Barnea (editors), Microbiological Energy Conversion. Pergamon Press, New York, pp. 205-216.

Krampitz, L.O. 1972. In A. Hollender et al. (editors), An Inquiry Into Biological Energy Conversion. The University of Tennessee, Knoxville, pp. 22 .

Krampitz, L.0. 1977. Potentials of hydrogen production through biophotolysis. In W.W. Watermani (edttor), symposium Papers. Clean Fuels from Biomass and Wastes. Institute of Gas Technology.

Krasna, A.I. and D. R. Rittenberg. 1954. Inhibition of hydrogenase by nitric oxide. Proc. Nat1. Acad. Sci. 40:225-227.

Krasnovskii, A.A., V.V. Nikandrof, G.P. Brin, I.N. Gogotov and V.P. Oshchepkov. 1975. Photoformation of hydrogen in solutions of Chlorella, NADH and chloroplasts. Dokl. Biochem. 225:509-511. 
Krogmann, D.W. 1973. In N.G. Carr and B.A. Whitton (editors), The Biulogy of Blue-green Algae. Blackwe11, Oxford, pp. 80-98.

Krogmann, D.W. 1977. Photosynthesis I. In A. Trebst and M. Avron (editors), Encyclopedia of Plant Physiology, New Series, Vol. 5. Springer-Verlag, Berlin-Heidelberg-New York, pp. 623-636.

Krogmann, D.W. and A.T. Jagendorf. 1959. Inhibition of the Hill reaction by fatty acids and metal chelating agents. Arch. Biochem. Biophys. 80:421-430.

Kuchkarova, M.A., P.M. Tokhri and M. Sadikov. 1973. Effect of concentrated pulsed sunlight on productivity of certain blue-green algae. Geliotekhnika 9:47-49 (Translation Applied Solar Energy 9:39-40).

Kumazawa, S. and A. Mitsui. 1978. Hydrogenase and nitrogenase participation in the photoproduction of hydrogen by marine blue-green algae. Plant Physiol. (Suppl.) 61:77.

Kurata, Y. 1962. Appearance of hydrogenase, nitrate reductase, dud aipartasc during the ontogeny of the frog. Expt1. Cell Kes. 28:424-429.

Lambert, G.R. and G.D. Smith. 1977. Hydrogen formation by marine blue-green algae. FEBS Letters 83:159-162.

Lang, N.J. and P. Fay. 1971. The heterocysts of blue-green algae: II. Details of ultrastructure. Pruc. R. Soc. London, Ser. B. 178:193-203.

Lee, J.K.H. and M. Stiller. 1967. Hydrogenase activity ill cell-frec preparation of Chlorella. Biochim. Biophys. Acta 132:503-505.

Lee, S.B. and P.W. Wilson. 1943. Hydrogenase and nitrugen fixation by Azotobacter. J. Biol. Chem. 151:337-385.

LeGal1, J., D.V. Dervartanian, E. Spilker, J.P. Lee and H.D. Peck,Jr. 1971. Evidence for the involvement of nonheme iron in the active site of hydrogenase from Desulfovibrio vulgaris. Biochim. Biophys. Acta 234:525-530.

T.ex, M. and W.D.P. Stewart. 1973. Algal nitrogenase, reductant pools and photosystem I activity. Biochim. Biophys. Acta 292:436 ‥443.

Lien, S. and T.T. Bannister. 1971. Muliple sitcs of DCIP reduction by sonicated oar chluspulast3. B10chem. Diaphya. Acta 245:465.

Lien, S. and A. San Pietro. 1975. An inquiry into biophotolysis of water to produce hydrogen. NSF/RANN Report.

Lien, S. and A. San Pietro. 1978a. On the rcactivity of nxygen with photosystem I electron acceptors. FEBS Letters, in press.

Lien, S. and A. San Pietro. 1978b. Interaction of plastocyanin acid and P700 in PSI reaction center particles from Chlamydomonas reinhardi and spinach. Arch. Biochem. and Biophys., in press. 
Lindstrom, E.S., R.H. Burris and P.W. Wilson. 1949. Nitrogen fixation by photosynthetic bacteria. J. Bacteriol. 58:313.

Lindstrom, E.S., S.M. Lewis and M.J.P. Winsky. 1951. Nitrogen fixation and hydrogenase in various bacterial species. J. Bacteriol. 61:481.

Lindstrom, E.S., S.R. Trove and P.W. Wilson. 1950. Nitrogen fixation by the green and purple sulfur bacteria. Science 112:197-198.

Lockshin, A. and R.H. Burris. 1965. Inhibitors of nitrogen fixation in extracts from Clostridium pasteurianum. Biochem. Biophys Acta 111:1-10.

Losada, M., M. Nozadi and D.I. Arnon. 1961. Photoproduction of molecular hydrogen from thiosulfate by Chromatium cells. In W.D. McElroy and B. Glass (editors), Light and Life. John Hopkins Press, Baltimore, pp. 570-575.

Ludden, P. and R.H. Burris. 1978. Purification and properties of nitrogenase from Rhodospirillum rubrum. Biochem. J. (submitted).

Magasanik, B., M. Prival, J. Brenchey, B. Tyler, A. Deleo, S. Streicher, R. Bender and C. Paris. 1975. Glutamine synthetase as a regulator of enzyme synthesis. In Horecker and Stadtman (editors), Current Topics in Cellular Regulation. Academic Press, New York, pp. 119-138.

Malkin, S. and L.W. Jones. 1968. Photoinhibition and excitation quenching in photosystem II of photosynthesis, from fluorescence induction measurements. Biochim. Biophys. Acta 162:297.

Malkin, R., A.J. Bearden, F.A. Hunter, R.S. Alberte and J.P. Thornber. 1976. Properties of the low-temperature photosystem I primary reaction in the P-700 chlorophyll a-protein. Biochem. Biophys. Acta 430:389-394.

Mantai, K.E. 1970. Effects of hydrolytic enzymes on coupled and uncoupled electron flow in chloroplasts. Plant Physiol. 45:563-566.

Marrs, B. 1974. Genetic recombination in Rhodopseudomonas capsulata. Proc. Nat1. Acad. Sci. $11: 971-973$.

Marrs, B. 1978. Mutations and genetic manipulations as probes of bacterial photosynthesis. Curr. Topics in Bioenerg. 8: 261-294.

Marrs, B. and H. Gest. 1973. Genetic mutations affecting the respiratory electron-transport system of the photosynthetic bacterium Rhodospeudomonas capsulata. J. Bacteriol. 114:1045-1051.

Maugh, T.H. 1972. Hydrogen: Synthetic fuel of the future. Science 178:849852.

McBride, A.C., S. Lien, R.K. Togasaki and A. San Pietro. 1977. Mutational analysis of Clamydomonas reinhardi: Applications to biological solar energy conversion. In A. Mitsue, S. Miyachi, A. San Pictro and S. Tamura (edilors), Biological Solar Energy Conversion. Academic Press, New York, pp. 77-86. 
McCarty, R.E. and A.T. Jagendorf. 1965. Chloroplast damage due to enzymatic hydrolysis of endogenous lipids. Plant Physiol. 40:725-735.

Mehler, A.H. 1951. Studies on reaction of illuminated chloroplasts. I. Mechanism of the reduction of oxygen and other Hill reagents. Arch. Biochem. Biophys. 33:65-77.

Meyer, J., B.C. Kelley and P.M. Vignais. 1978a. Nitrogen fixation and hydrogen metabolism in photosynthetic bacteria. Biochimie 60:245-260.

Meyer, J., B.C. Kelley and P.M. Vignais. 1978b. Effect of light on nitrogenase function and synthesis in Rhodopseudomonas capsulata. J. Bacteriol. 136:201-208.

Mitsui, A. and S. Kumazawa. 1977. Hydrogen production by marine photosynthetic organisms as a potential energy source. In A. Mitsui, $S$. Miyachi, A. San Pietro and S. Tamura (editors), Biological Solar Energy Conversion. Academic Press, New York, pp. 23-51.

Monty, K.J. and R.W. Beck. 1973. The genetic reengineering of photosynthetic microorganisms to obtain efficient hydrogen-producing photosynthesis. In $M$. Gibbs, A. Hollaender, B. Kok, L.O. Krampitz and A. San Pietro (editors), Proceedings of the Workshop on Bio-Solar Conversion. NSF/RANN Report, pp. 3335.

Morris P., G.U. Nash and D.0. Hall. 1978. The stability of electron transport (to be submitted).

Mortenson, L.E. 1972. Purification of nitrogenase from Clostridium pasteurianum. In A. San Pietro (editor), Methods in Enzymology, Vol. XXIV. Academic Press, New York, pp. 446-456.

Mortenson, L.E. and J.S. Chen. 1974. Hydrogenase. In J. Nielands (edjtor), Microbial Iron Metabolism. Academic Press, New York, pp. 231-282.

Mortenson, L.E., R.C Valentine and J.E. Carnahan. 1962. An electron transport factor from Clostridium pasteurianum. Biochem. Biophys. Res. Comm. 7:448-452.

Mortenson, L.E., R.C. Valentine and J.E. Carnahan. 1963. Ferreduxin in the phosphoroclastic reaction of pyruvic acid and 1ts relaliun to nitrogen fixation in Clostriduim pasteurianum. J. Biol. Chem. 238:794-800.

Myers, J. and G. Burr. 1940. Studies on photosynthesis. Some effects of light of high intensity on Chlorella. J. Gen. Physiol. 24:45-67.

NSF/NASA Solar Energy Pane1 1973. Solar Energy As a National Energy Resource. NSF/RANN-73-001.

Nakamura, H. 1937. Presence of hydrogenlyase in Rhodobacillus palustris and its role in the mechanism of bacterial photosynthesis. Acta Phytochim. $10: 211$. 
Nakamura, H. 1938. Role of hydrogenase in the metabolism of Rhodobacillus palustris. Acta Phytochim. 10:259.

Nakos, G. and L.E. Mortenson. 1971. Purification and properties of hydrogenase, an iron sulfur protein, from Clostridium pasteurianum W5. Biochem. Biophys. Acta 227:576-583.

Neilson, A., R. Rippka and R. Kunisawa. 1971. Heterocyst formation and nitrogenase synthesis in Anabaena, sp.: A kinetic study. Arch. Mikrobiol. $\underline{76}: 139-150$.

Newton, J.W. 1976. Photoproduction of molecular hydrogen by a plant algal symbiotic system. Science 191:559-561.

Nielson, A.H. and S. Nordlund. 1975. Regulation of nitrogenase synthesis in intact cells of Rhodospirillum rubrum: Inactivation of nitrogen fixation by ammonia, glutamine and asparagine. J. Gen. Microbiol. 91:53-62.

Nugent, N. 1972. In A. Hollaender et al. (editors), An Inquiry into Biological Energy Conversion, p. 24.

Nuhrenberg, B., D. Lesemann and A. Pirson. 1968. Zur Frage eines anaeroben Wachstums von einzelligen Grunalgen. Planta 79:162-180.

Ochiai, H., H. Shibata, T. Matsuo, K. Hashinokuchi and M. Yukawa. 1977. Immobilization of chloroplast photosynthesis. Agric. Biol. Chem. 41:721-722.

Oelze, J. and G. Drews. 1972. Membranes of photosynthetic bacteria. Biochim. Biophys. Acta 265:209-239.

Oesterheld, H. 1971. Das Verhalten von Nitratreductase, Nitritreductase, Hydrogenase und anderen Enzymen von Ankistrodesmus braunii bei Stickstoffmange1. Arch. Mikrobiol. 79:25-43.

Okamoto, T. and S. Katoh. 1977. Linolenic acid binding by chloroplasts. Plant Cell Physiol. 18:539-550.

Okayama, S,, T. Kakuno and T. Horio. 1970. Two different pigments capable of light-induced absorbance change at near infra-red region in chromatophores from Rhodospirillum rubrum. J. Biochem. 68:19-29.

Okayama, S., B.L. Epel, K. Erixon, R. Lozier and W.L. Butler. 1971. The effects of lipase on spinarh and Chlamydomonas chloroplasts. Blochim. Biophys. Acta 253:476-482.

Oquist, G., B. Martin and 0. Mărtensson. 1974. Photoreduction of 2,6dichlorophenol indophenol in chloroplasts isolated from Pinus silvestris and Picea abies. Photosynthetica 8:263-271.

Ordal, E.J. and H.O. Halverson. 1939. A comparison of hydrogen production from sugars and formic acid by normal and variant strains of F. Enli. J. Bacter101. 38:199-220. 
Ormerod, J.G. and H. Gest. 1962. Hydrogen photosynthesis and alternative metabolic pathways in photosynthetic bacteria. Bacteriol. Rev. 26:51-66.

Ormerod, J.G., K.S. Ormerod and H. Gest. 1961. Light-dependent utilization of organic compounds and photoproduction of molecular hydrogen by photosynthetic bacteria: Relationships with nitrogen metabolism. Arch. Biochem. Biophys. 94:449-463.

Oshchepkov, V.P., A.A. Nikitina, M.V. Gusev and A.A. Krasnovskii. 1973. Dok1. Akad. Nauk SSSR 213:739-742 (Engl. Trans1.: pp. 557-560).

Packer, L. 1976. Problems in the stabilization of the in vitro photochemical activity of chloroplasts used for hydrogen producliun. FEBS Lett. 61:17-19.

Parker, L. and A.C. Barnard. 1966. Preservation of photophosphorylation in glycerinated chloroplasts. Biochem. Biophys. Acta 120:443-448.

Packer, L. and W. Cullingford. 1978. Stuichiometry of $\mathrm{H}_{2}$ producclun by dil $\mathrm{L}_{11}$ vitro chluroplast, ferredoxin, hydrogenase reconstituted system. $\underline{Z}$. Naturforsch. 33C:113-115.

Packer, L, T. Komshi and P. Shieh. 1977a. Model systems reconstituted from bacteriorhodopsin. In R. Buvet, M.J. Allen, J.P. Massue (editors), Living Systems as Energy Converters. Elsevier/North-Holland Biomedical Press, Amsterdam, pp. 119-128.

Packer, L., E. l'el-Or and G. Papageorgion. 1977b. The potential of $\mathrm{H}_{2}$ production by photosyrllielic preparations from chloroplests and cyanobacteria. In R. Buvet, M.J. Allen and J.P. Massue (editors), Living Systems as Finergy Converlers. Elsevier/North-Holland Biomedical Press, Amsterdam, pr, 129-134.

Park, R.B., J. Kelly, S. Drury and K. Sauer. 1966. The Hill reaction of chloroplasts isolated from glutaraldehyde-fixed spinach leaves. Proc. Nat1. Acad. Sci. 55:1056-1062.

Parson, W.W. and G.D. Case. 1970. In Chromatium, a single photochemical reaction center oxidizes both cytochrome $\subseteq 552$ and cytochorome $c_{555^{\circ}}$ B1.nchim. B1ophys. AcLid 205:232 245.

Parson, W.W., R.K. Clayton and R.J. Cogdell. 1975. Excited states of phntosynthetic reaction centers at low redox potentials. Biochim. Biophys. Acta 387:265-278.

Paschenko, V.Z., A.A. Konoenko, S.P. Protasov, A.B. Rubin, L.B. Rubin and N.Ya. Uspenskaya. 1977. Probing the fluorescence emission kinetics of the photosynthetic apparatus of $R$, sphaernides, strain 1760-1, on a picosecond pulse fluorometer. Biochim. Biophys. Acta 461:403-412.

Peck, H.D. and H. Gest. 1954. Enzymic reduction of pyridine nucleotides by molecular hydrogen. Biochim. Biophys. Acta 15:587-588. 
Peck, H.D. and H. Gest. 1957a. Hydrogenase of Clostridium butylicum. J. Bacteriol. 73:569-580.

Peck, H.D. and H. Gest. 1957b. Formic dehydrogenase and the hydrogenlyase enzyme complex in coli-aerogenes bacteria. J. Bacteriol. 73:706-721.

Peck, H.D., A. San Pietro and H. Gest. 1956. Mechanism of hydrogenase action. Proc. Nat1 Acad. Sci. 42:13-19.

Petering, D., J.A. Fee and G. Palmer. 1971. The nxygen sensitivity of spinach ferredoxin and other iron-sulfur proteins. J. B1ol. Chem. 245:643653.

Peters, G.A., W.R. Evans, and R.E. Toria, Jr. 1976. Azolla/Anabaena azollae relationship: IV. Photosynthetically driven, nitrogenase-catalyzed $\mathrm{H}_{2}$ production. Plant Physiol. 59:119-126.

Peters, G.A., R.E. Torja, Jr. and S.M. Lough. 1977. Azolla/Anabaena azollae relationship: $\quad \mathrm{V} .{ }^{15} \mathrm{~N}_{2}$ fixation, acetylene reduction and $\mathrm{H}_{2}$ production. Plant Physiol. 59:1021-1025.

Peterson, R.B. and C.P. Wolk. 1978. Localization of an uptake hydrogenase in Anabaena. Plant Physiol. 61:688-691.

Pfennig, N. 1967. Photosynthetic bacteria. Ann. Rev. Microbiol. 21:285-324.

Pfennig, N. and H.G. Truper. 1974. The phototrophic bacteria. In R.E. Buchanan and N.E. Gibbons (editors), Bergcys Manual of Determinative Bacteriology, 8th Ed. William and Wilkins, Baltimore, pp. $24-\overline{64}$.

Porter, K.G. 1977. The plant-animal interface in freshwater ecosystems. Amer. Sc1. 65:159-170.

Postgate, J. 1961. Cytochrome $\underline{c}_{3}$. In Haematin Enzymes, Symp. Intern. Union Biochem. Canberra, pp. 407-418.

Postgate, J.R. 1971. In D.E. Hughes and A.H. Rose (editors), Microbes and Biological Productivity. Cambridge U. Press, Cambridge, pp. 287-307.

Prince, R.D., J.S. Le1gh and P.L. Dutton. 1976. Thermodynamic properties of the reaction center of Rhodopseudomonas viridis. In vivo measurement of the reaction center bacteriochlorophyll - primary acceptor intermediary electron carrier. Biochem. Biophys. Acta 440:622-636.

Prince, R.C. and J,M. OIson. 1976. Some thermudynamic and kinetic properties of the primary photochemical reactants in a complex from a green photosynthetic bacterium. Biochim. Biophys. Acta. 423:357-362.

Quispel, A. 1974. The Biology of Nitrogen Fixation. North-Holland, Ams terdam.

Rabinowitch, E.I. 1956. Photosynthesis and Related Processes. Interscience Publ. Inc., New York, pp. 1272-1281; 1433-1484. 
Radmer, R. and G. Cheniae. 1977. Mechanism of oxygen evolution. In J. Barker (editor), Prinary Processes of Photosynthesis. Elsevier, Amsterdam-New York-Oxford, pp. 303-348.

Radmer, R.J and B. Kok. 1977. Light conversion efficiency in photosynthesis. In A. Trebst and M. Avron (editors), Encyclopedia of Plant Physiology, New Series, Vol. 5. Springer-Verlag, Berlin-Heidelberg-New York, pp. 125-135.

Rao, K.K., L. Rosa and D.0. Hall. 1976. Prolonged production of hydrogen gas by a chloroplast biocatalytic system. Biochem. Biophys. Res. Commun. 68:2128 .

Rao, K.K., I.N. Gogotov and D.O. Hall. 1978. Ilydrogen evolution by chloroplast-hydrogenase systems: Improvements and additional observations. Binchinie 60:291-296.

Reeves, S.G., K.K. Rao, L. Rosa and D.O. Hall. 1976. Biocatalytic production of hydrogen. In H.G. Schlegel and J. Barnea (editors), Microbial Energy Conversion. Firich Golbe KG., Gotligen, pp. 235-243.

Renwick, G.M., C. Giunarro and S.M. Siegel. 1964. Hydrogen metabolism in higher plants. Plant Physiol. 39:303-306.

Repaske, R. 1962. The electron transport systems of Hydrogenomonas eutropha: I. Diphosphopyridine nucleotide reduction by hydrogen. J. Biol. Chem. 237: 1351-1355.

Ridley, S.M. 197\%. Interacelon u[ chloroplacto with inhihitors: Induction of chlorosis by diuron during prolonged illumination in vitro. Plant Physiol. 59:724 732.

Rippka, R., A. Neilson, R. Kunisawa and G. Cohen-Bazire. 1971. Nitrogen fixation by unicellular blue-green algae. Arch. Mikrobiol. 76:341-348.

Rivera-Ortiz, J.M. and R.H. Burris. 1975. Interactions among substrates and inhibitors of nitrogenase. J. Bdcletiul. 123;537-545.

Rockley, M.G., M.W. Windsor, R.J. Cogdell and W.W. Parson. 1975. Picosecond detection of an linterllediate in tho photnohemiral reaction of bacterial photosynthesis. Proc. Natl Acad. Sci. 72:2251-225.5.

Roclofetn, P.A. 1934. Metabolism of purple sulfur bacteria. Acad. Sci. Amsterdam 37:660-669.

San Pietro, A. 1972. Methods in Enzymology, Vol. XXIV (Photosynthesis and Nitrogen Fixation). Academic Press, New York.

Sasaki, H. 1966. Effects of culture conditions on hydrogenase activity of Scenedesmus $D_{3} \cdot$ Plant Cell Physiol. $\underline{7}: 231-241$.

Satoh, T., Y. Hoshino and H. Kitmura. 1974. Isolation of denitrifying photosynthetic bacteria. Agr. Biol. Chem. 38:1749-1751. 
Satoh, T., Y. Hoshino and H. Kitamura. 1976. Rhodospeudomonas sphaeroides forma sp. denitrificans, a denitrifying strain as a subspecies of Rhodopseudomonas sphaeroides. Arch. Microbiol. 108:265-269.

Sauer, K., P. Mathis, S. Acker and J.A. Van Best. 1978. Electron acceptors associated with P-700 in Triton solubilized Photosystem I particles from spinach chloroplasts. Biochim. Biophys. Acta 503:120-134.

Schick, H.J. 197la. Substrate and light dependent fixation of molecular nitrogen in Rhodospirillum rubrum. Arch. Mikrobiol. 75:89-101.

Schick, H.J. 1971b. Interrelationship of nitrogen fixation, hydrogen evolution, and photoreduction in Rhodospirillum rubrum. Arch. Mikrobiol. $75: 102-109$.

Schick, H.J. 1971c. Regulation of photoreduction in Rhodospirillum rubrum by ammonia. Arch. Mikrobiol. 75:110-120.

Schlegel, H.G. and J. Barnea. 1977. Microbial Energy Conversion. Pergamon Press, Oxford, p. 24.

Schneider, K. and H.G. Schlegel. 1977. Localization and stability of hydrogenases from aerobic hydrogen bacteria. Arch. Microbiol. 112:229-238.

Schreckenbach, . T. 1978. Properties of bacteriorhodopsin and its incorporation into artificial systems. Topics in Photosynthesis, Vol. III, in press.

Schubert, K.R. and H.J. Evans. 1976. Hydrogen evolution: A major factor affecting the efficiency of nitrogen fixation in nodulated symbionts. Proc. Nat 1 Acad. Sci. 73:1207-1211.

Seibert, M. 1978. Book Review - Biological Solar Energy Conversion. Solarr Energy $21: 355$.

Seibert, M. 1978. Picosecond events and their measurement. In. D. Rao Sanadi and L.P. Vernon (editors), Current Topics in Bioenergetics, Vol. 7. Academic Press, New York, pp. 39-73.

Seibert, M. and D. DeVault. 1970. Relations between the laser-induced oxidations of the high and low potential cytochromes of Chromatium $D$. Bioclinill. Biopliys. AcLa 205:220-231.

Seibert, M. and D. DeVault. 1971. Photosynthetic reaction center transients, P 435 and P 424, in Chromatium D. Biochim. Biophys. Acta 253:396-411.

Seihert, M., J.S. Connolly, T.A. Milne and T.B. Reed. 1978. Biological and Chemlcal Conversion at SERT. In Biological Sources of Energy and Chemical Feedstocks, AICHE Symposium Series, in press.

Selman, B.R. and T.T. Bannister. Trypsin inhibition of photosystem II. Biochim. Biophys. Acta 253:428-436. 
Serebryakova, L., N. Zorin and I.N. Gogotov. 1977. Purification and properties of chronatophore-bound hydrogenase from the bacterium Thiocapsa roseopersicina. Biokhimiya 42:740.

Shah, V.K. and W.J. Brill. 1973. Nitrogenase: IV. Simple method of purification to homogeneity of nitrogenase components from Azotobacter vinelandii. Biochim. Biophys. Acta 305:445-454.

Shanmugam, K.T., B.B. Buchanan and D.I. Arnon. 1972. Ferredoxins in 1ightand dark-growth photosynthetic cells with special reference to Rhodospirillum rubrum. Biochim. Biophys. Acta 256:477-486.

Shanmugam, K.T. and R.C. Valentine. 1975. Microbial production of ammonium ion from nitrogen. Proc. Natl Acad. Sci. 72:136.

Shanmugam, K.l'., F. O'Gara, K. Andersen and R.C. Valentine. 1978. Blological nitrogen fixation. Ann. Rev. Plant Physiol. 29:263-276.

Shieh, P. and L. Packer. 1976. Photoinduced potentials across a polymer stabilized planar membrane, in the presence of bacteriorhodopsin. Biochim. Biophys. Res. Commun. 71:603-609.

Siefert, E. 1976. Nitrogen fixation in facultative aerobic Rhodospirillaceae with photosynthetic or respiratory energy generation. In G.A. Codd, and W.D.P. Stewart (editors), Second International Symposium on Photosynthetic Bacteria. Dundee, p. 149.

Siegenthaler, P.A. 1972. Aging of the photosynthetic apparatus: IV. Similarities between the effects of aging and unsaturated fatty acrd in isolated spinach chloroplasts as expressed by volume changes. Bluchlin. Biophys. Acta 275:182-191.

Siegenthaler, P.A. and J. Horakova. 1975. Control of the photusynlhelic electron transport by free fatty acid and $\mathrm{Mn}^{2+}$ salts. In M. Avron (editor), Proc. III Int. Congress of Photosynthesis, Vol. 1. Elseview, Oxford, pp. $655-664$.

Siegenthaler, P.A. and A. Kawley. 1977. Aging of the photosynthetlc apparatus: $V$. Change in $\mathrm{pH}$ dependence of electron transport and relation to endogenous free fatty acids. Plant Science Letters 9:265-273.

Sironval, C. and 0. Kandler. 1958. Photooxidation processes in normal green Chlorella cells: I. The bleaching process. Biochim. Biophys. Acta 29:359368.

Sistrom, W.R. 1977. Transfer of chromosomal gencs mediated by plasmid R68.45 in Rhodopseudomonas sphaeroides. J. Bacter101. 131:526-532.

Skulachev, V.P. 1976. Conversion of light energy into electric energy by bacteriorhodopsin. FEBS Letters 64:23. 
Smith, R.V. and M.C.W. Evans. 1971. Nitrogenase activity in cel1-free extracts of the blue-green alga, Anabaena cylindrica. J. Bacteriol. 105:913917.

Smith, L.A., S. Hill and M.G. Yates. 1976. Inhibition by acetylene of conventional hydrogenase in nitrogenase-fixing bacteria. Nature 262:209-210.

Stanier, R.Y. and G. Cohen-Bazire. 1977. Phototrophic prokaryotes: The cyanobacteria. Ann. Rev. Microbiol. 31:225-274.

Stanier, R.Y., R. Kunisawa, M. Mandel and G. Cohen-Bazire. 1971. Purification and properties of unicellular blue-green algae (Order Chroococeales). Bacteriol. Rev. 35:171-205.

Stephenson, M. and L.H. Stickland. 1931. Hydrogenase: A bacterial enzyme activating molecular oxygen. Biochem. J. 25:205-214.

Stewart, W.D.P. 1973. Nitrogen fixation by photosynthetic microorganisms . Ann. Rev. Microbiol. 7: 283-316.

Stewart, W.D.P., A. Haystead and H.W. Pearson. 1969. Nitrogenase activity in heterocysts of blue-green algae. Nature 224:226-228.

Stewart, W.D.P. and H.W. Pearson. 1970. Effects of aerobic conditions on growth and metabolism of blue-green algae. Proc. $\underline{R}$. Soc. London Ser. B. $175: 293-311$.

Stewart, W.D.P. and P. Rowel1. 1975. Effects of methionine sulfoximine on the assimilation of newly fixed ammonia, acetylene reduction, and heterocyst production in Anabaena cylindrica. Biochem. Biophys. Res. Comm. 65:846-856.

Stiller, M. 1966. Hydrogenase mediated nitrite reduction in Chlorella. Plant Physiol. 41:348-352.

Striecher, S.L. and R.C. Valentine. 197.3, Comparative biochemistry of nitrogen fixation. Ann. Rev. Biochem. 42:279-302.

Stuart, T.S. and H. Gaffron. 1971. The kinetics of hydrogen photoproduction by adapted Scenedesmus. Planta 100:228-243.

Stuart, T.S. and H. Gaffron. 1972a. The mechanism of hydrogen photoproduction by several algae: $I$. The effect of inhibitors of photoproduction. P1anta 100:91-100.

Stuart, T.S. and Gaffron. 1972b. The mechanisms of hydrogen photoproduction by several algae: II. The contribution of photosystem II. Planta 106:101112.

Stuart, T.S. and H. Kaltwasser. 1970. Photoproduction of hydrogen by photosystem I of Scenedesmus. Planta 91:302-313. 
Takahama, U. and M. Nishimura. 1976. Effect of electron donor and acceptors, electron transfer mediators, and SOD on lipid peroxidation in illuminated chloroplast fragments. Plant Ce11 Physiol. 17:111-118.

Tel-Or, E., L.W. Luijk and L. Packer. 1978. Hydrogenase in $\mathrm{N}_{2}$-fixing cyanobacteria. Arch. Biochem. Biophys. 185:185-194.

Tel-Or, E. and W.D.P. Stewart. 1975. Manganese and photosynthetic oxygen evolution by algae. Nature 258:715-716.

Tel-Or, E. and W.D.P. Stewart. 1977. Photosynthetic components and activities of nitrogen-fixing isolated heterocysts of Anabaena cylindrica. Proc. R. Soc. Inndnn Ser. B. $198: 61-86$.

Thomas, J. 1970. The absence of the pigment of photosystem II of photosynthesis in heterocysts of a blue-green alga. Nature 228:181-183.

Thomas, J. and K.A.V. David. 1972. Site of nitrogenase activity in the bluegreen alga Anabaena sp.L-31. Nature New Biology 238:219-221.

Togasaki, R.K. 1973. A proposal to search for mutant strains carrying oxygen resistant hydrogenase. In M. Gibbs, A. Hollaender, B. Kok, L.D. Krampitz and A. San Pietro (editors), Proceedings of the Workshop on Bio-Solar Conversion. NSF/RANN Report, pp. 60-61.

Trebst, A. 1974. Energy conservation in photosynthetic electron transport of chloroplasts. Ann. Rev. Plant Physiol. 25:423-458.

Tso, M.-Y.W. 1974. Properties of the nitrogenase proteins from Clostridium pasteurianum: Molecular weight, subunit structure, isoelectric point and EPR spectra. Arch. Micrubiol. 99:71-80.

Uffen, R.L. 1976. Anaerobic growth of a Rhodopseudomonas species in the dark with carbon monoxide as sole carbon and energy substrate. Proc. Natl. Acad. Sci. 73:3298-3302.

Uffen, R.L. and R.S. Wolfe. 1970. Anaerobic growth of purple nonsulfur bacteria under dark conditions. J. Bacteriol. 104:462-472.

Valentine, R.C., L. Mortenson and J. Carnahan. 1963. The hydrogenase system of Clostridum pasteurianum. J. Biol. Chem. 238:1141-1144.

van der Western, H.M., S.G. Mayhew and C. Veeger. 1978. Separation of hydrogenase from intact cells of Desulfovibrio vulgaris. FEBS Letters 81:122126.

van Gorkom, H.J. and M. Donze. 1971. Localization of nitrogen fixation in Anabaena. Nature 234:241-242.

van Niel, C.B. 1941. The bacterial photosyntheses and their importance for the general problem of photosynthesis. Adv. Enzymol. 1:263-328. 
Vernon, L.P. Photochemical and electron transport reactions of bacterial photosynthesis. Bacteriol Rev. 32:243-261.

Wald, G. and R.B. Wooten. 1978. Human vision in the ultraviolet and the absorption spectrum of the lens. Presented at the 6 th Annual Meeting of the American Society for Photobiology, June 11-15, 1978, in Burlington, VT.

Walker, G.A. and L.E. Mortenson. 1974. Effect of magnesium adenosine 5'triphosphate on the accessibility of the iron of clostridial azoferredoxin, a component of nitrogenase. Biochem. 13:2382-2388.

Wall, J.D., P.F. Weaver and H. Gest. 1975a. Gene transfer agents, bacteriophages and bacteriocins of Rhodopseudomonas capsulata. Arch. Microbiol. 105:217-224.

Wall, J.D., P.F. Weaver and H. Gest. 1975b. Genetic transfer of nitrogenasehydrogenase activity in Rhodopseudomonas capsulata. Nature 258:630-631.

Wang, R., F.P. Healey and J. Myers. 1971. Amperometric measurement of hydrogen evolution in Chlamydomonas. Plant Physiol. 48:108-110.

Ward, M.A. 1970. Whole cell and cell-free hydrogenase of algae. Photochem. 9:259-266.

Wasserman, A.R. and S. Fleischer. 1968. The stabilization of chloroplast function. Biochem. Biophys. Acta 153:154-169.

Weare, N.M. 1978. The photoproduction of $\mathrm{H}_{2}$ and $\mathrm{NH}_{4}^{+}$fixed from $\mathrm{N}_{2}$ by a derepressed mutant of Rhodospirillum rubrum. Biochim. Biophys. Acta 502:486494.

Weare, N.M. and J.R. Benemann. 1972. Nitrogen fixation by Anabaena cylindrica: I. Localization of nitrogen fixation in the heterocysts. Arch. Mikrobiol. 90:323-332.

Weare, N.M and J.K. Benemann. 1973a. Nitrogen fixation by Anabaena cylindrica: I. Localization of nitrogen fixation in heterocysts. Arch. Mikrobiol. 90:323-332.

Weare, N.M. and J.R. Benemann. 1973b. Nitrogen fixation by Anabaena cylindrica: II. Nitrogenase activity during induction and aging of batch cultures. Arch. Mikrobiol. 93:101-112.

Weare, N.M. and J.R. Benemann. 1974. Nitrogenase activity and photosynthesis in Plectonema boryanum. J. Bacteriol. 119:258-265.

Weare, N.M. and K.T. Shanmugam. 1976. Photoproduction of ammonium ion from nitrogen gas in Rhodospirillum rubrum. Arch. Microbiol. 110:207-213.

Weaver, P. 1971. Temperature-sensitive mutations of the photosynthetic apparatus of Rhodospirillum rubrum. Proc. Natl Acad. Sci. 68:136-138. 
Weaver, P. 1975. Environmental and mutational variations in the photosynthetic apparatus of Rhodospirillum rubrum. Ph.D. dissertation, Univ. of Calif., San Diego. pp. $17 \overline{7}$

Weaver, P., K. Tinker and R.C. Valentine. 1965. Ferredoxin-linked DPN ${ }^{+}$ reduction by the photosynthetic bacteria Chromatium and Chlorobium. Biochem. Biophys. Res. Comm. 31:195.

Weaver, P.F., J.D. Wall and H. Gest. 1975. Characterization of Rhodopseudomonas capsulata. Arch. Microbiol. 105:207-216.

Weissman, J.C. and J.R. Benemann. 1977. Hydrogen production by nitrogenstarved cultures of Anabaena cylindrica. Appl. Environ. Microbio1. 33:123131.

Whiteley, H.R. and N.G. McCormick. 1963. Degradation of pyruvate by Micrococcus lactilyticus. J. Bacteriol. 85:382-393.

Wilcox, M., G.J. Mitchison and R.J. Smith. 1973a. Pattern formation in the blue-green alga Anabaena: I. Basic mechanism. J. Cell Sci. 12:707-723.

Wilcox, M., G.J. Mitchison and R.J. Smith. 1973b. Pattern formation in the blue-green alga Anabaena: II. Controlled proheterocyst regression. J. Cell Sci. 13:637-649.

Wimpenny, J.W.T. 1969. The cffect of $E_{h}$ [redox potential] on regulatory processes in facultative anaerobes. Biotechnol. Bioeng. 11:623-639.

Winter, H.C., and D.I. Arnon. 1970. Nitrogen fixation system of photosynthetic bacteria: I. Preparation and properties of a cell-free extract from Chromatium. Biochim. Biophys. Acta 197:170-179.

Winter, H.C. and R.H. Burris. 1968. Stoichiometry of the ATP requirement for nitrogen fixation and hydrogen evolution by a partially purified preparation of Clostridium pasteurianum. J. Biol. Chem. 243:942-946.

Winter, H.C. and R.H. Burris. 1976. Nitrogenase. Ann. Rev. Biochem. 45:409126.

Wintermans, J.F.G.M., P.H. Helnsing, P.J. Polman, J. van Gisbergen and J. Collard. 1969. Galactolipid transformation and photochemical activities of spinach ch1oroplasts. Biochim. Biophys. Acta 189:95=105.

Wittenberger, H. and R. Repaske. 1961. Studies on hydrogen in cell-free extracts of Hydrogenomonas eutropha. Biochim. Biophys. Acta 47:542-552.

Wolk, C.P. 1968. Movement of carbon from vegetative cells to heterocysts in Anabaena cylindrica. J. Bacteriol. 96:2138-2143.

Wolk, C.P., J. Thomas, P.W. Shaffer, S.M. Austin and A. Galonsky. 1976. Pathway of nitrogen metabolism after fixation of ${ }^{13} \mathrm{~N}$-labeled $\mathrm{N}_{2}$ by Anabaena cylindrica. J. Biol. Chem. 251:5027-5034. 
Wyatt, J.T. and J.K.G. Silvey. 1969. Nitrogen fixation by Gloeocapsa. Science 165:908-909.

Yagi, T. 1970. Solubilization, purification, and properties of particulate hydrogenase from Desulfovibrio vulgaris. J. Biochem. 68:649-657.

Yagi, T. 1976. Separation of hydrogenase-catalyzed hydrogen-evolution system from electron donating system by means of enzymic electric cell technique. Proc. Natl. Acad. Sci. 73:2947-2949.

Yagi, T. 1977. Study of the biophotolysis of water to produce hydrogen. In A. Mitsui, S. Miyachi, A. San Pietro and S. Tamura (editors), Biological Solar Energy Conversion. Academic Press, New York, pp. 61-68.

Yagi, T., M. Honya and N. Tamiya. 1968. Purification and properties of hydrogenases of different origins. Biochim. Biophys. Acta 153:699-705.

Yagi, T., A. Kimura, H. Daidoji, F. Sakai, S. Tamura and. H. Inokuchi. 1976. Properties of purified hydrogenase from the particulate fraction of Desulfovibrio vulgaris. J. Biol. Chem. 79:661-671.

Yamashita, T. and G. Tomita. 1974. Effects of manganese, calcium, dithiothreitol, and bovine serum albumin on the light reactivation of Trisacetone-washed chloroplasts. Plant Cell Physiol. 15:69-82.

Yamashita, T., J. Tsuji and G. Tomita. 1971. Reactivation of the Hill reaction of Tris-washed chloroplasts. Plant Cel1 Physiol $12: 117-126$.

Yates, M.G. and K. Planque. 1975. Nitrogenase from Azotobacter chroococcum: Purification and properties of the component proteins. Eur. J. Biochem. 60:467-476.

Yen, H.C. and B. Marrs. 1977. Growth of Rhodopsuedomonas capsulata under anaerobic dark conditions with dimethyl sulfoxide. Arch. Biochem. Biophys. $181: 411-418$.

Yoch,. D.C. and D.I. Arnon. 1970. Nitrogen fixation system of photosynthetic bacteria: II. Chromatium nitrogenase activity linked to photochemically generated assimilatory power. Biochem. Biophys. Acta 197:180-184.

Yoch, D.C. and D.I. Arnon. 1975. Comparison of two native ferredoxins from Rhodospirillum rubrum as electron acceptors for nitrogenase. J. Bacteriol. 121:743-745.

Zumft, W.G., L.F. Mortenson and G. Palmer. 1974. EPR studies on nitrogenase. Eur. J. Biochem. 46:525-535. 
No. of Copies

1

1

1

1

1

1

1

1

1

1
Distribution

Department of Energy: DOE, SERI Site Office Contracting officer Attn: Charles M. Skinner

Chicago Operations Office Interim Program Division Attn: M. E. Jackson

Division of Solar Technology Office of Asst. Director

for Administration Attn: R. H. Annan

Office of Asst. Secretary for Conservation \& Solar Applications Attn: R. Scott

Office of Solar, Geothermal, Electric \& Storage Programs Attn: Martin Adams

Division of Energy Technology Administration

Attn: S. Hansen

Division of Distributed Solar Technology Office of the Director Attn: R. San Martin

Division of Central Solar Technology

Office of the Director

Attn: H. Coleman

Division of Energy Storage Systems, ETS

Office of the Director

Attn: G. Pezdirtz

Diviston of Planning \& Energy Transfer, ETS

Office of the Director

Attn: Leslie Levine

Wind Energy Systems

Attn: L, Divolie 